\title{
Addressing fluorogenic real-time qPCR inhibition using the novel custom Excel file system 'FocusField2-6GallupqPCRSet-upTool-001' to attain consistently high fidelity qPCR reactions
}

\author{
Jack M. Gallup ${ }^{1^{*}}$ and Mark R. Ackermann ${ }^{1}$ \\ ${ }_{1}^{1}$ Department of Veterinary Pathology, College of Veterinary Medicine, lowa State University, Ames, lowa 50011-1250. USA. \\ *Corresponding Author: Jack M. Gallup, Department of Veterinary Pathology, College of Veterinary Medicine, lowa State University, Ames, lowa 50011- \\ 1250. USA. Phone: 1-515-294-5844. Fax: 1-515-294-5423. Email: eag@iastate.edu
}

Submitted: May 2, 2006; Revised: July 3, 2006; Accepted: July 10, 2006.

Indexing terms: Reverse Transcription; DNA, Complementary.

\section{ABSTRACT}

The purpose of this manuscript is to discuss fluorogenic real-time quantitative polymerase chain reaction (qPCR) inhibition and to introduce/define a novel Microsoft Excel-based file system which provides a way to detect and avoid inhibition, and enables investigators to consistently design dynamically-sound, truly LOG-linear qPCR reactions very quickly. The qPCR problems this invention solves are universal to all qPCR reactions, and it performs all necessary qPCR set-up calculations in about 52 seconds (using a pentium 4 processor) for up to seven qPCR targets and seventytwo samples at a time - calculations that commonly take capable investigators days to finish. We have named this custom Excel-based file system "FocusField2-6GallupqPCRSet-upTool-001" (FF2-6-001 qPCR set-up tool), and are in the process of transforming it into professional qPCR set-up software to be made available in 2007. The current prototype is already fully functional.

\section{PREFACE}

Bearing in mind that it is not possible to state with absolute certainty the exact causes of qPCR inhibitory phenomena, and since more than one kind of inhibition may be present at the same time, we begin this communication by creating a list of the top five most likely sources of such inhibition - two of which (inhibition Types 2 and 3) are inherently a function of one another. We propose that all five affect either the activity of reverse transcriptase enzymes, Taq DNA polymerases, or both. In order to avoid using sample RNA (or cDNA) at dilutions permissive of or conducive to real-time qPCR inhibitory phenomena (regardless of the type of inhibition), we have created the FF2-6-001 qPCR set-up tool which is used to analyze preliminary qPCR Test Plate data generated by up to seven qPCR targets from serial progressive dilutions of representative (Stock I) RNA or cDNA mixtures all used in fluorogenic hydrolysis probe-based qPCR. Once Test Plate threshold cycle $\left(\mathrm{CT}_{\mathrm{T}}\right)$ values are obtained for each target on any given Test Plate, they are entered into the
TestPlateResultsAnalysis2006.xls portions of the FF2-6001 qPCR set-up tool which the user interacts with in order to quickly and precisely identify the useful RNA dilution ranges for each qPCR target - within these ranges which each target can be expected to amplify without inhibition, with LOG-linearity and with high efficiency. The FF2-6-001 qPCR set-up tool then applies these ranges to final qPCR reaction designs allowing the investigator to formulate high-fidelity $\mathrm{qPCR}$ reactions every time since the FF2-6-001 file system ensures that each real-time qPCR reaction is carried out under the most dynamically sound conditions possible for each different genomic or transcriptomic target of interest. As a result, investigators are able to consistently attain credible real-time qPCR target and housekeeper $C_{T}$ values. The FF2-6-001 qPCR set-up tool is also universally adaptable to any master mix and $\mathrm{qPCR}$ reagent-use selection (e.g. SYBR Green, one-step and two-step, beacon, scorpion and hydrolysis probe methods) for both relative and absolute quantitative qPCR approaches. Since real-time qPCR is lauded by many as the most powerful tool in all of molecular 
biology for quantitative analysis of gene expression, and since it is still considered the tool of choice for validating micro-array data, any new ideas, methods or approaches that improve its precision in common practice represent important constructive advances furthering the responsible evolution of an already broadly-accepted scientific technique.

\section{INTRODUCTION}

A variety of problematic inhibitory phenomena have been reported that plague qPCR assays (1). Inhibition of the enzymatic reactions involved in generating real-time qPCR signals from specific cDNA templates using specific primers, fluorogenic probes, or combinations of primers and fluorogenic probes can severely impact the precision of absolute and relative gene expression quantitative analysis. Any factor, experimental, userintroduced, environmental or otherwise, that has an impact on the activity of RT (reverse transcriptase) enzyme and/or Taq polymerase used in any one-step real-time qPCR reaction will invariably affect the results generated. In worst-case scenarios, these deficiencies go unnoticed and remain unaddressed. Recently, others have suggested that many as-yet unidentified samplespecific substances (or impurities) are often carried over as a result of different RNA isolation methods (preceding real-time qPCR of any variety) which cause RT enzyme or Taq DNA polymerase-based qPCR inhibition $(1,2)$. Exogenous contaminants such as glove powder and phenolic compounds from the extraction process and plastic-ware (pipette tips, tubes and plates) can also have an inhibiting effect. With regard to tissue-specific inhibition of DNA amplification, tissue type was found to be the largest source of variance of inhibitory phenomena while primer sequences appeared to have the least affect. In other words, tissue type from which total RNA was extracted had the most significant effect on PCR kinetics, thus on final threshold cycle $\left(\mathrm{C}_{\mathrm{T}}\right)$ values $(1,4)$. This is thought to be caused by different kinds and amounts of cellular debris present in samples after RNA extraction $(2,3)$. Endogenous contaminants such as blood or fat are thought to play an important role in affecting both the PCR as well as the preceding reverse transcription reaction. Other inhibitory contaminants are thought to be hemoglobin, heme, porphyrin, heparin (from peritoneal mast cells), glycogen, polysaccharides and proteins, cell constituents, $\mathrm{Ca}^{2+}$, DNA or RNA concentration, and DNA (and possibly RNA) binding proteins (5-12). MicroRNA (miRNA) is not thought to be a contributing factor to $\mathrm{qPCR}$ inhibition since high thermocylcing temperatures $\left(94-95^{\circ} \mathrm{C}\right)$ most likely prevent the formation of stable RNA-binding complexes which might otherwise associate with template RNA (Ambion technical support information).

\section{Types of qPCR inhibition}

Because of the severe impact inhibition can have on results, we feel it is important to address it and attempt to identify the possible form(s) that may be present or active throughout real-time pPCR procedures (37). Toward this end, based on experimental observations of the dynamics of numerous real-time qPCR reactions, we have organized $\mathrm{qPCR}$ inhibitory phenomena into five semi-distinct categories; Types 1 through 5 (Figs. 1-6). We describe them as: inhibition of reverse transcriptase (RT) enzyme(s) and/or Taq DNA polymerase(s) by excessive rRNA and possibly tRNA in concentrated RNA samples (sample concentration-related template inhibition; Type 1 inhibition); inhibition from method of RNA isolation due to the carryover of inhibitory biological components or molecules (RNA isolation method-related inhibition; Type 2 inhibition); inhibition arising from the type of tissue or cell that sample RNA has been isolated from (sample-specific inhibition; Type 3 inhibition); inhibition arising as a result of the interaction of a specific qPCR target template with suboptimal concentrations, designs or any other thermodynamic factors concerning its specific probe and/or primer(s) (target-specific kinetic inhibition; Type 4 inhibition); and inhibition caused by compounds such as EDTA, GIT, TRIS, glycogen (sometimes used as a carrier agent during RNA isolation; inhibition of RT enzyme has been observed when glycogen is present in excess of $4 \mathrm{mg} / \mathrm{ml}$ during reverse transcription), $(13,14)$, or other user-introduced reagents (chemical inhibition; Type 5 inhibition). Although the reality of Type 6 inhibition (connoting all other as-yet unknown causes of qPCR inhibition) looms large, for the purposes of this paper, only proposed inhibition Types 1 through 5 are addressed.

Type 1 inhibition of reverse transcriptase (and possibly Taq DNA Polymerase) due to rRNA and tRNA is yet poorly understood, but it has been acknowledged and 
referred to in product literature as being of serious concern (15). Understandably, inhibition Types 2 and 3 will invariably be a function of one another since method of RNA isolation and tissue or cell type from which RNA is isolated will always affect one another distinctly, while all types of qPCR inhibition are diminished (and eventually eliminated) by sheer dilution of the RNA samples. Indeed, diluting RNA out too far can obviously result in the generation of weak or absent qPCR signals from lower abundance mRNAs in any transcriptome. Inhibition types 4 and 5 are more generally understood as they have been familiar concerns in the conventional PCR world since its inception in 1983. Since the qPCR studies used as examples in this paper involve the sole use of the TaqMan ${ }^{\circledR}$ (hydrolysis) probe method (which includes the use of sequence-specific forward and reverse primers), we discuss here only observations gathered by this approach using total tissue or cellular RNA in single-plex fluorogenic one-step real-time qPCR (Fig. 7). All reactions were run in an Applied Biosystems Incorporated (ABI) GeneAmp ${ }^{\circledR} 5700$ Sequence Detection System unless otherwise stated (in one case, a Stratagene Mx3005P real-time qPCR machine was employed - using ABI TaqMan ${ }^{\circledR}$ One-Step RT-PCR Master Mix Reagents Kit). Any experimental results shown in this paper are meant to illustrate the unique prowess of the FF2-6-001 qPCR set-up tool and to aid in discussing the concepts of $q P C R$ inhibition and optimal $q P C R$ target dynamic range; they are not intended to represent complete scientific study per se.

\section{Inhibition encountered in experimental assays}

By examining the results from numerous one-step realtime $\mathrm{qPCR}$ studies using total RNA isolated from mammalian tissue or mammalian cell cultures either by Trizol $^{\circledR}$ (14), or a column purification method (Rapid Total RNA Purification System, Cat. No. 11502-050, Marligen), we found that a direct relationship existed between the severity of qPCR inhibition and the method used to isolate sample total RNA. This was a clear example to us that qPCR inhibition Types 2 and 3 were interrelated. Most Trizol ${ }^{\circledR}$-isolated total RNA, when used in one-step real-time qPCR, showed inhibition until a final post-DNase, in-well (See Appendix 1) RNA dilution of $\sim 1: 150$. At 1:200 final (post-DNase, in-well) RNA dilutions and beyond, most targets (i.e. SBD-1, ovTTF-1, ovSP-A, ovSP-D, ovICAM-1, SMAP29, bRSV and
ovRPS15; see Appendix 14) showed lack of inhibition and began to behave as classic real-time qPCR templates. The only exception to this was hRIBO18S RNA, which did not exhibit normal real-time qPCR template behavior until a dilution of $\sim 1: 4,000$ and higher (Fig. 2). Significantly less qPCR inhibition was observed with RNA samples that were isolated using the Marligen column-based method (Clark-Sponseller equine studies, 2005-2006 unpublished). Inhibition for all samples disappeared at final (post-DNase, in-well) RNA dilutions of 1:50 and higher for equine targets IL-10, IL-12p35, IL12p40 and GA3PDH (Figs. 3, 4 and Apendix 14). RIBO18S RNA was not studied, so the effect of Marligen column isolation on this target is unknown. Final, in-well RNA concentrations were never greater than $0.5 \mathrm{ng} / \mu \mathrm{l}$ in any of these qPCR studies $(\sim 0.3 \mathrm{ng} / \mu \mathrm{l}$ seemed to work the best), so inhibition of RT enzyme and/or Taq DNA polymerase by excess RNA in the reaction wells (Type 1 inhibition) was reasonably eliminated as a source of any of the inhibition phenomena witnessed (since by the time most samples reached this final in-well concentration, they had already incurred dilutions of 1:3,000 or greater - certainly outside the range where most forms of inhibition would be reasonably expected, with the possible exception of inhibition Type 4) (See Appendix 2).

We further make the assumption that our one-step qPCR reactions are safely outside the realm where Type 1 inhibition might be expected. This is based on product literature and guidelines from $\mathrm{ABI}$ and others that 10 picograms to 100,000 picograms of total RNA per each 50 $\mu l$ one-step real-time qPCR reaction is generally considered to be the normal range within which one-step qPCR amplifications can be expected to exhibit favorable LOG-linear kinetics $(2,28,29,31,39)$. Routinely, we design our final $25 \mu \mathrm{l}$ qPCR reactions to contain no less than $0.005 \mathrm{pg}$ of total RNA per $25 \mu \mathrm{l}$ reaction (e.g. for the last point of typical standard curves for the hyperabundant housekeeper, $18 \mathrm{~S}$ ribosomal RNA) and no more than $12,500 \mathrm{pg}$ of total RNA per $25 \mu \mathrm{l}$ reaction mixture (i.e. for often rarely-expressed targets such as SBD-1, IL-10, IL-8 and TNF- $\alpha$ ). Above 12,500 pg total RNA per $25 \mu$ reaction, we begin to observe problematic qPCR inhibitory phenomena (with Trizol ${ }^{\circledR}$-isolated tissue total RNA) of Type 1, Type 2, Type 3 (and presumably Type 4) varieties. Interestingly, at first, the qPCR inhibition we observed seemed to be either a byproduct 
of Turbo-DNase (Ambion) treatment (Type 5 inhibition), or rRNA and tRNA inhibition of the RT enzyme during reverse transcription (Type 1 inhibition). But, then it became apparent that this inhibition was more likely due to the method of total RNA isolation (our final TurboDNase treated RNA samples never comprised more than $26 \%$ of each final one-step real-time qPCR reaction volume; an amount that is safely within Ambion product literature guidelines regarding the proper use of Turbo DNase-treated RNA in qPCR reactions). In our studies, Trizol $^{\circledR}$ RNA isolation (which we used for 15 different sheep tissues, 14 different chicken tissues, JS7 ovine lung cell and H441 human adenocarcinoma cell cultures) and Marligen column-based RNA isolation procedures (used for equine dendritic and macrophage cell cultures (ClarkSponseller, 2005-2006, Iowa State University)) were both followed by identical Turbo-DNase treatments. But, Trizol $^{\circledR}$-isolated RNA always showed a greater degree of qPCR inhibitory characteristics than Marligen columnisolated RNA samples. Since all conditions were identical for these samples except method of RNA isolation, this indicated to us that qPCR inhibition Types 2 and Type 3 were a function of one another. Further, in our studies, the possibility that Type 4 inhibition (target-specific kinetic inhibition) is a source of RT enzyme and/or qPCR (e.g. Taq DNA polymerase) inhibition seemed to be most probable only with the hyper-abundant $18 \mathrm{~S}$ ribosomal RNA target, whereas inhibition of RT enzyme by rRNA (and possibly tRNA) and chemical inhibition seem to mainly affect those targets which are only able to elicit ample qPCR signals when using more concentrated RNA during qPCR. In our previous work, Type 5 inhibition was clearly demonstrated with LCM RNA samples that received EDTA during DNase-treatment preceding fluorogenic one-step real-time qPCR; the ABI one-step master mix used was especially prone to even very small exogenously-introduced amounts of EDTA (which of course forms a chelate with divalent metal ions such as $\mathrm{Mg}^{2+}$ - keeping them from participating as crucial cofactors in enzymatic reactions such as reverse transcription and PCR) (16).

All 5 proposed types of inhibition present themselves during two-step qPCR as well (using cDNA synthesized separately, prior to subsequent qPCR procedures), but to a much smaller degree than is seen during one-step qPCR for the identical target. The differences here can be largely ascribed to the amount of template present and available for $\mathrm{qPCR}$ since cDNAs synthesized prior to qPCR are often $20 \mathrm{ng} / \mu \mathrm{l}$ or less and have already incurred enough dilution in most cases (since template RNA isolation) to have minimized or eliminated the chances that any of the five currently-proposed causes of qPCR inhibition would be present. Corresponding RNA samples in the same regard are often $200-1,000 \mathrm{ng} / \mu \mathrm{l}$ before use. Quite logically, the more concentrated one must use RNA samples during one-step qPCR in effort to find "quieter" target signals of interest, the higher the risk there is of allowing qPCR inhibitory phenomena of any variety to manifest itself. Since our studies have expanded to the use of total RNA isolated from ovine lung, nasal turbinate, trachea, rumen, abomasum, jejunum, ileum, spiral colon, rectum, liver, gall bladder, urinary bladder, kidney, uterus (adult) and placenta (fetus) tissue, and chicken bone marrow, jejunum, crop, testes, oviduct, lung, skin, spleen, liver, kidney, bursa, trachea, conjunctiva, tongue, ovine and human lung cell cultures, and equine macrophage and dendritic cell cultures (courtesy of Dr. Brett Sponseller and Sandra K. Clark), we have witnessed and have successfully dealt with numerous different qPCR inhibitory profiles (using the FF2-6-001 qPCR set-up tool). Others have acknowledged the importance of this battle as well $(1,3-$ $12,39)$. With regard to Trizol ${ }^{\circledR}$ versus Marligen columnbased RNA isolation, it is clear that inhibitory artifacts of RNA isolation can be augmented or diminished according to the method of RNA isolation employed, and by the extent of dilution RNA samples undergo prior to their use in qPCR.

On account of the inability of investigators to find an RNA isolation method which will not introduce one-step real-time qPCR inhibition at some point, of some kind to some degree, we found it an absolute necessity to create a tool (FF2-6-001) that could quickly reveal the dilution ranges within which each real-time $\mathrm{qPCR}$ target of interest can be amplified without inhibition. Our approach emphasizes (as do methodologies offered of most companies that provide the world with $\mathrm{qPCR}$ technology) the importance of performing preliminary qPCR RNA template dilution studies for all targets every time RNA samples are isolated for the purpose of gene expression analysis. What ABI describes as a "validation" plate, we call a "Test Plate" (Figs. 18, 22 and 28). 


\section{EXPERIMENTAL PROCEDURES}

\section{Fluorogenic real-time qPCR; one-step versus two-step}

Fluorogenic one-step (for final relative quantitative target analyses) and two-step real-time qPCR (for initial target primer-probe optimizations; primers and probes designed using ABI Prism Primer Express ${ }^{\mathrm{TM}}$ version 2.0) were carried out as described previously (16-24). The fluorogenic 5' nuclease assay (TaqMan ${ }^{\circledR}$ hydrolysis probe method) is a convenient, self-contained process which uses a fluorogenic probe consisting of an oligonucleotide to which a reporter dye and a quencher dye are attached. During PCR, the probe anneals to the target of interest between the forward and reverse primer sites. During extension, the probe is cleaved by the 5 ' nuclease activity of the DNA polymerase. This separates the reporter dye from the quencher dye, generating an increase in the reporter dye's fluorescence intensity. Once separated from the quencher, the reporter dye emits its characteristic fluorescence (Figs. 7 and 8). The threshold cycle, or $\mathrm{C}_{\mathrm{T}}$ value, is the cycle at which a significant increase in normalized reporter fluorescence, $\Delta R_{n}$, is first detected (See Appendix 3); where $\Delta R_{n}$ is calculated from $\mathrm{R}^{+}$and $\mathrm{R}_{\mathrm{n}}$, where $\mathrm{R}^{+}$is the $\mathrm{R}_{\mathrm{n}}$ value of a reaction containing all components, and $R_{n}{ }^{-}$is the $R_{n}$ value of an un-reacted sample (the baseline value or the value detected in the no-template control, NTC). $\Delta \mathrm{R}_{\mathrm{n}}$ is thus the difference between $\mathrm{Rn}^{+}$and $\mathrm{R}_{\mathrm{n}}{ }^{-}$and it is an indicator of the magnitude of the signal generated only by the fluorogenic PCR (25). For fluorogenic hydrolysis probe designs, we use 'C-probes' instead of 'G-probes' whenever possible since empirical data from $\mathrm{ABI}$ has shown that use of TAMRA-quenched probes containing more Cs than Gs improves the overall magnitude of fluorescent signal generated (i.e. greater overall $\Delta R_{n}$ is observed). Primer-probe sets were also designed to span genomic introns whenever feasible; especially probe sequences. However, when deciding whether to use the sense or anti-sense probe sequence in each case, we were careful to avoid using C-probes which contained a $\mathrm{G}$ on the $5^{\prime}$ end (immediately adjacent to the reporter dye) - a feature that should be strictly avoided since Guanine is a potent inhibitor of reporter dye fluorescence. It is important to note here, however, that the "C-probe versus G-probe" rationale does not apply to minor groove-binding non-fluorescent quencher (MBGNFQ)based probes. The ABI GeneAmp ${ }^{\circledR} 5700$ Sequence
Detection System measures the increase in the reporter dye's fluorescence during the thermal cycling of the PCR, and this data is then used by the sequence detection software to generate $C_{T}$ values for each target which we finish processing and interpreting using custom Excel files. We feel strongly that being able to process one's own $\mathrm{C}_{\mathrm{T}}$ values into final quantitative results is paramount since qPCR machines of all varieties cannot discern between erroneous (either user- or machineintroduced) signals and legitimate signals $100 \%$ of the time. Additionally, processing one's own data (rather than allowing qPCR machine processing) not only acquaints one directly with the interesting mathematical terrain associated with qPCR, it also exposes one firsthand to some of the fascinating intricacies and nuances associated with qPCR that are often not readily apparent to the user - all things which allow one to garner additional stratagems to apply to future troubleshooting and qPCR assay optimization endeavors.

\section{One-step real-time qPCR}

Fluorogenic one-step real-time qPCR differs from fluorogenic two-step real-time $\mathrm{qPCR}$ in three major regards: 1.) in a one-step approach, RNA is added directly as the nucleic acid template in qPCR reactions instead of cDNA, 2.) reverse primer concentrations have to be increased for use in one-step analyses due to firststrand synthesis requirements and, 3.) a different master mix is employed for one-step as opposed to two-step qPCR. One-step reactions typically contain both reverse transcriptase and Taq DNA polymerase enzymes and are subjected to thermocycler programs which address both enzymes in turn. For one-step real-time qPCR, we use ABI Cat. No. 4309169, TaqMan ${ }^{\circledR}$ One-Step RT-PCR Master Mix Reagents Kit. In this kit, $250 \mu$ of Multiscribe $^{\mathrm{TM}}$ (MuLV) RT enzyme $(10 \mathrm{U} / \mu \mathrm{l})$ arrives already pre-mixed with RNase inhibitor $(40 \mathrm{U} / \mu \mathrm{l})$ as a 40X solution. The one-step RT-PCR master mix in the kit (containing AmpliTaq Gold ${ }^{\circledR}$ hot-start DNA Polymerase, undisclosed amounts of $\mathrm{MgCl}_{2}, \mathrm{~A}, \mathrm{C}$ and $\mathrm{G}$ dNTPs and dUTP, $300 \mathrm{nM}$ ROX passive internal reference molecule, other ABI-proprietary buffer components, but no AmpErase $^{\circledR}$ UNG enzyme) arrives as a separate $2 \mathrm{X}$ solution ( $5 \mathrm{ml}$ total). Each of our final $25 \mu \mathrm{l}$ one-step realtime qPCR reactions contains: $12.5 \mu$ one-step master mix, $0.25 \mathrm{U} / \mu \mathrm{l}$ Multiscribe ${ }^{\mathrm{TM}} \mathrm{RT}$ enzyme, $0.4 \mathrm{U} / \mu \mathrm{l}$ RNase inhibitor, optimal forward primer and fluorogenic probe 
concentrations (as previously established for each target by two-step real-time qPCR according to classic ABI protocol, (25)), reverse primer concentrations adjusted for one-step use (See Appendix 4), nuclease-free water, and $6.5 \mu \mathrm{l}$ of each RNA sample/template. Before use, all solutions are gently vortexed and spun down, then allowed to undergo fluorogenic one-step qPCR reactions using the following thermocycler conditions: 35 minutes at $48^{\circ} \mathrm{C}$ (for reverse transcription; normally 30 minutes; $\mathrm{ABI}$ ), 10 minutes at $95^{\circ} \mathrm{C}$ (for AmpliTaq Gold ${ }^{\circledR}$ DNA polymerase hot-start activation), and 50 cycles of: 15 seconds at $95^{\circ} \mathrm{C}$ (for duplex melting), 1 minute at $58^{\circ} \mathrm{C}$ (for annealing and extension; normally $60^{\circ} \mathrm{C}$; $\mathrm{ABI}$ ). For pipetting accuracy purposes, we always prepare enough of each reaction mixture to accommodate $30 \mu$ reaction sizes but, in the end, use only $25 \mu$ of each in the final reaction wells in 96-well qPCR reaction plates.

\section{Two-step real-time qPCR}

Our use of fluorogenic two-step real-time qPCR is now limited only to performing preliminary optimization and validation plates for brand-new target primers and probes since it is generally less expensive than the corresponding one-step procedure. Toward this end, for two-step qPCR, we used ABI Cat. No. 4304437 TaqMan ${ }^{\circledR}$ Universal PCR Master Mix 2X which contains AmpliTaq Gold $^{\circledR}$ (hot-start) DNA Polymerase, undisclosed amounts of $\mathrm{MgCl}_{2}, \mathrm{~A}, \mathrm{C}$ and $\mathrm{G}$ dNTPs and dUTP (in order for the AmpErase $^{\circledR}$ UNG system to work), AmpErase ${ }^{\circledR}$ UNG Enzyme, $300 \mathrm{nM}$ ROX passive internal reference molecule, a PCR product carryover correction component and other proprietary buffer components. Primer optimization plates are run in a GeneAmp ${ }^{\circledR} 5700$ real-time PCR machine (GeneAmp ${ }^{\circledR} 5700$ Sequence Detection System, ABI) using the following thermocycler conditions (a specific thermocylcer program created and optimized by ABI to be used specifically with the TaqMan ${ }^{\circledR}$ Universal PCR Master Mix 2X, and two or three other related ABI $2 X$ Master Mix reagents): Hold for 2 minutes @ $50^{\circ} \mathrm{C}$ to activate the AmpErase ${ }^{\circledR} \mathrm{UNG}$ enzyme (See Appendix 5), Hold for 10 minutes @ 95 ${ }^{\circ} \mathrm{C}$ (to "hot-start" activate the AmpliTaq Gold ${ }^{\circledR}$ DNA polymerase) and then 50 cycles of 15 seconds @ $95^{\circ} \mathrm{C}$ (for duplex melting) followed by 1 minute @ $60^{\circ} \mathrm{C}$ (to accomplish the annealing and extension phases of the PCR). Each 50-cycle run lasts 2 hours and 14 minutes, after which the GeneAmp ${ }^{\circledR} 5700$ sequence detection system software and custom Microsoft Excel files are used in conjunction with one another to analyze and interpret the resultant fluorogenic qPCR $\mathrm{R}_{\mathrm{n}}$ or $\mathrm{C}_{\mathrm{T}}$ values. For all optimization trials, each sample is analyzed in either triplicate or quadruplicate. On the primeroptimization plate for each target, primer amounts that, upon analysis, provide the highest $R_{n}$ value with the lowest primer concentration(s) are identified as the optimal concentrations for each primer pair for each of the respective qPCR targets of interest. To test each probe for optimal efficacy, a second plate is designed for each target to enable the testing of various concentrations of each probe ranging from $25 \mathrm{nM}$ to $225 \mathrm{nM}$ in the presence of optimal primer concentrations (as already established by the primer-optimization plate in each case). For each probe, in each well, each $25 \mu \mathrm{l}$ PCR reaction contains the [two-step]-identified optimal concentrations of each primer for each target, $2.5 \mu \mathrm{l}$ of 1:5 or 1:10-diluted Stock I cDNA (See Appendix 6), $12.5 \mu \mathrm{l}$ of the ABI commercial master mix (mentioned above) and nuclease-free water. For the purpose of providing real-life examples for this paper, we address several targets of interest to us including: sheep beta-defensin-1 (SBD-1), ovine thyroid transcription factor-1 (ovTTF-1), ovine surfactant protein A (ovSP-A), ovine surfactant protein D (ovSP-D), and housekeepers ovine ribosomal protein S15 (ovRPS15) and human 18S ribosomal RNA (hRIBO18S) (Figs. 22, 23, 27, 28 and Appendix 14). For these targets, we found optimal primer [two-step] concentrations in each case to be $300 \mathrm{nM}$ and $900 \mathrm{nM}$ for SBD-1, $1 \mu \mathrm{M}$ and $1 \mu \mathrm{M}$ for ovTTF-1, $300 \mathrm{nM}$ and $300 \mathrm{nM}$ for ovSP-A, $300 \mathrm{nM}$ and $300 \mathrm{nM}$ for ovSP-D, $1 \mu \mathrm{M}$ and 1 $\mu \mathrm{M}$ for ovRPS15, and $50 \mathrm{nM}$ and $50 \mathrm{nM}$ for hRIBO18S forward and reverse primer concentrations, respectively. For one-step analyses, (for reasons already discussed above regarding the partial use of reverse primers due to first-strand syntheses), these same primer sets were used at $500 \mathrm{nM}$ and $1 \mu \mathrm{M}$ for SBD-1, $1 \mu \mathrm{M}$ and $1 \mu \mathrm{M}$ for ovTTF-1, $500 \mathrm{nM}$ and $500 \mathrm{nM}$ for ovSP-A, $500 \mathrm{nM}$ and $500 \mathrm{nM}$ for ovSP-D, $1 \mu \mathrm{M}$ and $1 \mu \mathrm{M}$ for ovRPS15, and 50 $\mathrm{nM}$ and $50 \mathrm{nM}$ for hRIBO18S RNA forward and reverse primer concentrations, again respectively. Each reaction mixture on each optimization plate for each target was run in triplicate or quadruplicate in order to bolster the statistical significance of sample assessments. In all cases, replicate sample well $\mathrm{C}_{\mathrm{T}}$ values never deviated more than $0.5 \%$ from one another, lending high credence to the technique's consistency, stability and reproducibility 
(Figs. 9 and 10). Probe-optimization plates were also run in the GeneAmp ${ }^{\circledR} 5700$ sequence detection system using the same thermocycler program as used for the primeroptimization plates. For analysis of the data from probeoptimization plates, the combination of reactants that yielded the lowest $C_{T}$ values with the lowest probe concentrations were chosen as the optimal fluorogenic probe concentration in each case (which we found to be $150 \mathrm{nM}, 150 \mathrm{nM}, 50 \mathrm{nM}, 100 \mathrm{nM}, 150 \mathrm{nM}$ and $200 \mathrm{nM}$ for SBD-1, ovTTF-1, ovSP-A, ovSP-D, ovRPS15 and hRIBO18S RNA probes, respectively - and we used these same probe concentrations for one-step qPCR as well). Next, as a validation test that target and endogenous reference (housekeeper) cDNA amplification reactions were all proceeding at acceptable efficiencies across a spectrum of Stock I cDNA concentrations, a third plate (the validation Test Plate) was designed to enable the testing of various concentrations of cDNA ranging from full-strength Stock I cDNA to a 1:15,625 (e.g. the seventh in a series of progressive 1:5 dilutions) dilution of Stock I cDNA. In each well, constant (optimal) concentrations of forward and reverse primers and constant (optimal) concentrations of probe were used along with $12.5 \mu \mathrm{l}$ of ABI (Cat No. 4304437) master mix, $2.5 \mu$ l of sequentiallydiluted Stock I cDNA and nuclease-free water. Also included on this plate, were wells identical to the ones just described, but instead of ovine target primers and probe, they contained either the endogenous reference/housekeeper (hRIBO18S RNA) forward and reverse primers and probe at their optimal real-time concentrations (50 nM primers and $200 \mathrm{nM}$ probe; as established by ABI for this target) or ovRPS15 forward and reverse primers and probe at their optimal concentrations. Validation plates included all samples in triplicate and were run in the GeneAmp ${ }^{\circledR} 5700$ sequence detection system using the same universal thermocycler protocol as used for the primer-probe optimization plates, and resulting $C_{T}$ values were subsequently analyzed using custom Excel files $(16,19)$.

\section{RNA isolation and cDNA synthesis}

\section{RNA isolation from whole tissue samples}

Briefly, entire tissue samples (1-2 grams of each in cryovials stored at $-80^{\circ} \mathrm{C}$ immediately post-necropsy) are carefully weighed, placed immediately into $3 \mathrm{ml}$ of Trizol $^{\circledR}$ reagent inside nuclease-free $50 \mathrm{ml}$ conical centrifuge tubes (Greiner-USA Scientific) and homogenized for 30 seconds using a TH OMNI Homogenizer (OMNI International, Inc.) to obtain Trizol ${ }^{\circledR}$-tissue pre-homogenates. Measured amounts of Trizol $^{\circledR}$ are then added to calculated portions of each prehomogenate to obtain $0.091 \mathrm{mg}$ tissue per $\mathrm{ml}$. This makes each tissue homogenate as experimentally similar as possible and ensures that the RNA extraction capabilities of Trizol ${ }^{\circledR}$ itself are not exceeded (as per manufacturer's guidelines). After brief vortexing, $1.1 \mathrm{ml}$ of each final Trizol ${ }^{\circledR}$-adjusted homogenate is transferred to a nucleasefree $1.5 \mathrm{ml}$ vial (USA-Scientific) and allowed to sit for 5 minutes at room temperature. $200 \mu \mathrm{l}$ nuclease-free chloroform (Fisher Scientific) is added to each and tubes are shaken vigorously for 15 seconds. Samples are allowed to sit for 3 minutes at room temperature then microfuged at $12,000 \times g$ for 10 minutes at $4^{\circ} \mathrm{C}$. Top aqueous layers are carefully removed and transferred into new nuclease-free $1.5 \mathrm{ml}$ vials, and $500 \mu \mathrm{l}$ nucleasefree 2-propanol (Fisher Scientific) is added to each. Samples are briefly vortexed, allowed to stand at room temperature for 10 minutes, then microfuged at $12,000 \mathrm{x}$ $g$ for 10 minutes at $4^{\circ} \mathrm{C}$. Large white pellets are visible at the bottom of each sample tube at this point and the 2propanol is subsequently dumped from each tube followed by three washes with pre-cooled $\left(-20^{\circ} \mathrm{C}\right) 75 \%$ nuclease-free ethanol prepared with nuclease-free water (Sigma-Aldrich, Ambion). The first two of these washes are carefully dumped off, while the third wash is vortexed until each pellet is swirling in solution to more fully wash any lingering guanidine isothiocyante (GIT) or other salts out from underneath each pellet - salts which might otherwise inhibit subsequent procedures. Next, all samples are microfuged at $15,300 \times g$ for 5 minutes at $4^{\circ} \mathrm{C}$, the final $75 \%$ ethanol supernatant is carefully dumped off, and samples are air-dried for approximately 35 minutes under a fume hood. $170 \mu \mathrm{l}$ of nuclease-free $0.1 \mathrm{mM}$ EDTA (Sigma) prepared in HPLCgrade water (Fisher) and adjusted to $\mathrm{pH} 6.75$ is added to each pellet (See Appendix 7), each sample is vortexed briefly, heated to $65^{\circ} \mathrm{C}$ for 5 minutes (to aid in RNA pellet resolubilization), vortexed briefly again, then stored at $4^{\circ} \mathrm{C}$. RNA isolates are then assessed at 1:50 dilution for quantity and purity by spectrophotometry at $260 \mathrm{~nm}$ and $280 \mathrm{~nm}$ followed immediately by DNase treatment with TURBO DNase (TURBO DNA-free kit, Ambion). Each DNase treatment reaction consists of 60 to $70 \mu \mathrm{l}$ RNA isolate, 8 to $18 \mu \mathrm{l}$ nuclease-free water, $10 \mu \mathrm{l}$ 
10X TURBO DNase Buffer and $12 \mu \mathrm{l}$ TURBO DNase enzyme. Reaction mixtures (100 $\mu \mathrm{l}$ each) are placed into an Applied Biosystems Incorporated GeneAmp ${ }^{\circledR} 2400$ thermocycler (Perkin Elmer/ABI) for 30 minutes at $37^{\circ} \mathrm{C}$. $1 \mu \mathrm{l}$ DNase Inactivation Reagent per $10 \mu \mathrm{l}$ solution is added to each tube. The tubes are incubated for 2 minutes at room temperature with intermittent vortexing every 10 to 15 seconds, and then centrifuged at 10,000 $\mathrm{g} g$ for 1.5 minutes to pellet the Inactivation Reagent. Next, if RNA is to be used directly in one-step qPCR applications, $80 \mu \mathrm{l}$ is carefully recovered from each DNase-treatment reaction; the upper transparent layer containing the RNA is transferred to a new tube (care is taken to avoid $\sim 15-25 \%$ of the solution on the bottom of each tube - which is the pelleted Ambion DNase Inactivation Reagent polymer complex that can inhibit PCR reactions) and diluted 1:10 with nuclease-free water (Ambion) resulting in $800 \mu \mathrm{l}$ of each RNA isolate to use for [FF2-6-001-calibrated] real-time qPCR analyses. However, for one-step qPCR analyses, it is important to note two things at this point: 1.) even at 1:10 dilution post DNase treatment, the RNA samples are still too concentrated to generate uninhibited qPCR target signals, and 2.) we never freeze the RNA samples from this point on before their use in qPCR; they are stored at $4^{\circ} \mathrm{C}$ in nuclease-free $1.5 \mathrm{ml}$ vials. Age-matched samples and Stock I solution-derived standards are run on the final $\mathrm{qPCR}$ plates. Prior to isolating total RNA from cultured cells, we collect cells from culture flasks by standard methods, pre-homogenize them in 1 or $2 \mathrm{ml}$ of Trizol ${ }^{\circledR}$ by hand-pipetting, then store the resulting cell pellet-Trizol ${ }^{\circledR}$ pre-homogenates at $-80^{\circ} \mathrm{C}$ until they are needed for total RNA isolation.

\section{To freeze or not to freeze RNA samples}

A controversial maneuver we perform is to never freeze our RNA isolates before use. One can freeze RNA isolates and use them later - but, we prefer to use them immediately to avoid any potential issues that might arise from freeze-thawing RNA. In order to minimize the potential effects of RNA degradation on qPCR results, we use only 'age-matched' RNA samples (RNAs isolated, DNase-treated and stored at $4^{\circ} \mathrm{C}$ on the same day) and corresponding standards (prepared from agematched Stock I solutions) during final one-step qPCR analyses. In the event that Stock I solutions are out of date with newer sample unknowns, previously- generated age-matched standard curves are used for quantitative analysis. A major reason we currently avoid freezing RNA is based on our observations of shifts in target $\mathrm{C}_{\mathrm{T}}$ values after using freeze-thawed total RNA Trizol ${ }^{\circledR}$-isolated from whole sheep lung in $\mathrm{qPCR}$ applications. These shifts, curiously, are often to lower $\mathrm{C}_{\mathrm{T}}$ values - indicating either improved reverse transcription efficiency (presumably due to less, or different secondary structures on shorter transcripts) (See Appendix 8) or possibly due to less reactants being used up during firststrand synthesis (during reverse transcription) on account of there being shorter freeze-fractured/truncated transcripts to work with; leaving more reactants available during the fluorogenic PCR phase, thereby improving the 'voracity' of the PCR. But, no matter the reason, this was troubling enough that we have since avoided freezing tissue and cell culture RNA isolates entirely. However, we have indeed observed that rarer targets (i.e. IL-10) in Stock I solutions tend to exhibit steadily weaker qPCR signals over a three month period, but it is not clear yet if this indicates degradation of RNA stored at $4^{\circ} \mathrm{C}$, or if it is the result of using primers and probes that have been repetitively freeze-thawed. One of the features of a closed system is that it eventually breaks down; so we advise investigators to use their RNA samples and Stock I preparations as quickly as possible (when using real-time one-step qPCR). Two-step realtime qPCR has the added advantage that cDNA is more stable, but, even with one-step real-time qPCR; transcriptomic profiles are skewed to some degree always in direct accordance with the method of reverse transcription used.

Laser capture microdissection (LCM)-derived RNA sample isolates

We have developed a different line of reasoning altogether to handle RNA obtained by laser capture microdissection (LCM). Because there is precious little RNA in most LCM-acquired RNA isolates, we have not studied the behavior of LCM RNA samples under as many different conditions as we would like to. In addition, the fact that LCM-derived RNA samples are often tiny to begin with (e.g. 25 cells worth of RNAcontaining total cell isolate) also means that it cannot withstand some of the immense dilutions spoken of elsewhere in this paper. But, we have used unfrozen and once-frozen LCM-derived total cell extracts directly in 
real-time one-step qPCR without noticeable differences in final results as long as samples were isolated from sections less than 8 days old in each case (16). In addition, given the different methodologies involved, there is no reason to think that the same rules would apply to LCM-derived RNA as apply to the relatively abundant RNA we get from tissues and cell cultures; extraction methods are different, carryover of potentially inhibitory biological material during RNA isolation is minimal, and sample component composition during qPCR is different (See Appendix 9). Truly, one of the great features of real-time $\mathrm{qPCR}$ is that it relies on very small sequence regions for successful amplification ( 150 bases or less typically). The law of averages would seem to favor the notion that the very small real-time qPCR regions of amplification will be left intact after multiple sample freeze-thaws and even outright RNA degradation - which is the very reason that real-time qPCR still yields spectacular results on highly-abused nucleic acid samples. In fact, we have demonstrated that extensively-freeze-thawed, five-year-old whole lung tissue Trizol ${ }^{\circledR}$-isolated total RNA used in one-step realtime fluorogenic qPCR generated nearly identical $\mathrm{C}_{T}$ values for several targets as it did on the first day of its isolation (RNA sample from ewe 265, Caverly-GruborGallup-Ackermann, 2002 unpublished). Because of this, we believe real-time qPCR will remain one of the most important, reliable tools for genetically analyzing very old and degraded RNA and DNA samples given its extreme sensitivity and modest requirement that only very small stretches of nucleic acid sequences within samples need remain intact.

CDNA synthesis using SuperScript ${ }^{m}$ III and a custom reverse transcription buffer

When two-step qPCR is to be run, the RNA isolates above are not diluted 1:10 post-DNase treatment, but instead, used directly as templates for complementary deoxyribonucleic acid (cDNA) synthesis (for use as samples or Stock I cDNAs in two-step qPCR), we use SuperScript ${ }^{\mathrm{TM}}$ III RT enzyme (Invitrogen) for reverse transcription. We prepare and use our own 10X reverse transcription buffer formulation (300 mM TRIS: $\mathrm{HCl}, 625$ $\mathrm{mM} \mathrm{KCl}, \mathrm{pH} 8.3$ ) in order that the ionic strength of our resulting cDNA solutions is similar to the ionic strength of the two-step master mix we use (TaqMan ${ }^{\circledR}$ Universal PCR Master Mix 2X, ABI). Briefly, reverse transcription master mix containing 3.38\% nuclease-free water, 31.17 $\mathrm{mM}$ TRIS, $64.94 \mathrm{mM} \mathrm{KCl}, 5.71 \mathrm{mM} \mathrm{MgCl}$, $2.08 \mathrm{mM}$ dNTP mix, $2.6 \mu \mathrm{M}$ random hexamers and $0.0222 \mu \mathrm{g} / \mu \mathrm{l}$ TURBO DNase-treated RNA is heated for 5 minutes at $65^{\circ} \mathrm{C}$ then snap-cooled on ice for at least 1 minute. We pre-dilute our TURBO DNase-treated RNA samples such that adding $36 \mu \mathrm{l}$ of each RNA to each final $100 \mu \mathrm{l}$ reverse transcription reaction results in all reactions containing $2.1389 \mu \mathrm{g}$ total RNA. Two to four such $100 \mu \mathrm{l}$ reactions are created from the same original reverse transcription master mix for all samples. Samples are spun down, and RNAse inhibitor $(20 \mathrm{U} / \mu \mathrm{l}, \mathrm{ABI})$ and SuperScript $^{\mathrm{TM}}$ III RT enzyme (200 U/ $\mu$ l, Invitrogen) are finally added to each cooled sample reverse transcription mixture (now 200 to $400 \mu \mathrm{l}$ each). The final concentrations attained of each reverse transcription component are: $3.25 \%$ nuclease-free water, $30 \mathrm{mM}$ TRIS, $62.5 \mathrm{mM} \mathrm{KCl}, 5.5 \mathrm{mM} \mathrm{MgCl} 2,2 \mathrm{mM}$ dNTPs $(0.5 \mathrm{mM}$ each of dATP, dCTP, dTTP and dGTP), $2.5 \mu \mathrm{M}$ random hexamers, $3.5 \mathrm{U} / \mu \mathrm{l}$ SuperScript ${ }^{\mathrm{TM}} \mathrm{III}$ RT enzyme, $0.4 \mathrm{U} / \mu \mathrm{l}$ RNAse inhibitor and $0.021389 \mu \mathrm{g} / \mu \mathrm{l}$ TURBO DNasetreated RNA. These reagents are vortexed gently, split into $100 \mu \mathrm{l}$ amounts into nuclease-free $0.2 \mathrm{ml}$ tubes (Midwest Scientific), and the tubes are placed into the GeneAmp ${ }^{\circledR} 2400$ thermocycler (which only accepts samples of $100 \mu \mathrm{l}$ or less) for reverse transcription using thermocycler conditions of: 5 minutes at $25^{\circ} \mathrm{C}, 45$ minutes at $53^{\circ} \mathrm{C}, 15$ minutes at $70^{\circ} \mathrm{C}$, followed by a safety hold at $4^{\circ} \mathrm{C}$.

Concerns over the use of cDNA in two-step fluorogenic real-time qPCR

For those who prefer to make their own cDNAs beforehand in pursuit of two-step real-time qPCR as the relative quantitative tool of choice, it is interesting to note that cDNAs, when reverse transcribed from Trizol ${ }^{\circledR}$ isolated RNAs showing original sample o.d.260nm readings (at 1:50 dilution) of 0.011 to 0.022 and higher are (by the time they are synthesized and diluted i.e. 1:10 before use in $\mathrm{qPCR}$ ) already safely outside the dilution range where most qPCR inhibition would exist. For column-isolated RNAs, the lowest acceptable original o.d.260nm value at 1:50 dilution for each RNA isolate can be calculated to be about 0.00275 to 0.0055 in the same regard. These observations apply to fairly standard reverse transcription reactions wherein $2 \mu \mathrm{g}$ of RNA is used per each $100 \mu \mathrm{l}$ reverse transcription reaction for cDNA 
synthesis (according to standard ABI practice) whereas 1 $\mu \mathrm{g}$ of RNA is used per each $100 \mu \mathrm{l}$ reverse transcription reaction during Invitrogen SuperScript ${ }^{\mathrm{TM}}$ II reverse transcription reactions. Additionally, to improve the overall yield of all cDNA synthesis reactions, it has been recently noted that priming reverse transcription reactions with random pentadecamers (as opposed to random hexamers or other primers) boosts cDNA yields by 2 -fold while increasing the number of detectable transcripts by 11-fold (26) (See Appendix 10). In our experience, qPCR inhibition is still evident with the most concentrated cDNA standards or samples examined for the presence of the frequently-used housekeeping gene, $18 \mathrm{~S}$ ribosomal RNA, so care should be taken to dilute all similarly destined cDNAs at least 500 to 1,000-fold further before trustworthy $\mathrm{C}_{\mathrm{T}}$ values can be generated from such robustly-abundant target transcripts (See Appendix 11). An additional caveat to note regarding two-step real-time qPCR is that rare targets are often not amplified as efficiently by two-step as they are by onestep real-time qPCR. This, we have concluded, is the very result of cDNA templates already having suffered considerably more dilution along the way from RNA isolation, through reverse transcription reactions and any additional dilutions before qPCR takes place. We have found our strongest qPCR signals from rare targets using one-step as opposed to two-step real-time qPCR. Further, by setting up one-step real-time qPCR plates in strict accordance with what the FF2-6-001 qPCR set-up tool (see Figs. 11 through 39 for depictions and descriptions of the different portions of the FF2-6-001 file system) reveals to us about the proper dynamic range of each target, we avoid diluting our RNA samples too much or too little and are therefore able to preserve maximal qPCR signal strength from each target amplification of interest while at the same time avoiding all qPCR inhibitory phenomena. Real-time signal (either target or housekeeper-derived) contributions generated from genomic DNA-contaminated samples during qPCR can be mathematically addressed by custom files as well (Fig. 42).

\section{Housekeeping gene considerations}

Another area of concern has been choosing appropriate housekeepers for $\mathrm{qPCR}$, and most recently it appears that Ubiquitin, various Transcription factors, Transferrin receptor and Ribosomal Protein S15 are all thought to be fairly stable housekeepers at this point, whereas GA3PDH, $\beta$-actin and $\beta$-tubulin have been given mixed reviews as of late. It is also possible that the same housekeeper's usefulness may vary from tissue to tissue, but Ubiquitin still seems to be quite stable in this regard $(1,2)$. However, in vivo (endogenous) housekeepers may become a thing of the past as more investigators explore the use of in vitro synthetic constructs or transcripts from highly disparate species (which exhibit no homology with the genome of the species being studied) - e.g. a jellyfish photoprotein (aequorin; GenBank accession number L29571) cRNA was successfully used as a 'reference gene' (as an externally-introduced 'housekeeping' gene) in recent murine studies at the University of Bonn, in Bonn, Germany. The foreign reference jellyfish cRNA was found to be just as reliable as three other endogenous murine housekeeping genes ( $\beta$-actin, GA3PDH and HPRT1) in that study (29). Normalization of gene expression using expressed Alu repeat elements is also currently being proposed (40), which will be highly useful for primate RNA samples. In addition, RNA samples taken from other mammalian genomes (for the purposes of qPCR) which house similarly unique (species-specific) repetitive genetic elements (many of which, like Alu sequences, are found within the untranslated regions of numerous mRNAs throughout the transcriptome), (41), might also take advantage of this approach, while RNA samples from animals with indigenously fewer unique repeats, such as birds, may benefit little from it (42).

\section{Review of basic real-time qPCR math}

Crucial to the proper interpretation of any real-time qPCR data is a clear understanding of the mathematical principles underlying generation of the data. Though it is not the intent of this manuscript to promulgate the entire possible range of the math involved, it is nonetheless important to touch on the most relevant equations and concepts; some of which are likely generally familiar and accepted, and one or two of which may be unique. In brief, the ideal slope $(\mathrm{m})$ of the dilution curve for any real-time $\mathrm{qPCR}$ target is invariably $-1 / \mathrm{LOG}_{10}(2)$ or the value "-3.3219..." etc. Such a slope indicates a reaction Efficiency or 'Efficacy' (E) of 1 (or 100\% Efficiency), which correlates to an Exponential Amplification (ЕАмP) value of 2 (indicating a perfect doubling of template 
every cycle). When efficacy of template doubling per cycle is sub-optimal, $\mathbf{E}<1$ and $\mathbf{E}$ Aмp $<2$, e.g. if $\mathbf{E}=0.83$, then $\mathbf{E}_{\text {AMP }}=1.83$ since the expressions for $\mathbf{E}$ and $\mathbf{E}$ AMP are $\left[10^{(-1 / \mathrm{m})}-1\right]$ and $10^{(-1 / \mathrm{m})}$, respectively. When $\mathrm{E}$ is not known, the expression, " $2^{\Delta \Delta \mathrm{C} t}$ ” (or " $2^{-\Delta \Delta \mathrm{C} t}$ ") can sometimes be used to compute the approximate fold change in gene expression between control and treated samples (or normal vs. abnormal, diseased vs. nondiseased, or any sample vs. an appropriately-selected "calibrator" sample, etc.), but this expression is simplistic in that it entirely ignores the impact that $\mathbf{E}$ has on the target and housekeeper reactions in each case (36). When E is known for targets and housekeepers, the $2^{-\Delta \Delta C t}$ expression can be expanded into: Fold increase $=\mathbf{~}(2 \mathbf{x}$

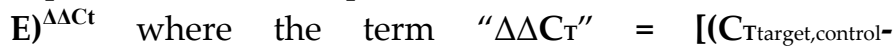

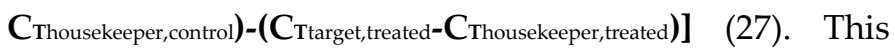
("expanded $2^{\Delta \Delta C t \text { ") }}$ equation generates similar (though not identical) results to the "Pfaffl Equation" (28) and the "ISU Equation" (see below) only when the term " $(2 \times \mathrm{E})$ " is replaced by the more precise term " $(1+E)$ " to yield the

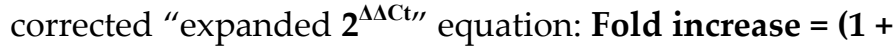

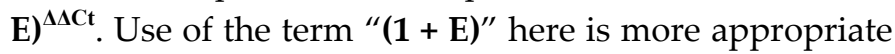
since it is in direct keeping with the original universal expression for all PCR amplifications: " $\mathbf{X}_{\mathbf{n}}=\mathbf{X}_{\mathbf{o}}(\mathbf{2})^{\mathrm{n}}$," which, for less-than-100\%-efficient reactions, by necessity becomes: " $\mathbf{X}_{\mathbf{n}}=\mathbf{X}_{\mathbf{0}}(\mathbf{1}+\mathbf{E})^{\mathbf{n}}$." In this equation, " $\mathbf{X}_{\mathbf{0}}$ " represents the initial number of target copies, " $\mathbf{n}$ " represents the number of cycles elapsed, " $\mathbf{X}_{\mathbf{n}}$ " represents the number of target amplicons generated after " $\mathbf{n}$ " cycles, and " $E^{\prime \prime}=$ Efficiency $\left(\left[10^{(-1 / m)}-1\right]\right),(36)$. When the

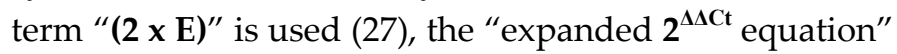
is prone to underestimating fold differences between samples, whereas using $\mathbf{2}^{\mathbf{\Delta \Lambda C t}}$, by itself, consistently overestimates fold differences since it is inherently erroneous in that it assumes all $\mathrm{qPCR}$ reactions to be $100 \%$ efficient. $2^{\Delta \Delta C t}$ is nonetheless a very helpful and informative approximation when efficiencies are unknown.

\section{Efficiency of reaction versus exponential amplification}

It is always important for one to differentiate between "E" and "EAmp" since the Pfaffl Equation uses "EAmp" instead of " $E$ " when solving for relative quantitative and absolute quantitative gene expression results. These two terms are often confused in the literature and are mistakenly represented as interchangeable, which they are not. As a result, investigators can be thrown off course during the computation of their qPCR results. The Pfaffl Equation can be written as follows:

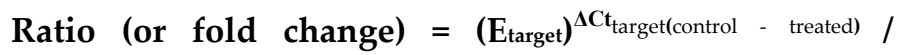
(Ehousekeeper) ${ }^{\Delta \mathbf{C t}} \mathbf{t}_{\text {housekeeper(control - treated) }}$

where $\mathrm{R}=$ "ratio" or calculated fold change in a specific target gene's presence or expression level when comparing RNA isolated from a treated (or infected) plant or animal tissue or cell type to RNA from the corresponding normal, control or calibrator RNA samples (28). The value often written as " $E$ " in the Pfaffl Equation is indeed "EAmp"; 10 10 (-1/m), and should not be confused with the symbol " $E$ " which connotes amplification reaction efficiency; $[\mathbf{1 0}(-1 / \mathrm{m})-1]$. In addition to the Pfaffl Equation, there is another important partial equation that can be repetitively incorporated into a mathematical expression to form an equation (the ISU Equation) which generates values identical to that of the Pfaffl Equation. However, the ISU Equation makes room for the investigator to plug in the values of " $\mathrm{m}$ " and " $\mathrm{b}$ " from target and housekeeper standard curves and is derived from a partial equation indirectly alluded to in ABI User Bulletin \#2 (31), namely: "Qty = 10((CT-b)/m)," where "Qty" = the relative calculated quantity for any target, $\mathrm{C}_{\mathrm{T}}=$ the observed $\mathrm{C}_{\mathrm{T}}$ generated for the particular target or housekeeper being evaluated, and " $m$ " and " $b$ " are the slope and y-intercept, respectively, of that target or housekeeper's standard curve (which are plots of $\mathrm{LOG}_{10}$ of the Stock I or sample dilution factors or "LOG 10 input," versus $C_{\mathrm{T}}$ ). The expression "Qty $=\mathbf{1 0}($ ((CT-b)/m)" can be directly assembled into the ISU Equation in the following way:

\section{Ratio (or fold change) $=$}

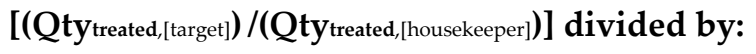
$\left[\left(\right.\right.$ Qty $\left._{\text {control, }, \text { target] })}\right) /\left(\right.$ Qty $\left.\left._{\text {control, }, \text { housekeeper })}\right)\right]$

Notice that, implicit in the ISU Equation, are the Efficiency (E) values for housekeeper and target gene amplifications by virtue of the equation's direct inclusion of " $\mathrm{m}$ " and " $\mathrm{b}$ " values from the corresponding target and housekeeper standard curves. Although one finds that the Pfaffl and ISU equations both generate identical results, be aware that these values are not yet amenable 
to sound statistical analysis - the resulting values must be logarithmically transformed, using any logarithmic base (Figs. 40 and 41). We have chosen to transform to LOG base 2 values (LOG 2 ) in accordance with Gilsbach et al. (29). In this form, qPCR (and PCR) data of any kind appropriately lends itself to correct parametric, t-test and/or box-plot statistical analyses (29, 30 and Dr. Marcia de Macedo, 2004 unpublished). We LOG transform our qPCR data as soon as we have calculated our relative quantity values (either before or after division by housekeeper values). Subsequently, treatment group averages, standard deviations within treatment groups and standard error of the mean (s.e.m.) error bar ranges are all calculated from the LOG-transformed quantity values. Once this first stage of data processing is complete, control group averages are then directly subtracted from themselves and all related treatment group averages (so all control groups appear at "0" level expression), a maneuver which is supported by the law of logarithms wherein LOG A/B = (LOG A - LOG B), and finally, new standard error bars are recalculated using the equation:

\section{$\sqrt{\text { s.e.m. }{ }^{2} \bar{x}+\text { s.e.m. }{ }^{2} \bar{y}}$}

which can be derived through statistical variance equations. LOG transformation of PCR data of any kind is a necessity - it is the nature of PCR to show higher variability with lower mean quantity values due to the ever increasing Monte-Carlo effect with decreasing presence of target template in nucleic acid samples (2, 37). This reality is exposed only after LOG transforming quantitative $\mathrm{qPCR}$ data. If $\mathrm{PCR}$ data is not LOG transformed, one tends to see an opposite, counterintuitive trend: i.e. increasing variance with higher relative quantity means - which is definitely not true as many qPCR investigators can certainly attest to $(2,29,30$ and Dr. Marcia de Macedo, unpublished 2005). The trend most commonly observed in qPCR shows that final quantitative results generated from consistently lower $\mathrm{C}_{\mathrm{T}}$ values are generally more stable from replicate to replicate, from sample to sample (low variance), but once target or housekeeper $\mathrm{C}_{\mathrm{T}}$ values rise above 40 , quantitative data begins to exhibit greater and greater degrees of statistically unacceptable variance due to the Monte-Carlo effect in addition to the background "noise" of the assay itself (resulting from the increasing accumulation of, and fluorescent signals from cleaved or displaced probe fluorogens and/or fluorescence-capable quenchers as the PCR proceeds) $(32,33)$. In our work, it has often been informative to additionally categorize qPCR targets according to the $\mathrm{C}_{\mathrm{T}}$ range within which we usually expect them to appear during qPCR. Since $C_{T}$ values are directly indicative of original target template abundance, we have created four categories into which most qPCR targets seem to fit, namely: 1.) rare transcripts; ( $\mathrm{C}_{\mathrm{T}}$ range of 38-47), 2.) intermediateabundant transcripts; (Ст 26-37), 3.) abundant transcripts (housekeepers such as GA3PDH, $\beta$-actin, $\beta$-tubulin and RPS15); (Ст 20-25), and 4.) hyper-abundant transcripts (i.e. $18 \mathrm{~S}$ ribosomal RNA); (Cт 12-19). It is within the latter portion of the "rare transcripts" $\mathrm{C}_{\mathrm{T}}$ range noted above that investigators can also expect to experience the Monte-Carlo and assay "noise" effects to some degree. This "rare transcript" status can result from target mRNA being either endogenously rare by nature, made rare by experimental treatment or disease, by sheer sample degradation, or by over-diluting templatecontaining RNA or cDNA samples during qPCR set ups.

\section{qPCR sample dilution and $\mathrm{C}_{\mathrm{T}}$ relationships}

To continue, the final important mathematical relationships which are essential to one's understanding of the 'mathematical terrain' associated with qPCR include the following interesting expressions:

A.) $\mathbf{2}^{\lambda}=\mathbf{f}$, where " $\lambda$ " = the ideal expected frequency of appearance of $\mathrm{C}_{\mathrm{T}}$ values for any dilution series between or among samples and " $\mathrm{f}$ " = the known dilution factor between or among samples. Expression A can be rearranged to give expression $\mathrm{B}$ :

B.) $\lambda \mathbf{L O G}_{10}(\mathbf{2})=\operatorname{LOG}_{10}(\mathbf{f})$, which can be rearranged further into expression $\mathrm{C}$ :

C.) $\lambda=\operatorname{LOG}_{10}(\mathbf{f}) / \mathrm{LOG}_{10}(\mathbf{2})$, which can be rearranged to result in an interesting expression for Efficiency (not Exponential amplification) using the same variables:

D.) $\mathbf{E}=\mathbf{f}^{(1 / \lambda)}-\mathbf{1}$, or: $\mathbf{E}=\mathbf{f}^{(1 / \Delta \lambda)}-\mathbf{1}$ (when " $\mathbf{f}^{\prime \prime}$ is known), and $\mathbf{E}=\Delta \mathbf{f}^{(1 / \lambda)}-\mathbf{1}$ (when " $\lambda$ " is known)

The utility of expressions A and C above become immediately obvious when one realizes, for instance, 
that a serial 1:2 progression of diluted standards should ideally generate curves crossing threshold (generating $C_{T}$ values) at a frequency of "LOG $10(\mathbf{f}) / \mathrm{LOG}_{10}(2)$ " or 1 cycle apart; since $\mathbf{f}=\mathbf{2}$ in this case, the final expression here becomes "LOG ${ }_{10}(2) / \mathrm{LOG}_{10}(2)=1 . "$ If the serial progression were 1:7, $\mathrm{C}_{\mathrm{T}}$ values obtained from the corresponding amplification curves would be expected to be spaced "LOG $10(7) / \mathrm{LOG}_{10}(2)$ " or 2.80973 cycles apart. When serial progressive dilutions of samples are 1:10, $\mathrm{C}_{\mathrm{T}}$ values from the amplification curves would be expected to be spaced "LOG $10(10) / \mathrm{LOG}_{10}(2)$ " or 3.3219 cycles apart, and so on. On the other hand, when solving for " $\lambda$," if for instance the observed $\mathrm{C}_{\mathrm{T}}$ values of a progressive target dilution series were observed to be about 2.3219 cycles apart, one can calculate that the progressive dilution series factor is " $2{ }^{\lambda "}$ or $2^{2.3219}$ or " 5 " (indicating that the underlying dilution pattern was based on serial progressive 1:5 dilutions of the qPCR sample RNA, cDNA, Stock I, viral RNA or DNA, etc.). This 5-fold difference in initial target template amounts between samples reveals the utility of the expression, " $\mathbf{2}^{\mathbf{\Lambda C T}}$ ", or

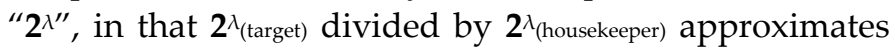
the Pfaffl equation, and $\operatorname{EAMP}^{\lambda}{ }_{\text {(target) }}$ divided by

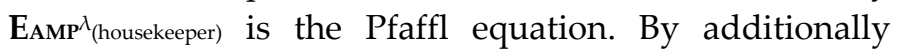
dividing the resulting value of the above expression, $\left[\mathbf{2}^{\lambda_{\text {(target) }}} / \mathbf{2}^{\lambda_{\text {(housekeeper) }}}\right.$, by the $\mathbf{2}^{\lambda}$ value of a calibrator

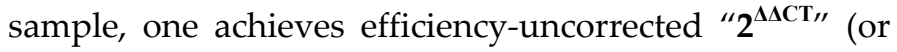
" $2^{-\Delta \Delta C T "}$ ) analysis of qPCR data (36). On the other hand, dividing the resulting value of the expression, [EAMP ${ }^{\lambda}$ (target) / $\mathrm{EAMP}^{\lambda}$ (housekeeper) $_{\text {, }}$ by the $\operatorname{EAMP}^{\lambda}$ value of a calibrator

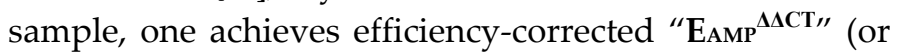
"ЕАмP ${ }^{-\Delta \Delta C T ")}$ analysis of qPCR data. Values generated by this latter equation are identical to results obtained from both Pfaffl and ISU equations. When fold change in gene expression is not calculated in comparison to a calibrator sample's target expression levels, the equations $\left[2^{\lambda_{\text {(target) }}} /\right.$ $2^{\lambda}{ }_{\text {(housekeeper) }}$ or $\left[\mathrm{EAMP}^{\lambda}{ }_{\text {(target) }} / \mathrm{EAMP}^{\lambda}{ }_{\text {(housekeeper) }}\right.$ ] suffice to reveal fold differences in target gene expression between samples. But, in order to statistically assess the data generated by any of these quantitative equations correctly, LOG-transformation of the resulting values is necessary $(29,30,36)$. Any departures from expected $C_{T}$ frequencies $(\lambda)$ of course indicate departures from ideal amplification reaction efficiencies, and for dealing with non-ideal situations (which predominate in practice), we have developed the equation, $-\mathrm{LOG}_{10}(\mathbf{f}) \times\left(1 / \mathrm{LOG}_{10}(2)-\right.$ $\left.\left(\left(1 / \operatorname{LOG}_{10}\left(\left(\left(10^{\left(1 /\left(\left(\Delta \mathrm{Ct}_{\mathrm{t}} / \mathrm{LOG}_{10}(\mathrm{f})\right)\right)\right.}\right)\right)\right)\right)\right)\right)$, to predict $\mathrm{C}_{\mathrm{T}}$ appearances for any dilution factor between or among samples at any amplification reaction efficiency (E). The FF2-6-001 qPCR set-up tool is based on such equations.

\section{Efficiency of target amplification concerns}

It is important to note that the efficiencies of $\mathrm{qPCR}$ amplification reactions are initially only as good as primer and/or probe designs allow. But, equally important are the nucleic acid template dilutions used on a per-target basis. Greater than $100 \%$ efficiency (indicative of Type 1 inhibition in our experience) may be observed, and different primer-probe designs (even for the same target) will exhibit varying degrees of susceptibility (or be differentially prone) to each type of inhibition. These potentially confounding phenomena indeed present ongoing challenges to enzymologists and other scientists to further elucidate the molecular mechanisms underlying each particular form of qPCRrelated inhibition. In general, the slope of a qPCR target standard curve is the best indicator of whether or not there are problems with one's qPCR primer-probe designs or template dilutions. Further, after optimizing primers and probes and determining optimal template dilutions for each qPCR target, by running standard curves for all targets on each $\mathrm{qPCR}$ plate, one can logistically side-step two common qPCR pit-falls: 1.) since all qPCR reactions for each target on a plate can be assumed to be governed by the same target-specific reaction efficiency (or indeed, inefficiency), including standard curves on each plate (for each target) essentially controls for plate-specific variations for each qPCR target since all same-qPCR target samples on any given qPCR plate will be judged on the same 'kinetic playing-field' as their standard curves are (i.e. all sample targets and their corresponding standards on each plate can be thought to have experienced the same environment together throughout a qPCR amplification) and, 2.) ordering and testing multiple primer-probe sets for the same target is cost-prohibitive for many labs (unless one is willing to sacrifice time and target specificity by using SYBR Greenbased real-time assays during optimization). Preparing standard curves for each different target on each plate provides a reliable way for investigators to get valid qPCR information even when using sub-optimal primerprobe designs as long as the Monte-Carlo effect is not present as an additional, confounding factor $(2,37)$. It is important to emphasize that these ideas appear to be most rigorous in the aftermath of running a proper Test 
Plate for all targets beforehand. It has been our experience almost $100 \%$ of the time, that when we design our real-time primer-probe qPCR sets using Primer Express v. 2.0, our resulting observed reaction efficiencies are consistently in the $90-110 \%$ range - but, again, only after we have responsibly performed the appropriate Test Plate(s) and analyzed the data using the FF2-6-001 qPCR set-up tool.

\section{The high importance of running a Test Plate}

On occasion, one may observe larger departures from ideal efficiencies among series of plates using the same standard curve template source, but, even then, efficiencies as low as $60 \%$ and as high as $140 \%$ can still be used to acquire credible data if the standards and samples on a single plate are weighed against one another for that plate alone and not cross-compared to results from other plates which have exhibited significantly different efficiencies for the same targets. However, when identical standards and/or inter-plate calibrators generate nearly identical $\mathrm{C}_{\mathrm{T}}$ values for the same target(s) from plate to plate, investigators can directly compare results among plates with confidence. Still, far and above any other single issue regarding onestep qPCR optimization, we are solidly convinced that the most powerful thing one can do to attain ideal (or near-ideal) efficiencies from any qPCR target amplification is run a Test Plate to physically determine which specific RNA dilution ranges work best for each different qPCR target. For a good example of this see Figures 5 and 6 . The three (never-before-tried) primer and probe sets used in this particular study/example (Brockus-Harmon-Gallup-Ackermann, 2006 unpublished) were designed using Primer Express v.2.0, never (twostep)-optimized, and used directly at 'saturating concentrations' in each case (i.e. primers at $1 \mu \mathrm{M}$, and probes at $150 \mathrm{nM}$ ). After running a Test Plate for all three targets to identify the optimal RNA dilution range for each, we were able to obtain virtually $100 \%$ efficiency from each target amplification in the final qPCR study. Since we have repeated this approach successfully numerous times with other genes, we are confident that it is template dilution that affects the efficiency of realtime qPCR reactions to the greatest degree - barring any obvious thermodynamic flaws in real-time qPCR primer/probe designs or reaction formulations. Again, any qPCR RNA sample's ability to inhibit qPCR reactions can be diminished and eventually eliminated entirely the further one dilutes RNA samples in effort to attain the useful ranges for each target (as dictated by what one discovers by appropriate Test Plate analyses). There is indeed a "happy sample dilution range" for each qPCR target.

The effect(s) of sheer sample dilution

In most cases, useful RNA dilution ranges are so dilute (with respect to the originally-isolated RNA samples themselves) that most qPCR inhibitory phenomena has already been eliminated by the time the reactions are run. Factors known and unknown (which would normally bring about real-time qPCR inhibition when more concentrated sample RNAs are used) present no threat to qPCR reaction kinetics whatsoever after ample RNA sample dilution has occurred. Once ideal qPCR template dilution ranges are established for each different target, intended real-time qPCR reactions are allowed to proceed undaunted by inhibition of any kind. In this way, one can use the sensitivity of the real-time qPCR technique itself in its own favor since most targets can be detected - even when RNA is diluted extensively (e.g. most housekeepers still give robust $\mathrm{qPCR}$ signals even when diluted out beyond 1:1,000,000!) (See Appendices 11 and 12). Template dilutions thus serve a two-fold purpose: 1.) they achieve optimal template concentrations for each qPCR target of interest, and, 2.) they aid in greatly reducing and eliminating all potential forms of qPCR inhibition. Real-time qPCR inhibition can indeed be muted and even eliminated merely by RNA sample dilution in most cases, therefore leaving all nucleic acid target templates within each RNA sample genuinely available to participate in highly efficient (andtherefore-quantitatively-accurate) qPCR amplifications. Once rendered non-existent by dilution, it simply doesn't matter what type of sample-related inhibition could have had the potential to manifest itself during qPCR using more concentrated RNA; once it is carefully and premeditatedly eliminated by dilution, it is no longer of any consequence. Clearly, preliminary qPCR Test Plates serve to verify where each target reaction's optimal, noninhibitory RNA dilution range is by examining an RNA sample (or mixture of RNA samples, i.e. Stock I) that is truly representative of all RNA samples examined in each particular qPCR study. In the event that the optimal dilution of an RNA sample for a rare-but-present qPCR 
target impinges on that target's ability to amplify, further purification of sample RNA may be necessary to minimize its inhibitory characteristics (2). Toward addressing and attaining each of these important objectives, the FF2-6-001 qPCR set-up tool is well suited.

Finding optimal dilution ranges for each qPCR target by running a Test Plate

Before a qPCR Test Plate procedure can be correctly performed, it is often helpful that all qPCR primers and probes have already been optimized on cDNA template (by two-step qPCR) weeks or months prior to using them in hydrolysis probe-based fluorogenic one-step qPCR reactions. Or, if optimization is not affordable cost or time-wise, one may simply use saturating concentrations of primers $(1 \mu \mathrm{M})$ and probes $(150 \mathrm{nM})$ for all targets. Additionally, if two-step optimizations have already been carried out, reverse primer concentrations should all be increased at least $200 \mathrm{nM}$ in each case (for use in one-step qPCR) unless saturating concentrations are already being used. Reverse primers are more highly exhausted by one-step than two-step qPCR on account of their being incorporated into the amplicons during firststrand synthesis (16). By running a preliminary, universally-useful qPCR template dilution Test Plate (Figs. 18 and 22) for all targets in a one-step real-time qPCR assay over a (post-DNase, in-well) dilution range spanning from 1:38.46 to $1: 5,000,000$ ) of a representative RNA sample or RNA mixture (See Appendix 13), we quickly identify the useful dilution ranges for each particular qPCR target by using FF2-6-001 custom Excel files TestPlateResultsAnalysis2006.xls and TestPlateResultsAnalysis2006b.xls (Figs. 22-29 and 34). In all cases, immediately after Turbo-DNase treating our RNAs, we dilute them 1:10 with nuclease-free water and place the RNAs at $4^{\circ} \mathrm{C}$ for safe-keeping (never $-80^{\circ} \mathrm{C}$ ); we never freeze our isolated RNAs before use. The $\mathrm{C}_{\mathrm{T}}$ values obtained from the Test Plate are entered into the TestPlateResultsAnalysis2006.xls file, the user then selects points for each target dilution study which give the best efficiency for each target and activates the appropriate pre-programmed macros which function to accept the user's modifications and serve to help identify the optimal/useful RNA sample dilution ranges for each qPCR target. After the investigator has selected the dilution points for each qPCR target which demonstrate lack of qPCR inhibition, high reaction efficiency (generally accepted to be efficiencies between 80 and $110 \%$ ) and LOG-linear behavior, the FF2-6-001 qPCR setup tool quickly calculates the appropriate progressive dilution series for each target's optimal sample dilution, optimal standard curve range and standard dilution series, all serial dilutions required of the Stock I solution and RNA samples, and all master mix/primer and probe amounts to complete the entire qPCR set-up. As a general rule, it is always wise for the investigator to include standard curves for each different target on every plate since this (in theory) allows qPCR studies to tolerate lower amplification efficiencies without unacceptably compromising relative target expression $C_{T}$ analyses. Since all samples on a plate are subjected to the same environment, lower efficiency target reactions analyzed on plates including the corresponding standard curves (at least 3-point standard curves indicating efficiencies no lower than $60 \%$ ) still yield results that are truly reflective of relative target expression. The FF2-6001 qPCR set-up tool-determined dilution ranges additionally represent the useful standard curve dilution ranges for each target - within which sample unknowns and calibrators are specifically diluted so they will most likely appear between the first two standards of each Test-Plate-data-determined useful dilution curve for each different qPCR target (based on Stock I Test Plate analysis). A "sample aiming device" feature additionally allows the user to globally adjust this latter parameter as well (Fig. 39). The FF2-6-001 qPCR set-up tool's TestPlateResultsAnalysis2006.xls and TestPlateResultsAnalysis2006b.xls files are also used to make sure that real-time qPCR signals from each target remain sufficiently strong at the outer (most dilute) region of each assay by revealing the limit of 'signal exhaustibility' for each target. This information is used to ensure that each sample RNA's highest-but-useable dilution retains enough $\mathrm{qPCR}$ signal strength to allow them to remain useful as qPCR samples (e.g. as the most dilute target or housekeeper standard, etc.). The FF2-6001 qPCR set-up tool saves time by automatically performing numerous and necessary calculations and it is a goal of ours to transform it into user-friendly software that can either be purchased on $C D$, or 
downloaded by visiting the link: http://www.dna.iastate.edu/frame qpcr res.html in the near future.

\section{MasterEntrySheet.xls user interface portion of the FF2-6-001 qPCR set-up tool}

The MasterEntrySheet.xls portion of the FF2-6-001 qPCR set-up tool is the main user interface wherein the investigator can enter RNA sample o.d.260nm and o.d.260nm $/ 280 \mathrm{~nm}$ readings and the dilution factor at which o.d.260nm and $0 . d .260 \mathrm{~nm} / 280 \mathrm{~nm}$ readings were taken. This interface is also used to tell the FF2-6-001 qPCR set-up tool the method of RNA isolation, DNase treatment conditions, which samples will be included in the Stock I mixture, how much of each sample and standard are desired to complete the entire study, all Test Plate, Sample Plate and NRC (no reverse transcription control) Plate requirements, sample use, inter-plate calibrator and NTC usages (Figs. 11-17 and 20). The Stock I dilution profile for the Test Plate can also be adjusted to more fully interrogate the signal dynamics of any RNA or cDNA dilution range of interest, but, in order to save on precious RNA or cDNA samples, we suggest using the default file settings for Test Plate runs in the vast majority of all real-time qPCR situations. Instructions on how to use the FF2-6-001 qPCR set-up tool will be included either within the tool files themselves, or in an accompanying manual. The MasterEntrySheet.xls user interface file is connected (by equations and Visual Basic macros) to 22 other Excel files which make up the entire FF2-6-001 device. Each file is a unique tool in and of itself which has been carefully designed to perform numerous specific calculations within thousands of active cells. The results of one file are used by multiple other files in sequence to carry out extensively layered algorithms. Appropriate "error" messages and other reminders also appear within the files to inform the investigator when mathematically impossible demands have been entered into the system. The FF2-6-001 qPCR set-up tool also automatically identifies samples with problematically low RNA or cDNA concentrations and tells the user which samples will be expected to exhibit qPCR inhibition. After three main global macros have been activated and allowed to run, Sheet 2 within the MasterEntrySheet.xls file provides all the printable information investigators will need to set-up everything for each entire qPCR study (Figs. 19, 22, 31-35).

\section{DISCUSSION}

Given the meticulous nature of real-time qPCR, it is clear to many who perform this technique that any timesaving device during design and set-up is highly valuable (Figs. 43 and 44). Our own use of the FF2-6-001 tool has saved incredible amounts of time during $\mathrm{qPCR}$ set-ups. The development of such a tool became an absolute necessity for us after frequently dealing with as many as sixty samples and seven qPCR targets at a time - for which well-rendered preliminary targets tests and set-up calculations often took several days. With the advent of liquid-handling robot technology (Fig. 45), a marriage between such machines and the FF2-6-001 qPCR set-up tool would be most helpful and indeed welcome in the qPCR world. Addressing qPCR inhibition is of utmost importance toward attaining accurate quantitative data, and it is necessary for all qPCR investigators to be able to clearly demonstrate that they are using their qPCR samples at non-inhibitory concentrations (no matter what the cause of inhibition is). Manuscripts lacking such proof yet espousing accurate qPCR results should be read with caution since qPCR inhibition, in particular, is perhaps the most problematic feature of the assay, and we feel it has not yet been addressed as much as it really should be. We hope that this manuscript serves a role in that regard. As a case in point, what if RNA sample-related one-step real-time qPCR inhibition were to remain uncorrected or unaddressed during routine analysis for $\mathrm{H} 5 \mathrm{~N} 1$ in infected duck tissues for example (Fig. 46) and, what if studies using Northern analyses to assess gene expression or viral presence produced data which indicated a much higher fold gene expression or viral presence than correlate real-time qPCR studies showed? Such scenarios could be explained on the troubling basis that sample RNA (or cDNA) was not responsibly ascertained to be non-inhibitory to the qPCR assay itself beforehand. This is why it is so important to run a Test Plate using a mixture of some or all of the DNase-treated RNAs (or cDNAs) in an experiment as a Stock I RNA (or cDNA) solution - and test this Stock I for each target (up to 7 targets in our designs) in singlet (to save on master mix) along a dilution profile typically ranging from 1:10diluted Stock I, on out to 1:1,300,000-diluted Stock I (which translates into a range of 1:38.46 to $1: 5,000,000$ final in-well sample dilutions). Keeping track of the approximate nanograms of RNA or cDNA per $\mu$ for 
each sample throughout all procedures (by taking into account all dilutions incurred by each sample since original o.d.260nm readings were performed for each individual RNA) becomes important when trying to identify possible causes of observed inhibitory phenomena based on final in-well sample RNA or cDNA concentrations. In cases where one is using extremely small amounts of total RNA in-well (e.g. as with many housekeeping targets), one has already eliminated inhibition Types 1, 2, 3 and 5 inhibition by dilution alone, but, one has not eliminated the possibility that sequencespecific interactions with specific primers and probe for each qPCR target could still be causal agents of inhibition (38). This is complex and has been discussed recently as being tissue-specific as well $(1,2)$. As yet unknown or unidentified causes of qPCR inhibition (i.e. "Type 6") may indeed abound.

\section{CONCLUSIONS}

In closing, it is important to note that we have crafted the FF2-6-001 qPCR set-up tool to address as many features of qPCR as possible in order that users are able to swiftly attain precise qPCR set-ups specifically tailored to each experiment's unique dynamics. Investigators can speed things along toward meaningful real-time qPCR results in other crucial ways as well by: 1.) using primers and probes that have already been optimized on cDNA and have been shown to be able to generate reliable, high efficiency dilution/calibration/standard curves days or weeks in advance (or one may use $1 \mu \mathrm{M}$ primers and 150 $\mathrm{nM}$ probe in all cases where primer-probe optimizations have not yet been performed), 2.) identifying the best, sample-specific RNA isolation technique which yields RNA isolates that exhibit the least amount of inhibitory phenomena during qPCR; and sticking with that method while bearing in mind that Trizol ${ }^{\circledR}$ isolation is still the cheapest way to go, 3.) running a Test Plate for all targets of interest using a representative sample or mixture of samples (e.g. Stock I), 4.) analyzing Test Plate results to identify the target-specific dilution ranges within which each different target generates a near-ideal slope (e.g. -3.3219) while exhibiting LOG-linear behavior, then, diluting all samples into these multiple ideal ranges so each sample can be used for each different target within each target's specific useful dilution range. This not only improves confidence in targets being able to amplify within the useful range of their standard curves, but also ensures that inhibition of any variety is absent and that high fidelity reactions can be consistently expected - all things which the FF2-6-001 qPCR set-up tool quickly and faithfully calculates, 5.) identifying, validating and using at least two reliable sample-specific housekeepers in each qPCR study, 6.) making sure all nucleic acid samples are treated identically before qPCR (i.e. DNase-treatment conditions, etc.) - including the RNA or DNA used to generate absolute or relative standard curves, and 7.) running standard curves on each and every plate for each target tested - never forget that it is always correct to run standard curves on every plate - for this way, samples and standards both suffer the same degree of reaction efficiency or inefficiency whichever the case may be, thus allowing one to obtain more precise relative data. For fluorogenic real-time qPCR, our own bias is toward using the hydrolysis probe method in a one-step approach exclusively in all situations since it has the added advantage of being able to use forward and reverse primers to further reinforce the specificity of the fluorogenic probe in target amplifications by acting as 'rooks [primers] guarding the fidelity of the [probe] king' - making doubly sure that only a highly-specific reaction takes place - especially in cases where one, two, or all three of these players can be designed to span a genomic intron - or introns - or other strategically advantageous regions. MGBNFQ probes allow even more possibilities. And finally, fortunately, it is the nature of PCR to amplify extremely small amounts of starting nucleic acid template material, and our studies have all benefited from this classic feature in that all tissue RNAs isolated for all studies so far (and subsequently diluted appropriately on a target-by-target basis to each of their optimal non-inhibitory, LOG-linear ranges) have exhibited solid target signals. We contend that all Stock I solutions will be useful if they are comprised of the experimental samples involved in each qPCR study. Stock I solutions in and of themselves (by virtue of them being composed of either portions of all the samples in a study, or portions of those samples most expected to contain all qPCR targets of interest) represent self-mitigating/self-attenuating tools already tailored to the specific confines (known and unknown) of each particular qPCR study. A "closed system" is formed this way - a system that by default is allowed to establish its own characteristic dynamic(s) since, by design, it uses the very stuff it is made of in order to study itself. 


\section{APPENDICES}

\section{Appendix 1}

Final, in-well dilution of sample RNA refers specifically to the dilution that each RNA sample incurs post DNasetreatment by the time it exists in the PCR plate reaction wells. In our lab, for Turbo DNase-treating RNA, we typically use 60 to $80 \mu \mathrm{l}$ of RNA sample in each $100 \mu \mathrm{l}$ DNase-treatment reaction, which, after inactivation reagent is added, each become $110 \mu \mathrm{l}$ - from which $80 \mu \mathrm{l}$ of each final DNase-treated RNA sample is recovered. The DNase-treated RNAs are then immediately diluted 1:10 with nuclease-free water (Ambion) and stored at $4^{\circ} \mathrm{C}$ (not $-80^{\circ} \mathrm{C}$ as commonly suggested). After optimal dilutions for each target (as established by FF-2-6-001-based Test Plate analyses) have been carried out, $7.8 \mu \mathrm{l}$ of each optimally-diluted RNA sample is subsequently used in each final $30 \mu \mathrm{qPCR}$ reaction mixture (of which $25 \mu \mathrm{l}$ is added to the final 96-well qPCR reaction plates). The in-well dilution of each RNA sample is thus 0.26 in each case. So the most concentrated RNA sample possible (post DNase-treatment, in-well) in our one-step real-time qPCR studies is a 1:38.46-diluted RNA sample (e.g. 0.1 [immediately post-DNase dilution factor] $x 0.26$ [in-well dilution factor]). But, this dilution is rarely useful as it consistently demonstrates severe qPCR inhibition; no amplification of target signals. Consequently, it is only useful as the sample on Test Plates which most clearly exhibits the stark reality of real-time qPCR inhibitory phenomena (possibly all five types). We routinely use all of our DNase-treated sample RNAs within 6 months and have found most of them to be stable (stored at $4^{\circ} \mathrm{C}$ ) for over three years as real-time qPCR templates (which is highly contrary to the plethora of technical literature which warns against this). We have designed the FF2-6001 qPCR set-up tool to keep track of all RNA sample dilutions at every step along the way throughout each entire qPCR procedure; from initial RNA spectrophotometer $260 \mathrm{~nm}$ and $280 \mathrm{~nm}$ readings on. This feature makes it possible for us to know the ng/ $\mu \mathrm{l}$ in-well RNA concentrations for each final target qPCR reaction (see Figures 37 and 38).

\section{Appendix 2}

Type 4 inhibition is especially difficult to assess or identify when using commercial master mixes since such reagents are restrictive in that they are very rarely altered by investigators before use in qPCR. $\mathrm{Mg}^{2+}$ and $\mathrm{dNTP}$ concentrations, along with other corporately undisclosed proprietary components (including passive reference molecules such as "ROX") are assumed to be "optimal" as is - as purchased from the manufacturer. But, as most conventional PCR users know, adjusting $\mathrm{Mg}^{2+}$ concentrations, in particular, has profound effects on the efficacy of PCR reactions in general, and such adjustments to commercial master mixes would undoubtedly influence the kinetics of primer-probe interactions with qPCR target templates. Adjusting, for instance, $\mathrm{ABI}$ master mix $\mathrm{Mg}^{2+}$ concentration from $7.5 \mathrm{mM}$ to $5.5 \mathrm{mM}$ has been demonstrated be more appropriate for $\mathrm{PPCR}$ amplification of the ubiquitously-abundant $18 \mathrm{~S}$ ribosomal RNA [housekeeping] transcript (34), but, in practice, most investigators find such adjustments too nebulous or laborious to pursue. The "high-throughput" philosophy of real-time qPCR relies heavily on the existence of immediately-available, ready-to-use, pre-optimized (yet notoriously expensive) reagents, and as a result, the impetus for investigators to manipulate [pre-made] master mix components in effort to study the finer thermodynamic details of primer-probe interactions with real-time qPCR target templates under different conditions (e.g. to more fully explore the nature of Type $4 \mathrm{qPCR}$ inhibition) is diminished in many cases. The reality that many important proprietary components in key reagents can never be openly discussed (for fear of violating copyrights or company privacy policies) ultimately limits the rate at which such questions might be answered.

\section{Appendix 3}

$\mathbf{R}_{\mathbf{n}}$, or normalized reporter fluorescence, is the level of fluorescence detected during PCR. $R_{n}$ is calculated by dividing the reporter signal by the passive internal reference dye, rhodamine-5-carboxy-X (ROX). During PCR, $R_{n}$ increases as target nucleic acid is amplified until the reaction approaches a plateau. ROX is a proprietary passive internal reference dye that does not participate in the PCR reaction where the " $\mathrm{X}$ " in each form of ROX differs from company to

Gallup and Ackermann - Addressing fluorogenic real-time qPCR inhibition using the novel custom Excel file system 'FocusField2-6GallupqPCRSet-upTool001 ' to attain consistently high fidelity qPCR reactions

www.biologicalprocedures.com 
company (which is why ROX from different sources does not work the same). ROX emits a constant background fluorescent signal throughout the reaction. If there is a change in the delivered volumes of PCR Master Mix due to pipetting errors or sample evaporation, there will be a change in the intensity of fluorescence produced from the ROX molecule. e.g. if a sample has slightly evaporated - the components in the mixture are more highly concentrated and thus would give off more fluorescent signal per unit volume; this is true not only for ROX, but your target and endogenous reference reactions as well. Most quantitative PCR machines automatically correct for these changes in sample volume by normalizing all signals to ROX. The emission intensity of the target fluorescence signal (the target gene, sequence or message, or endogenous reference signal you are looking for) is divided by the emission intensity of ROX. Theoretically, a perfect plate would contain equal amounts of ROX in every well - but in practice, even wellrendered/executed triplicates can show unacceptable variations in signal intensity, and if this problem is due to master mix addition discrepancies, ROX is used to correct for that (as well as non-PCR-related well-to-well fluctuations in fluorescence). ABI instruments absolutely require ROX to generate $C_{T}$ and $R_{n}$ values correctly, while BIO-RAD fluorogenic real-time PCR instruments do not. In the absence of ROX, more inconsistent $C_{T}$ and $R_{n}$ values are expected from the ABI GeneAmp ${ }^{\circledR} 5700$ Sequence Detection System (according to technical support, ABI). The ability (of the ABI GeneAmp ${ }^{\circledR} 5700$ Sequence Detection System) to use ROX to normalize for non-PCR-related, well-to-well fluctuations in fluorescence is achieved by using fluorescence readings taken at $95^{\circ} \mathrm{C}$ in the baseline region, and is apparently "essential" for reproducible results. However, the ABI GeneAmp ${ }^{\circledR} 5700$ Sequence Detection System cannot differentiate between reporters, TAMRA or ROX dyes, as it uses a total reading of each well. Therefore, there is no normalization by ROX in the ABI GeneAmp ${ }^{\circledR} 5700$ Sequence Detection System. "However, the background used to calculate the delta $R_{n}$ value provides more reliable data because of ROX addition" (Justin Liao, ABI technical support). TAMRA-quenched probes do not require an internal reference dye; they can use TAMRA itself (in newer, post ABI GeneAmp ${ }^{\circledR} 5700$ Sequence Detection System machines, i.e. ABI GeneAmp ${ }^{\circledR}$ Models 7300 and 7500). ROX, TAMRA, FAM, VIC etc., are all measured together on the ABI GeneAmp ${ }^{\circledast} 5700$ Sequence Detection System; the ROX passive reference normalizing signal is not shown separately; only varying intensities of black and white are measured - not color. Since ABI master mixes contain $300 \mathrm{nM}$ ROX, while Stratagene master mixes are formulated to contain $30 \mathrm{nM}$ ROX (when ROX is used), it is important to note that investigators using ABI master mixes on Stratagene qPCR machines (Mx4000, Mx3000 and Mx3005P) cannot hope to use ROX as an agent for normalizing reporter fluorescence because the ABI ROX signal is simply too strong. This is due to the fact that different amounts [and perhaps kinds] of ROX are optimal for each of the two machines since a different technology is used to measure well to well fluorescence in Stratagene machines as opposed to the 'halogen flood lamp' method employed by ABI.

\section{Appendix 4}

It is important to note here that all reverse primer concentrations were increased by at least $200 \mathrm{nM}$ in concentration for all one-step reactions (above what their apparent optimal concentrations were observed to be during initial twostep optimization evaluations; but never above $1 \mu \mathrm{M}$ ). This is necessary since all reverse primers are utilized to unknown extents during first-strand synthesis in all one-step qPCR processes; the reverse transcription phase of such reactions are not primed by (i.e.) random hexamers, but instead by the sequence-specific reverse primers themselves thereby limiting reverse primer presence to unknown extents during the final (PCR) phase of each target amplification reaction. In recent experience, we have found that boosting reverse primer concentrations (beyond what two-step primer-probe optimization trials initially indicated) preceding one-step qPCR analyses has improved the overall fidelity of all qPCR target reactions tested so far. Further, we find that using 'saturating concentrations' of primers (1 $\mu \mathrm{M}$ each) and probe $(150 \mathrm{nM})$ is suitable for all qPCR targets (abundant and rare), especially after responsible preliminary qPCR Test Plate analyses have been performed on all targets beforehand. 


\section{Appendix 5}

To protect new qPCR assays from carryover contamination by amplicons generated from prior experiments in the same work area, many master mixes (including several ABI master mixes) contain dUTP instead of dTTP in order to take advantage of an enzyme known as "UNG" which destroys all uracil-containing amplicons left over from prior reactions in the same qPCR work area. AmpErase ${ }^{\circledR} \mathrm{UNG}$ (ABI) is employed largely for two-step qPCR procedures but not for the particular one-step qPCR procedure we use. UNG cannot be used when one-step qPCR is performed using the TaqMan Gold RT-PCR Kit (ABI) or the TaqMan ${ }^{\circledR}$ One-Step RT-PCR Master Mix Reagents Kit (the master mix we use). UNG enzyme is active at the temperatures used for reverse transcription $\left(48^{\circ} \mathrm{C}\right)$ so it would remove uracil bases that are incorporated into newly synthesized complementary DNA (cDNA) strands; all nascent transcripts would be immediately digested by UNG as they are synthesized. The Uracil DNA-Glycosylase enzyme (UDG) also known as 'UNG,' hydrolyzes uracil-glycosidic bonds on single and double stranded dU-containing DNA. Treating pipettes and reaction mixtures with AmpErase ${ }^{\circledR}$ UNG enzyme before each new PCR will destroy any old template containing uracil and therefore prevent re-amplification of carryover PCR products left over in the PCR room that may have drifted into new reaction tubes during set-up; in most cases, using AmpErase ${ }^{\circledR} \mathrm{UNG}$ at $1 \mathrm{U} / 100 \mu \mathrm{l}$ reaction is sufficient. However, AmpErase UNG can be used to remove prior amplicon contamination in one-step qPCR when using the TaqMan EZ RT-PCR Core Reagents (ABI). The rTth DNA Polymerase contained in the kit is thermally stable and is used at temperatures at which AmpErase ${ }^{\circledR}$ UNG is inactive. Because one-step EZ RT-PCR utilizes dUTP, amplicons generated during this reaction contain uridine residues. Since we cannot use UNG in our one-step master mix, we entirely avoid contaminating our work areas with prior amplicons by bleaching all surfaces before working, and by never pulling the plate cap strips off of any qPCR plates that have already been run.

\section{Appendix 6}

Stock I cDNA refers to a cDNA or mixture of selected cDNAs from which it is shown by preliminary, real-time qPCR tests to express positively for all targets of interest to the particular qPCR study at hand. The " $1: 5$ " or " $1: 10$ " dilutions refer to the chosen dilution of any "full-strength" Stock I cDNA whose original concentration is that which was obtained directly from reverse transcription reaction(s). Typical reverse transcription (or cDNA synthesis) reactions yield approximately $20 \mathrm{ng} / \mu \mathrm{l}$ cDNA when assuming each reaction to be $100 \%$ efficient.

\section{Appendix 7}

pH-ing RNA storage buffers to between 6.4 and 7.0 (e.g. Ambion Cat. No. 7000, $1 \mathrm{mM}$ sodium citrate solution, $\sim \mathrm{pH}$ 6.4) helps to minimize 2'-hydroxyl base-catalyzed self-hydrolysis of RNA molecules. DNA (or cDNA) storage buffers are safe at pH 8.0 (e.g. Ambion Cat. No. 9849, TE pH 8.0 or Cat. No. 9856, 1 M Tris, pH 8.0).

\section{Appendix 8}

That less secondary structures are allowed to form on shorter freeze-fractured templates, therefore allowing the reverse transcription phase to happen more efficiently, though speculative, is an additional possibility [comment by Dr. Brett Sponseller as relayed to us by Iowa State University Research Associate, Sandra K. Clark].

\section{Appendix 9}

In 2005, we assisted Invitrogen in the creation of a new master mix for use exclusively with very small RNA samples from cells - including LCM-derived RNA isolates used in one-step real-time qPCR. To answer questions as to whether or not LCM-derived RNA was stable after freeze-thawing, and whether or not directly-extracted total cellular contents could be used in one-step real-time qPCR applications, we were invited to help Invitrogen develop this master mix 
based on an already-existent product line of theirs: CellsDirect ${ }^{\mathrm{TM}}$. This endeavor consisted of an effort between us and key Invitrogen personnel: Sharon Lahn, Ginger Lucero M.F.S. and Dr. Wolfgang Kusser, and resulted in the formulation of the Invitrogen product: CellsDirect ${ }^{\mathrm{TM}}$ One-Step RT-PCR Kit, Part No. 46-7201 (16, 35, and see also Fig. 47).

\section{Appendix 10}

Use of pentadecamers (26) should now replace the use of random octamers (as suggested by Invitrogen) or random hexamers (as suggested by $\mathrm{ABI}$ ) to prime reverse transcription reactions, especially reactions which aim to reverse transcribe $18 \mathrm{~S}$ ribosomal RNA in addition to mRNA. Since 18S ribosomal RNA transcripts have no poly(A) tails (like histone-encoding mRNAs), it is summarily inappropriate for investigators to use poly(dT) constructs to prime reverse transcription reactions for it. Use of poly $(\mathrm{dT})$ would not allow $18 \mathrm{~S}$ ribosomal RNA transcripts to be effectively transcribed during reverse transcription (although a small amount will always be reverse transcribed into cDNA because of normal, expected low-level RT mis-priming events; Trish at ABI Technical Services). Further, improving cDNA yields from reverse transcription reactions can of course enhance qPCR detection of rare targets. Many companies (including Invitrogen, Stratagene and ABI) offer RT enzymes which function at temperatures above $48^{\circ} \mathrm{C}$ (i.e. from 50 up to $60^{\circ} \mathrm{C}$ ). Higher reverse transcription temperatures serve to limit thermodynamically-favorable-yettroublesome formations of common secondary RNA structures (e.g. hairpin loops, hammerhead formations, sticky complementary regions etc.) thereby making it easier for RT enzymes to stay on RNA transcripts longer in order to produce fuller-length cDNAs. 'RNase H status' of each different RT enzyme is also a feature which companies alter according to needs of investigators. The RNase $\mathrm{H}$ activity of RT enzymes functions to degrade sample RNA as soon as it is used as template for cDNA synthesis. But, since most qPCR amplicons average $100 \mathrm{bp}$, while an RNase H-RT enzyme (an RT enzyme lacking RNase $\mathrm{H}$ activity) can provide an advantage when synthesizing long cDNA products, it does not provide a similar advantage for the shorter amplicon regions such as those amplified by real-time qPCR. In fact, RNase H-RT can limit the sensitivity of qPCR detection. If RNA template is not degraded after first-strand cDNA synthesis, it can complementarily bind to the newly-synthesized cDNA and restrict its accessibility to complementary primers and probes during subsequent PCR amplification. RNase $\mathrm{H}+$ mediated destruction of template RNA can prevent this problem and improve the sensitivity of qPCR analysis. On another front, Promega corporation reminds us that adding more units (U) of RT enzyme per unit volume reverse transcription reaction allows the reactions to be skewed in favor of reverse transcribing 'mRNAs' instead of the normally, dominantly-transcribed, 18S ribosomal RNA. Rarer targets can be more efficiently reverse transcribed into cDNA this way; Promega technical notes suggest the use of $3.125 \mathrm{U} / \mu \mathrm{l}$ for reverse transcription instead of $1.25 \mathrm{U} / \mu \mathrm{l}$ in this regard. Finally, it is important to keep in mind that any tampering with RNA isolates (including linear amplification, method of reverse transcription, freezethawing, etc.) always invites the risk of skewing original RNA profiles away from what they originally were. And this, in turn, can greatly affect real-time qPCR results.

\section{Appendix 11}

A little-known tertiary dynamic of qPCR is that normalization of target values by endogenous housekeeper values is most precise when the $\mathrm{C}_{\mathrm{T}}$ values for both appear within the same cycle range (Trish, ABI technical support). In other words, sample RNA and cDNA, when used to assess endogenous housekeeping transcripts by qPCR, should be diluted such that the resulting amplifications cross threshold (generate $C_{T}$ values) within the same region that the target amplifications do. The hyper-abundant endogenous housekeeper, $18 \mathrm{~S}$ ribosomal RNA, often requires sample RNA or cDNA dilutions of 1:4,000 or higher (up to 1:10,000) before its $\mathrm{C}_{\mathrm{T}}$ values appear within (or at least much nearer) most other target $C_{T}$ ranges. Reducing amount of probe (and sometimes primers) for such strong signals reduces the voracity at which they amplify (a common practice in multiplex qPCR to prevent robustly-expressed target amplifications from exhausting master mix dNTPs before less abundant target transcript amplifications are able to use them) and provides another way for single-plex real-time qPCR users to influence $\mathrm{C}_{\mathrm{T}}$ values of any target or

Gallup and Ackermann - Addressing fluorogenic real-time qPCR inhibition using the novel custom Excel file system 'FocusField2-6GallupqPCRSet-upTool001 ' to attain consistently high fidelity qPCR reactions

www.biologicalprocedures.com 
housekeeper. By reducing the amplification efficiency (E) of certain target or housekeeper amplifications (e.g. by limiting probe amounts) so that they yield $\mathrm{C}_{\mathrm{T}}$ values more in keeping with other target or housekeeper $\mathrm{C}_{\mathrm{T}}$ values, one theoretically obtains better relative quantitative qPCR data.

\section{Appendix 12}

Given the following assumptions that: 1.) typical eukaryotic cells contain about 20 pg of total RNA, that 2.) $83 \%$ of total cellular RNA is ribosomal RNA (28S, 18S, $5.8 \mathrm{~S}$ and $5 \mathrm{~S}$ rRNA), 15\% is transfer (tRNA), 2\% is messenger RNA (mRNA), that 3.) $24 \%$ of all rRNA is $18 \mathrm{~S}$ rRNA, that 4.) the average eukaryotic mRNA size is $~ 2000$ bases, and that 5 .) the average nucleotide $\mathrm{MW}=330 \mathrm{~g} / \mathrm{mole}$, one can calculate (using Avagadro's number as $6.02214199 \times 10^{23}$ transcripts/mole) that there are roughly 360,000 total mRNA transcripts per cell at any given moment. Further, if one assumes that 25,000 differently-encoded mRNAs co-exist at any time, one can calculate that there are about $10^{5.4}$ more $18 \mathrm{~S}$ rRNA transcripts present than there are of any specific type of target mRNA (using a MW of $624 \mathrm{kDa}$ for the human 18S rRNA transcript based on NCBI Accession \#M10098). This clearly explains why 18S rRNA often generates real-time qPCR $\mathrm{C}_{\mathrm{T}}$ values up to 18 cycles earlier than most other mRNA targets, and why RNA samples must be diluted so extensively in order to measure 18S RNA signal appropriately by qPCR. Other endogenous redundantlycopied housekeeping genes also exhibit relatively earlier-appearing $\mathrm{C}_{\mathrm{T}}$ values, but none so dramatic as $18 \mathrm{~S}$ rRNA.

\section{Appendix 13}

The representative RNA to be used as template on the Test Plate should be a mixture of only those sample RNAs in any given experiment which are reasonably expected to contain all the real-time targets of interest in the study. Including RNA samples which are not expected to contain one or all of the targets of interest serve only to dilute the RNA mixture away from its usefulness on the Test Plate. Using a mixture of the experimental (1:10 pre-diluted) RNAs themselves also controls for RNA sample preparation within the experiment itself - eliminating errors that can be introduced by using an experimentally exogenous source of Test Plate or standard curve RNA prepared differently from the way the experimental sample RNAs have been. We have found it to be extremely imperative that one use a mixture of the experimental sample RNAs themselves not only as template for the Test Plate, but also as the source of template from which all standard curves and inter-plate calibrators (inter-plate calibrators we use as an extra standard sample or as a sample placed on multiple plates in order to ascertain the fidelity of amplification among multiple plates in cases where data from one plate is to be compared with data from another) for the entire experiment are prepared. This illustrates the critical need for one to think ahead during extensive qPCR studies in order that one does not run short on such important template mixtures at some unforeseen point (the FF2-6-001 qPCR set-up tool calculates this parameter as well). We call such RNA mixtures "Stock I." Our typical Stock I RNA solutions vary in size from $600 \mu \mathrm{l}$ to 1,500 $\mu \mathrm{l}$ depending on how many Test Plates, final qPCR sample plates (using standard curves and inter-plate calibrators), and NRC plates each study requires. We strongly advise investigators to create drawings of all the plates to be run in each qPCR study and use them to manually confirm how much Stock I RNA (or cDNA) and how much of each sample RNA (or cDNA) will be needed. These values are also calculated by the FF2-6-001 qPCR setup tool, but it is always good for the investigator to cross-corroborate these calculations since it is easy for users to unknowingly introduce logistical mistakes during extensive qPCR set-ups. 


\section{Appendix 14}

Table 1: Successful primer and TaqMan ${ }^{\circledR}$ probe designs. Primers-probe sets which have yielded favorable qPCR amplifications using the parameters identified using the FF2-6-001 qPCR set-up tool invention. 6FAM or VIC $=5^{\prime}$ Fluorescent reporter dye, TAMRA $=3{ }^{\prime}$ Fluorescent quencher dye. MGBNFQ = 3' Minor groove binding non-fluorescent quencher.

Ovine (Ovis aries) studies: Caverly-Grubor-Derscheid-Meyerholz-Lazic-Olivier-Gallup-Ackermann

SBD-1 Fwd primer: 5'-CCATAGGAATAAAGGCGTCTGTG Probe: 5'-6FAM-CCGAGCAGGTGCCCTAGACACATGA-TAMRA

Rev primer: 5'-CGCGACAGGTGCCAATCT

Designed by us using ABI Prism Primer Express $^{\mathrm{TM}}$ v2.0 and accession \#U75250

ovTTF-1 Fwd primer: 5'-TCCCAGGCGCAGGTGTAT

Probe: 5'-6FAM- AGCTGGAGCGACGCT-MGBNFQ

Rev primer: 5'-CGGACAGGTACTTCTGCTGCTT

Designed by us using ABI Prism Primer Express $^{\mathrm{TM}}$ v2.0 and accession \#DQ010920

ovSP-A Fwd primer: 5'-TGACCCTTATGCTCCTCTGGAT

Probe: 5'-6FAM-TGGCTTCTGGCCTCGAGTGCG-TAMRA

Rev primer: 5'-GGGCTTCCAAGACAAACTTCCT

ovSP-D Fwd primer: 5'-ACGTTCTGCAGCTGAGAAT Rev primer: 5'-TCGGTCATGCTCAGGAAAGC

ovICAM-1 Fwd primer: 5'-CAAGGGCTGGAACTCTTCCA Rev primer: 5'-GGTCGATGGCAGGACATAGG

SMAP29 Fwd primer: 5'- GGCCCAACTGTTCTCCGAAT Rev primer: 5'- GCAGACCCTTAGGACTCTTTCCT

ovRPS15 Fwd primer: 5'-CGAGATGGTGGGCAGCAT Rev primer: 5'-GCTTGATTTCCACCTGGTTGA

Designed by us using ABI Prism Primer Express ${ }^{\mathrm{TM}}$ v2.0 and accession \#AF076633

Probe: 5'-6FAM-TTGACTCAGCTGGCCACAGCCCAGAACA-TAMRA

Designed by us using ABI Prism Primer Express $^{\mathrm{TM}}$ v2.0 and accession \#AJ133002

Probe: 5'-6FAM-CACCTCAGCCCCCAGGAAGCTCC-TAMRA

Designed by us using ABI Prism Primer Express $^{\mathrm{TM}}$ v2.0 and accession \#NM001009731

Probe: 5'-6FAM-ATCAGAATAGCTGGGTGAATTGTGGGCC-TAMRA

Designed by us using ABI Prism Primer Express ${ }^{\mathrm{TM}}$ v2.0 and accession \#L46854

Probe: 5'-VIC-CCGGCGTCTACAACGGCAAGACC-TAMRA

Designed by us using ABI Prism Primer Express ${ }^{\mathrm{TM}}$ v2.0 on a sequence given to us courtesy of Dr. Sean W. Limesand, Dept. of Pediatrics, Univ. of Colorado Health Sciences Center, Perinatal Research Center, PO Box 6508, F441, Aurora, CO $(16,19)$

Probe: 5'-VIC-TGCTGGCACCAGACTTGCCCTC-TAMRA Designed by ABI using accession \#XO3205

*hRIBO18S Fwd primer: 5'-CGGCTACCACATCCAAGGAA Rev primer: 5'-GCTGGAATTACCGCGGCT

*This primer-probe set is a theoretically faulty thermodynamic design, but it still works very well. See reference (34) for more information.

bRSV

Fwd primer:

CAGTCAAGAATATTATGCTTGGTCATG

Rev primer:

CCTAACTTTTGTGCATATTCATAGACTTC

5'- Probe: 5'-6FAM-CAACCTGTTCCATTTCTGCTTGTACGCTG-TAMRA

Designed by us using ABI Prism Primer Express ${ }^{\mathrm{TM}}$ v2.0 and accession

5'- \#NC_001989

hRPS15 Fwd primer: 5'-CCTTCAACCAGGTGGAGATCA

Probe: 5'-VIC-CCGAGATGATCGGCCACTACCTGG-TAMRA

Rev primer: 5'-CATGCTTTACGGGCTTGTAGGT Designed by us using ABI Prism Primer Express ${ }^{\mathrm{TM}}$ v2.0 and accession \#BC105810

Equine (Equis caballus) studies: (Clark-Sponseller)

Equine IL- Fwd primer: 5-GATCTCCCAAATCCCATCCA

10 Rev primer: 5'-AGGAGAGAGGTACCACAGGGTTT

Probe: 5'-6FAM-CCAAGGAGCTGATTCAGCTCTCCCAGAA-TAMRA

Designed by us using ABI Prism Primer Express ${ }^{\mathrm{TM}}$ v2.0 and accession \#U38200

Equine IL- Fwd primer: 5'-GGCCAGATCCGTGTCCAA

12 p40 Rev primer: 5'-GGATACGGATGCCCATTCG

Probe: 5'-6FAM-CCAGGGACCGCTACTACAGCTCATCCT-TAMRA

Designed by us using ABI Prism Primer Express ${ }^{\mathrm{TM}}$ v2.0 and accession \#Y11129

Equine Fwd primer: 5'-CCCACCCCTAACGTGTCAGT

GA3PDH Rev primer: 5'-TCTCATCGTATTTGGCAGCTTTC

Probe: 5'-6FAM-TGGATCTGACCTGCCGCCTGG-TAMRA

Designed by us using ABI Prism Primer Express ${ }^{\mathrm{TM}}$ v2.0 and accession \#AF157626

Chicken (Gallus gallus) studies: (Brockus-Harmon-Gallup-Ackermann)

\begin{tabular}{|c|c|c|}
\hline Gallinacin & primer: & Probe: 5'-6FAM-AGAGTGGCTTCTGTGCATTTCTGAAGTGC-TAMRA \\
\hline & $\begin{array}{l}\text { GGAAGGAAGTCAGATTGTTTTCGA } \\
\text { Rev primer: 5'-GAGCATTTCCCACTGATGAGAGT }\end{array}$ & $\begin{array}{l}\text { Designed by us using ABI Prism Primer Express }{ }^{\mathrm{TM}} \text { v2.0 and accession } \\
\text { \#AF033335 }\end{array}$ \\
\hline Gallinacin & Fwd primer: 5'-GGAGGGTCCTGCCACTTTG & Probe: 5'-6FAM-AGGGTGTCCCAGCCATCTAATCAA-TAMRA \\
\hline 2 & Rev primer: 5'-CGGAACCCGAAGCAGCTT & $\begin{array}{l}\text { Designed by us using ABI Prism Primer Express }{ }^{\mathrm{TM}} \text { v2.0 and accession \# } \\
\text { AF033336 }\end{array}$ \\
\hline Chicken & Fwd primer: 5'- CCATGGTGACCACGGGTAAC & Probe: 5'-VIC-CCCTCTCCGGAATCGAACCCTGATT-TAMRA \\
\hline 18S rRNA & Rev primer: 5'-GGATGTGGTAGCCGTTTCTCA & $\begin{array}{l}\text { Designed by us using ABI Prism Primer Express }{ }^{\mathrm{TM}} \text { v2.0 and accession } \\
\text { \#AF173612 }\end{array}$ \\
\hline
\end{tabular}


FIGURES

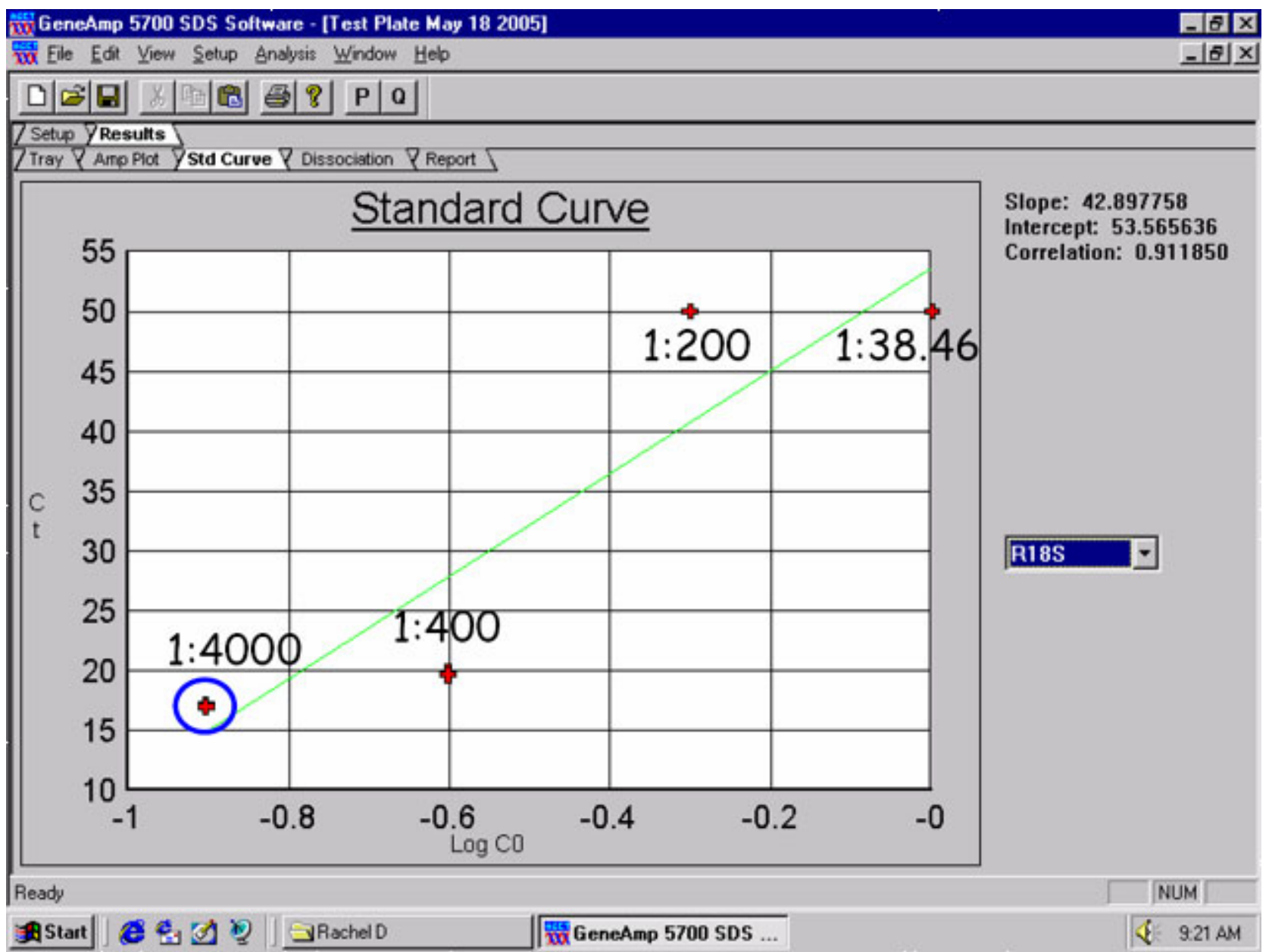

Fig. 1: qPCR amplification of $18 \mathrm{~S}$ ribosomal RNA using Trizol-isolated RNA from H441 cells (with 1.8-2.0 RNA purity ratios observed) appear to demonstrate inhibition Types 1, 2 and 3 with the 1:38.46 dilution and inhibition Types 1 (and presumably 4) with the 1:200 and 1:400 dilutions shown here. Trizol ${ }^{\circledR}$ was used for RNA isolation from $\mathrm{H} 441$ cells (1.8-2.0 RNA purity ratios observed). Whole lung tissue total RNA isolates show the same sample-related inhibition threshold for $18 \mathrm{~S}$ ribosomal RNA to be $\sim 1: 4,000$ as well - and this is seen commonly with the hyper-abundantly expressed target, ribosomal 18S RNA when sample RNA has been isolated using Trizol ${ }^{\circledR}$. 


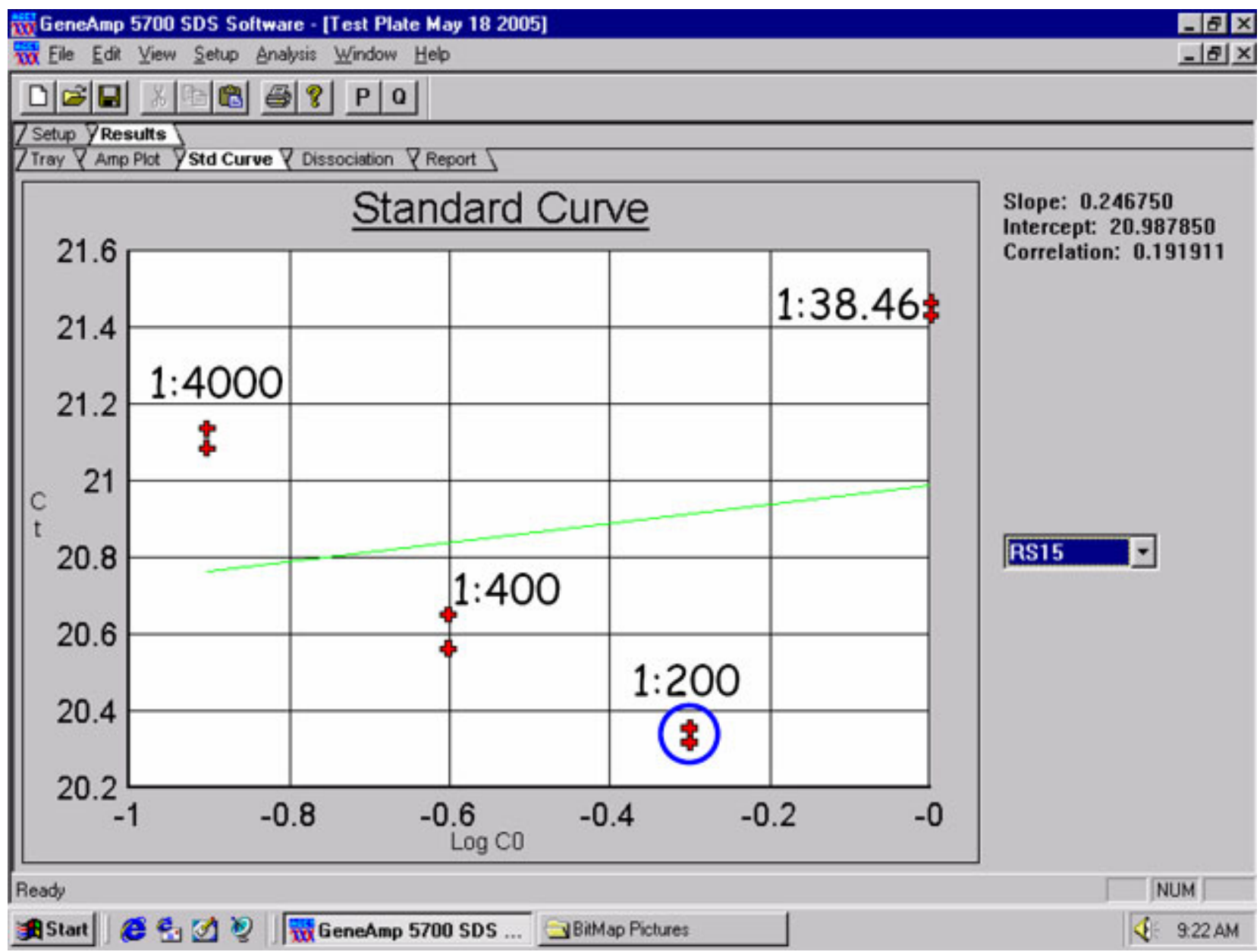

Fig. 2: Housekeeper hRPS15 amplifications using Trizo|-isolated RNA from H441 cells (with 1.8-2.0 RNA purity ratios observed) appear to demonstrate inhibition Types 1, 2 and 3 with the 1:38.46 dilution shown here. Whole lung tissue total RNA isolates show the same sample-related inhibition threshold to be $\sim 1: 200$ as well - and this is seen with most intermediately-abundant targets when sample RNA has been isolated using Trizol ${ }^{\circledR}$. Human ribosomal protein S15 (hRPS15) primers and probe were used here at $1 \mu \mathrm{M}$ and $150 \mathrm{nM}$, respectively. 


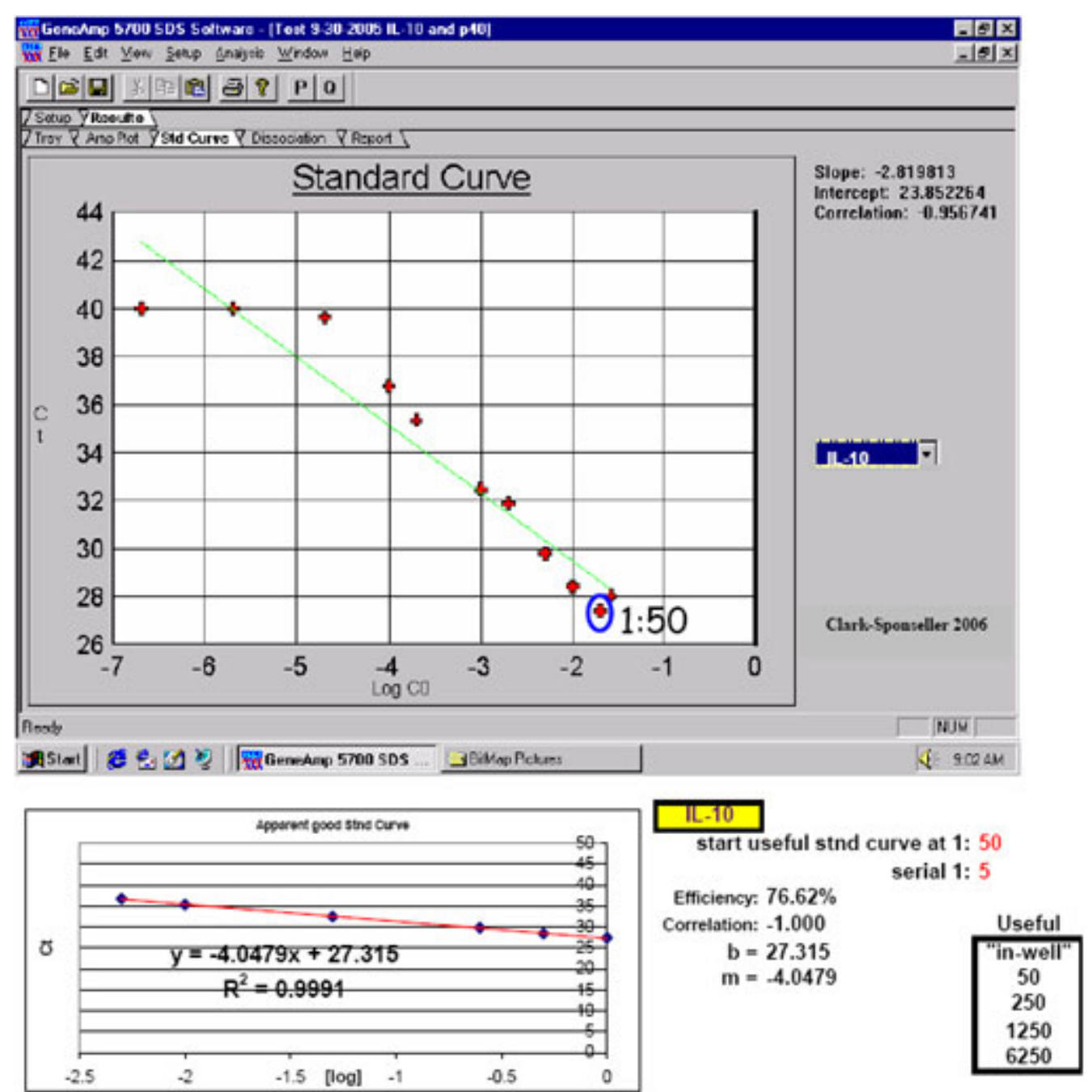

Fig. 3: (Marligen) column-isolated/purified RNA exhibits a lower threshold of qPCR inhibition. Inhibition Types 1, 2 and 3 are presumably demonstrated with the first dilution point shown here. Marligen Rapid Total RNA Purification System RNA isolation from equine dendritic cells: inhibitory phenomena are not apparent beyond a dilution of 1:50 using RNA isolated by this method. Rare qPCR targets often exhibit lower amplification efficiencies. 


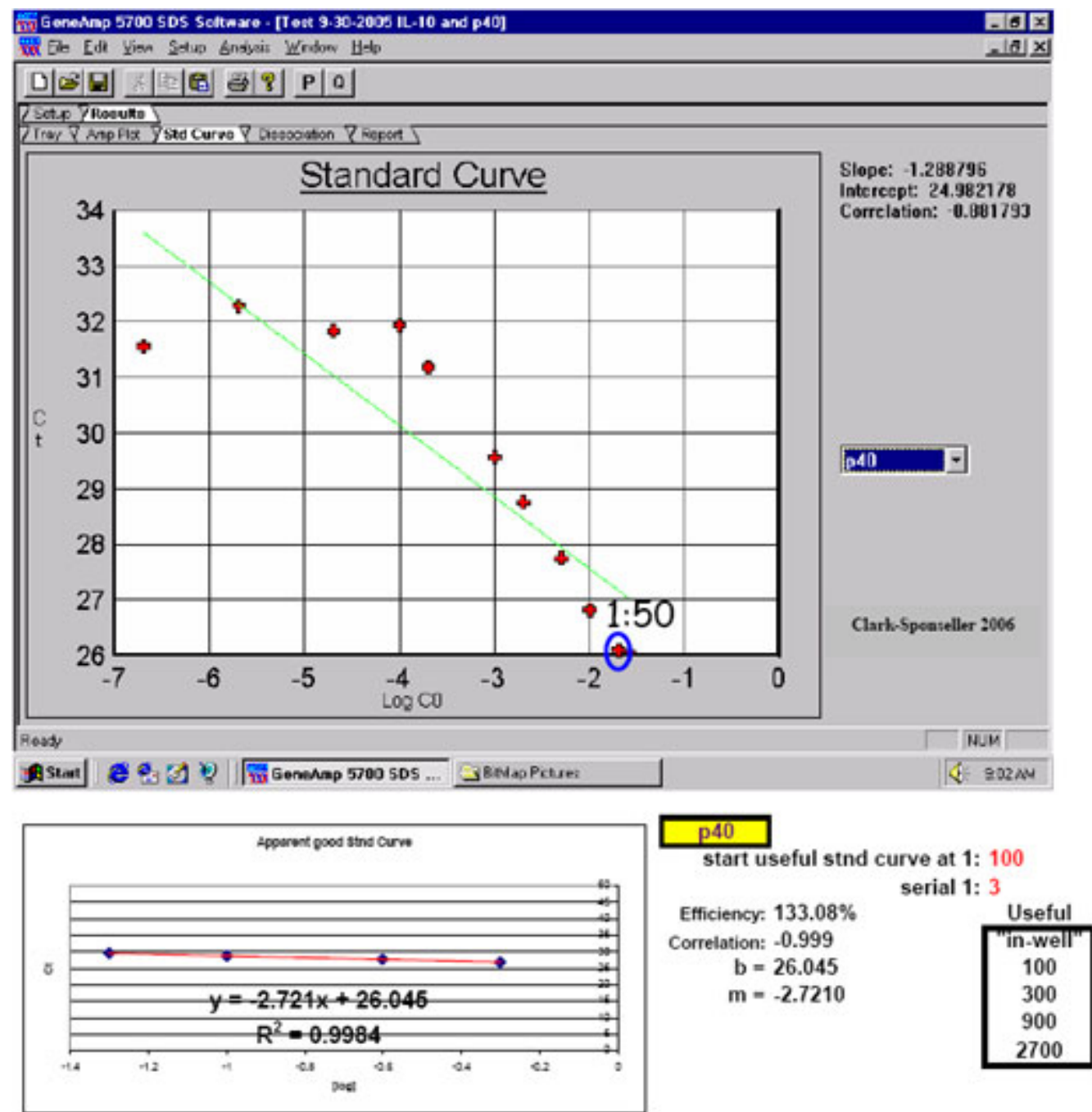

Fig. 4: (Marligen) column-isolated/purified RNA exhibits a lower threshold of qPCR inhibition. Inhibition Types 1, 2 and 3 are presumably demonstrated with the first dilution point again shown here. Marligen Rapid Total RNA Purification System RNA isolation from equine dendritic cells: inhibition is slightly apparent beyond a dilution of 1:50 using RNA isolated by this method; an amplification efficiency of $133.08 \%$ here indicates possibly lingering inhibition of the first point(s) of the apparent optimal standard curve RNA sample dilution region for equine IL-12p40. However, since singlet samples were run here, this observation is useful as a warning only to a certain extent; successful, uninhibited qPCR was carried out for this target using the RNA dilution range selected here. 

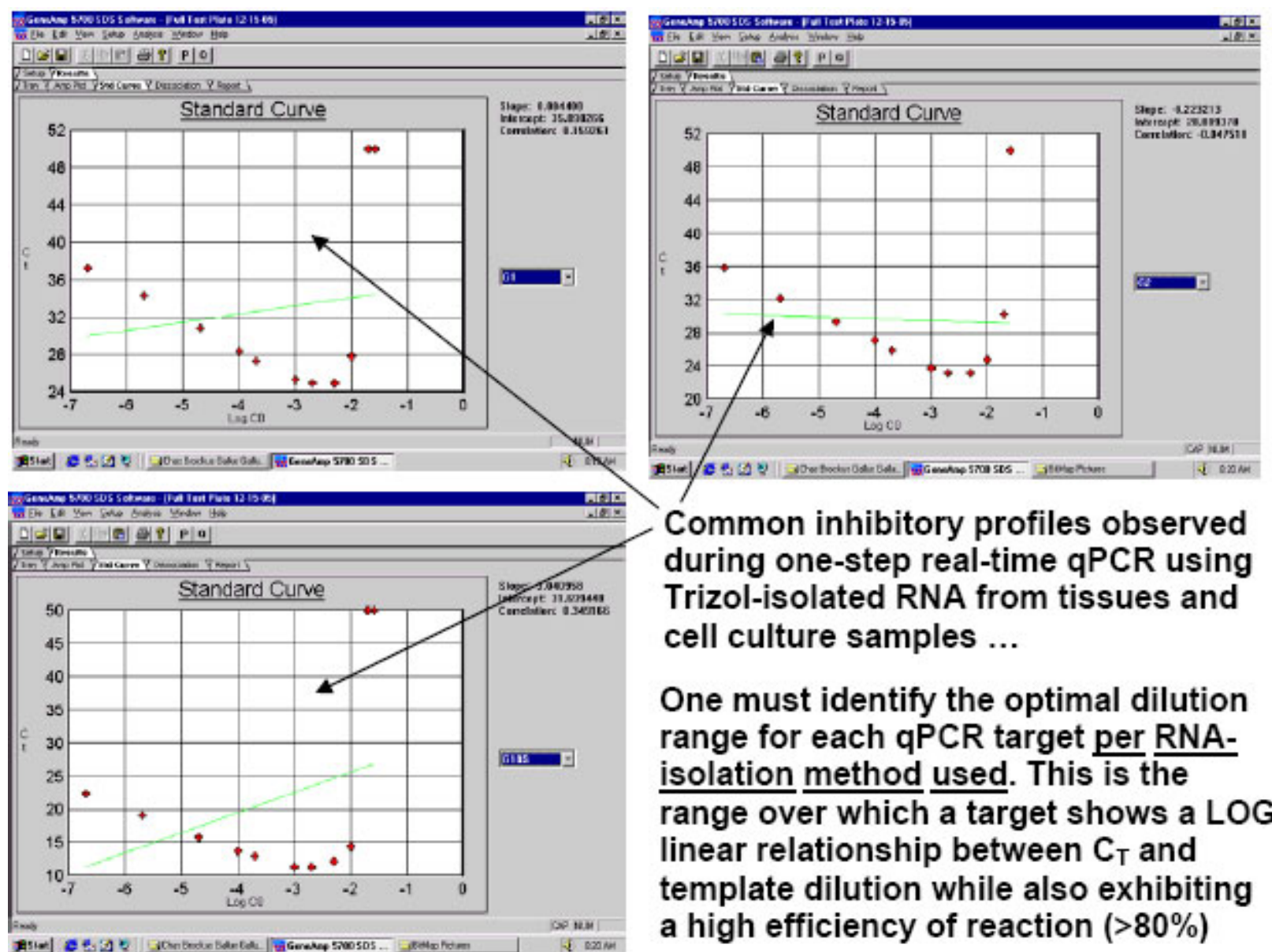

One must identify the optimal dilution range for each qPCR target per RNAisolation method used. This is the range over which a target shows a LOG linear relationship between $\mathrm{C}_{\mathrm{T}}$ and template dilution while also exhibiting a high efficiency of reaction ( $>80 \%$ )

Fig. 5: Demonstration of typical inhibitory qPCR profiles exhibited on qPCR Test Plates by the more concentrated RNA samples (on the right hand side of each graph) in a progressive dilution series. Targets here were Gallus gallus Gallinacin 1, Gallinacin 2 and Gallus gallus 18S ribosomal RNA (the single housekeeper). Stock I here was an equivolumetric mixture of the 26 total tissue RNA samples used in this study: just after their isolation by Trizol method, each RNA pellet was resolubilized in $150 \mu \mathrm{l}$ of $0.1 \mathrm{mM}$ EDTA pH 6.75 , warmed to $65^{\circ} \mathrm{C}$ for 5 minutes, and their $260 \mathrm{~nm}$ and $260 \mathrm{~nm} / 280 \mathrm{~nm}$ measurements at 1:50 were taken. $70 \mu \mathrm{l}$ of each resolubilized RNA was then Turbo-DNAse treated [70 $\mu$ I RNA isolate $+10 \mu \mathrm{l}$ 10X Turbo DNase Buffer + $20 \mu \mathrm{l}$ Turbo DNase enzyme (40 Units); and finally $10 \mu \mathrm{l}$ Inactivation Reagent] and $80 \mu \mathrm{l}$ of each was then diluted 1:10 with nuclease-free water. Subsequently, $50 \mu \mathrm{l}$ of each of these 1:10 RNA isolates was mixed together into a single tube attaining a final volume of 1,300 $\mu$ l. This was the Stock I RNA solution from which all standards and inter-plate calibrators were prepared. It was also the mixture which served as the source of the serially-diluted template samples for the Test Plate which we ran early on to identify the best RNA dilution ranges for each of the 3 targets. All calculations for this study were quickly performed by the FF2-6-001 qPCR set-up tool. 


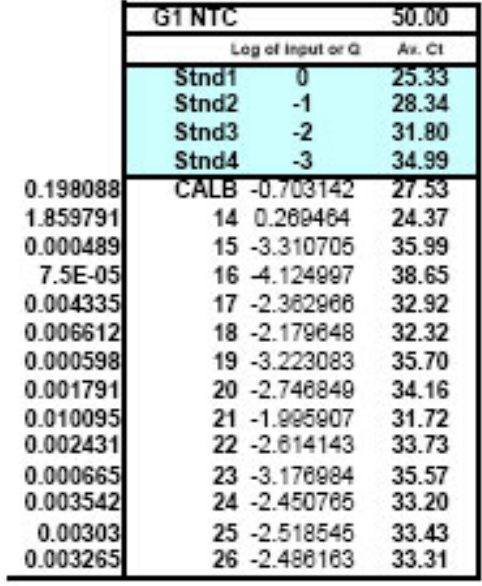

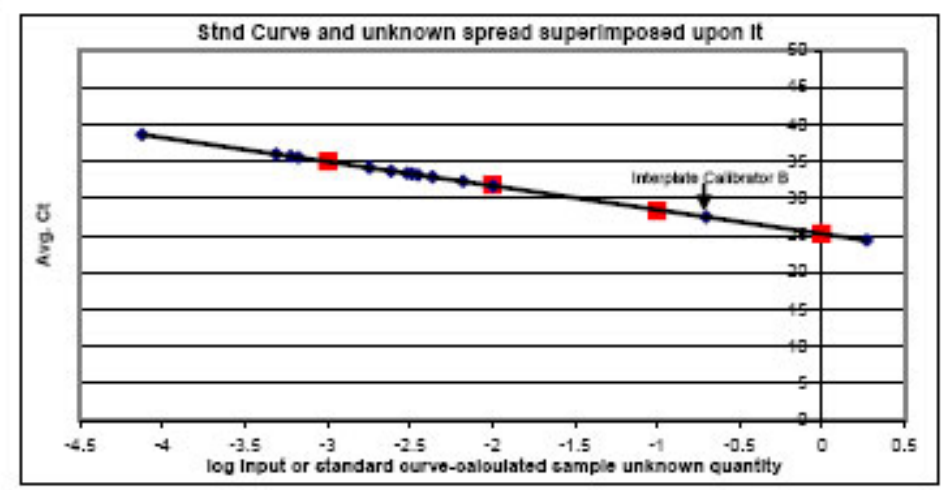

\begin{tabular}{|c|c|c|c|}
\hline & $\mathbf{N}$ & & 41.93 \\
\hline & \multicolumn{2}{|r|}{ Loy input of of } & Anc a \\
\hline & Stnd1 & & 16.03 \\
\hline & Stnd2 & -0.69897 & 18.09 \\
\hline & Stnd3 & -1.39794 & 20.36 \\
\hline & Stnd4 & -2.09691 & 23.10 \\
\hline 0.374137 & CALF & -0.426909 & 17.31 \\
\hline 0.091145 & 14 & -1.040266 & 19.37 \\
\hline 0.021801 & 15 & -1.681515 & 21. \\
\hline 0.008362 & 16 & -2.077668 & 22.85 \\
\hline 0.09862 & 17 & -1.006035 & 19.25 \\
\hline 0.01085 & 18 & -1.964578 & 22.47 \\
\hline 0.097286 & 19 & -1.011947 & 19.27 \\
\hline 0.158263 & 20 & -0.80062 & 18.56 \\
\hline 0.129757 & 21 & -0.886868 & 18.85 \\
\hline 0.055264 & 22 & -1.257557 & 20.10 \\
\hline 0.127101 & 23 & -0.885849 & 18.88 \\
\hline 0.050382 & 24 & -1.297727 & 20.23 \\
\hline 0.111636 & 25 & -0.852196 & 19.07 \\
\hline 0.10612 & 26 & -0.974204 & 19. \\
\hline
\end{tabular}

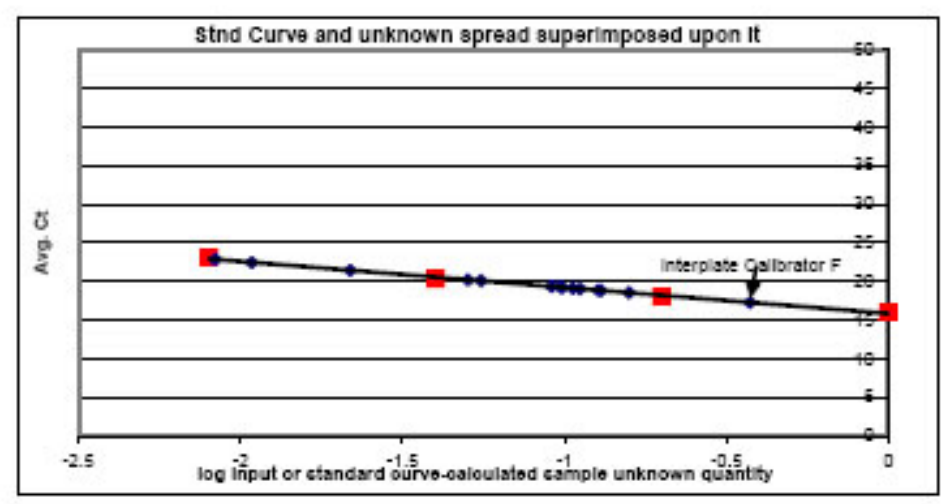

Fig. 6: Typical results obtained using FF2-6-001 qPCR set-up tool which first calculated the Test Plate set-up, then processed the Test Plate data for Gallinacin 1 (G1), Gallinacin 2 (G2), and Gallus gallus ribosomal 18S RNA (used as the housekeeping gene) and, in turn, the FF2-6-001 qPCR set-up tool additionally used that information to calculate the optimal dynamic set-up for each target on each of the final qPCR experimental plates (including sample RNA dilutions for each target, inter-plate calibrator dilutions of Stock I for each target, dilutions of Stock I to create all the standards for each target, and all master mix calculations for all Sample Plates and an NRC Plate). Notice how all unknowns fell within the trustworthy portion of the standard curves for G1 and its corresponding ribosomal 18S RNA housekeeper. The same was found for G2 and its corresponding ribosomal 18S RNA housekeeper (graphs not shown). NRC results from this study showed that all contaminating (genomic DNA) target signals were greater than 14 cycles away from the genuine housekeeper $C_{T}$ values - presenting no consequence whatsoever during data analysis. The fact that 14 different tissue types were used in this study speaks well for the ability of the FF2-6-001 qPCR set-up tool to be able to work with and solve for a variety of potentially variant qPCRinhibitory features from a myriad of tissue types. 26 total normal tissues were evaluated here; 13 from a male chicken and 13 from a female chicken: bone marrow, jejunum, crop, testes (male chicken) oviduct (female chicken), lung, skin, spleen, liver, kidney, bursa, trachea, conjunctiva and tongue. After identifying the optimal RNA dilution ranges for each target, fluorogenic real-time one-step qPCR was successfully carried out under absolutely LOGlinear conditions exhibiting virtually $100 \%$ efficiency for each target in the total absence of inhibition of any variety using saturating concentrations of primers $(1 \mu \mathrm{M})$ and probes $(150 \mathrm{nM})$ for all three targets (Brockus-Harmon-Gallup-Ackermann, 2005 unpublished).

Gallup and Ackermann - Addressing fluorogenic real-time qPCR inhibition using the novel custom Excel file system 'FocusField2-6GallupqPCRSet-upTool001 ' to attain consistently high fidelity qPCR reactions

www.biologicalprocedures.com 

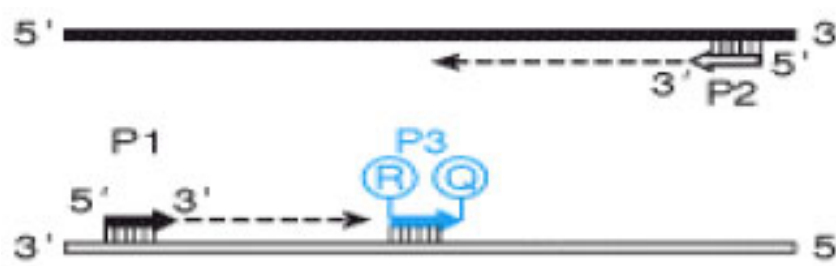
5
P1 = Forward Primer

$\mathrm{P} 2=$ Reverse Primer

P3 = Fluorogenic TaqMan $^{\circledR}$ hydrolysis probe
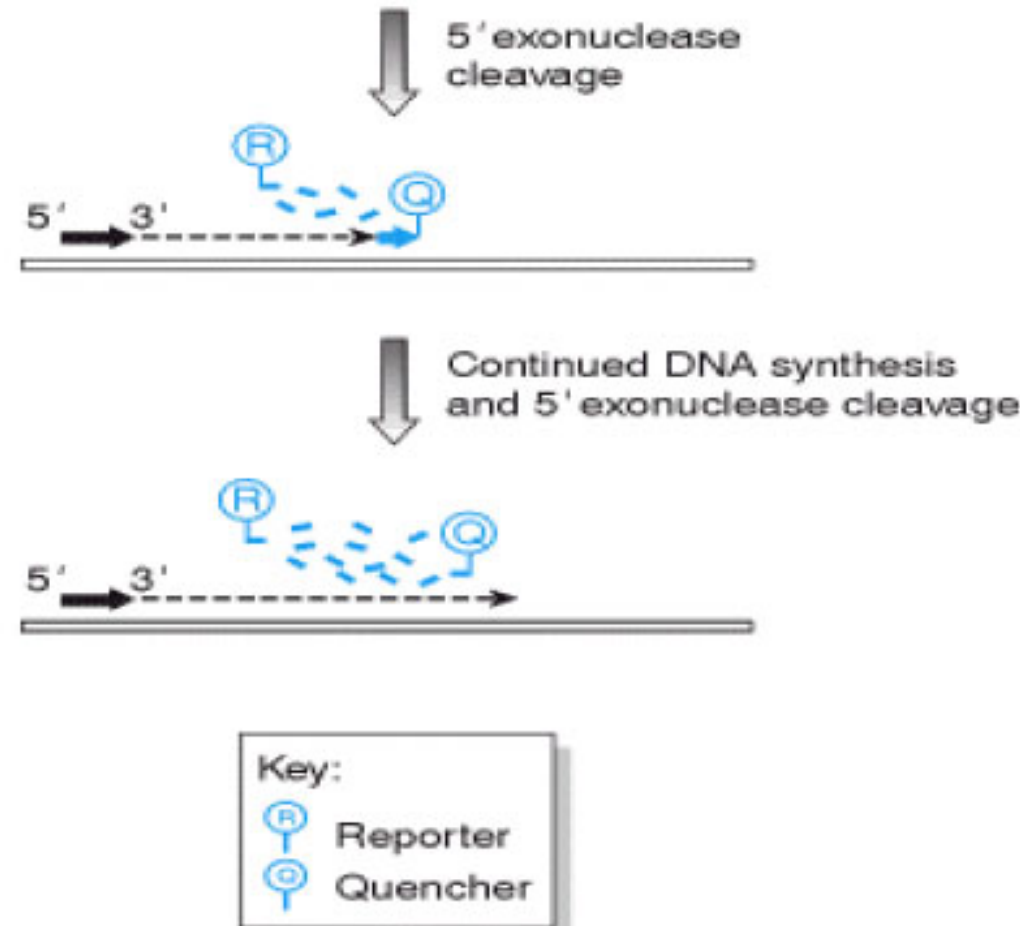

Fig. 7: The TaqMan ${ }^{\circledR}$ 5' exonuclease assay. In addition to two conventional PCR primers, P1 and P2, which are specific for the target sequence, a third primer, P3 (called the 'probe'), is designed to bind specifically to a site on the target sequence downstream of the forward primer binding site. The probe is labelled with two fluorophores, a reporter dye (R) is attached at the 5 ' end while a quencher dye (D), which has a different emission wavelength to the reporter dye, is attached at its 3' end. Because the 3' end is blocked, the probe cannot by itself prime any new DNA synthesis. During the PCR reaction, Taq DNA polymerase synthesizes a new DNA strand primed by the forward primer, and as the enzyme approaches the probe, its 5' to 3' exonuclease activity progressively degrades the probe from its 5 ' end. The end result is that the nascent DNA strand extends beyond the probe binding site and the reporter and quencher dyes are no longer bound to the same molecule. As the reporter dye is no longer in close proximity to the quencher, the resulting increase in reporter emission intensity becomes easily detectable. This all occurs in "real time" as monitored by the photomultiplier tube(s) in the instrument. 


\section{Methods of fluorescence detection}
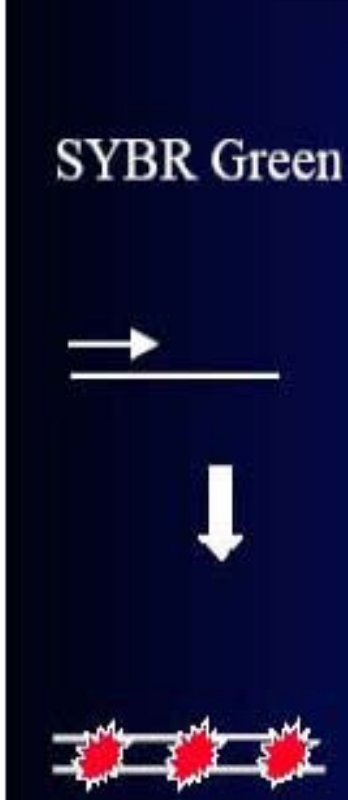
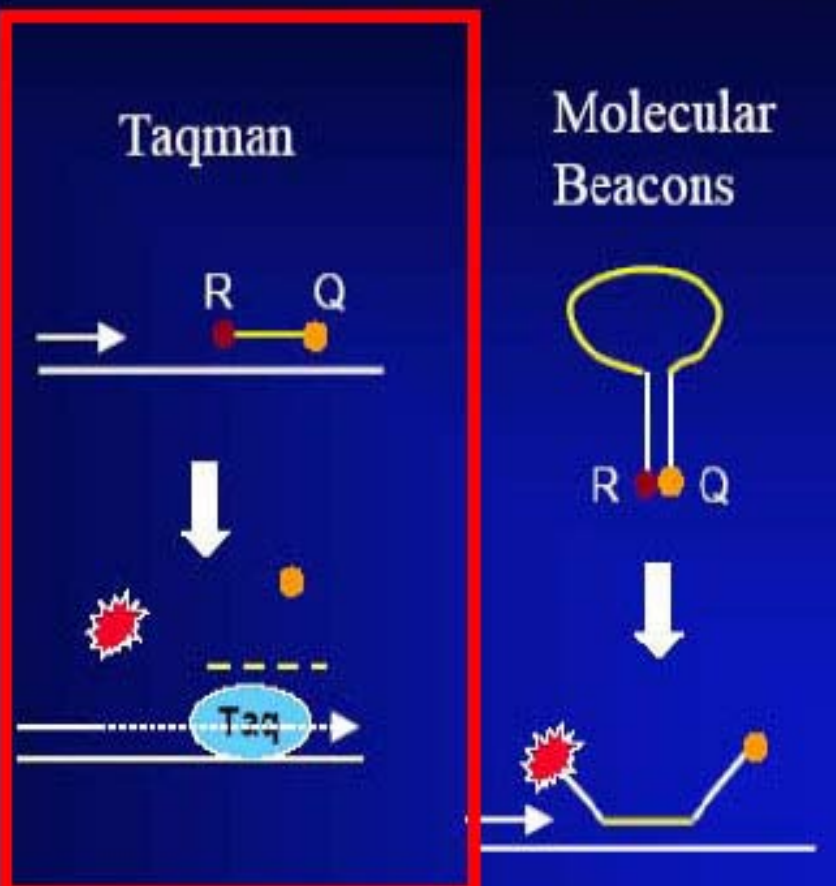

Light Cycler

D A
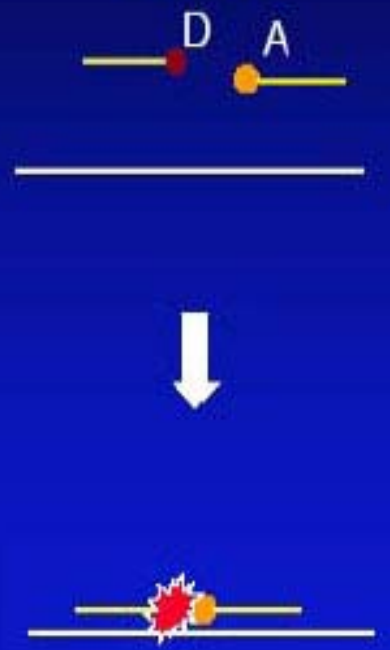

Nigel Walker, NIEHS (www) http///dir.niehs.nih.qov/microarrav/realtime.pdf

Fig. 8: Different approaches to fluorogenic qPCR; we use the highlighted TaqMan ${ }^{\oplus}$ hydrolysis probe-based real-time qPCR method. All primers and probes are optimized and validated according to ABI procedural guidelines (31) using all-target-inclusive (Stock I) cDNA prepared from Turbo DNase-treated total RNA isolated (using Trizol ${ }^{\circledR}$ ) from whole tissue homogenates as described previously (17-20). Our optimization approach is a very common/well-known procedure whereby one first studies different combinations of primer concentrations in the range of $50 \mathrm{nM}-900 \mathrm{nM}$ while keeping the probe at a constant 200 or $225 \mathrm{nM}$, after which the probe is studied by challenging it from $25 \mathrm{nM}$ to $225 \mathrm{nM}$ while primers are used at their optimal concentrations. All samples are performed in triplicate or quadruplicate during these evaluations to bolster significance of final evaluations. After optimization, a 'validation plate' or Test Plate is performed on up to eleven serial dilutions of the same cDNA or RNA (starting with full-strength cDNA or RNA which is assigned a relative dilution strength value of " 1 ") using the optimal primer and probe concentrations established during optimization for each target. The highest $R_{n}$ (normalized reporter fluorescence) value achieved using the lowest primer concentrations is the indicator by which one selects the appropriate optimal primer concentrations in each case; the higher the $R_{n}$, the higher the magnitude of real-time fluorescent signal. Once the $R_{n}$ value no longer increases with increasing primer concentrations, one has effectively attained the useful optimal primer concentrations. $C_{T}$ values (not $R_{n}$ values) are evaluated during probe optimizations, and the lowest $C_{T}$ (threshold cycle) value with the lowest probe concentration is the criteria by which one chooses optima probe concentrations. Once $C_{T}$ values no longer decrease with increasing probe concentration, one has effectively attained the useful optimal probe concentration. Little known is the fact that most real-time target signals can be found with greater than $75 \%$ amplification efficiency simply using 'saturating concentrations' of primers $(1 \mu \mathrm{M})$ and probes $(150 \mathrm{nM})$ in most experimental situations if optimal RNA dilution ranges are established for each target and inhibition is entirely avoided (unpublished multiple observations from our lab, 2001-2006). 


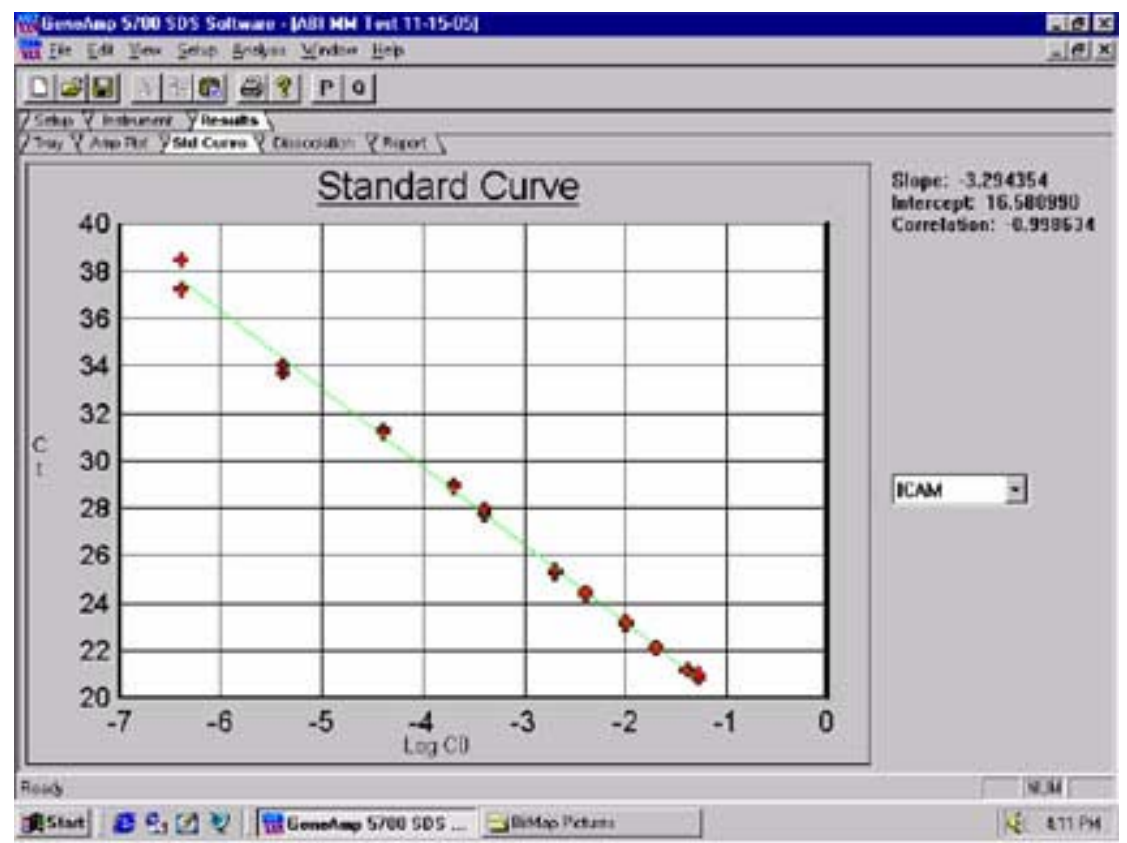

\begin{tabular}{|c|c|c|c|}
\hline Well & Type & Primer/Probe & ct \\
\hline A1 1 & NTC & ICAM & 50 \\
\hline$A 2$ & STND & ICAM & 20.88 \\
\hline A3 & STND & ICAM & 21.15 \\
\hline A.4 & STND & ICAM & 22.1 \\
\hline$A B$ & STND & ICAM & 23.13 \\
\hline$A B$ & STND & ICAM & 24.37 \\
\hline A7 & STND & ICAM & 25.20 \\
\hline AB & STND & ICAM & 27.74 \\
\hline AO & STND & ICAM & 20.03 \\
\hline$A_{10}$ & STND & ICAM & 31.3 \\
\hline A11 & STND & ICAM & 33.73 \\
\hline$A_{12}$ & STND & ICAM & 38,48 \\
\hline$B 1$ & NTC & ICAM & 50 \\
\hline 82 & STND & ICAM & 21 \\
\hline 83 & STND & ICAM & 21.16 \\
\hline 84 & STND & ICAM & 22,12 \\
\hline B5 & STND & ICAM & 23.2 \\
\hline Be & STND & ICAM & 2444 \\
\hline 87 & STND & ICAM & 26.37 \\
\hline B8 & STND & ICAM & 27.08 \\
\hline$B 9$ & STND & ICAM & 28.0 \\
\hline 810 & STND & ICAM & 31.24 \\
\hline B11 & STND & ICAM & 34.04 \\
\hline Bi2 & STND & ICAM & 37,24 \\
\hline$c_{1}$ & NAC & ICAM & $50^{\circ}$ \\
\hline $\mathrm{Cl}_{2}$ & NAC & ICAM & 50 \\
\hline
\end{tabular}

Fig. 9: Example of the consistency of data generated under favorable/optimal conditions by qPCR (compare this to the results shown in Fig. 10). ABI Cat. No. 4309169, TaqMan ${ }^{\circledR}$ One-Step RT-PCR Master Mix Reagents Kit and the ABI GeneAmp ${ }^{\circledR} 5700$ Sequence Detection System were used. 


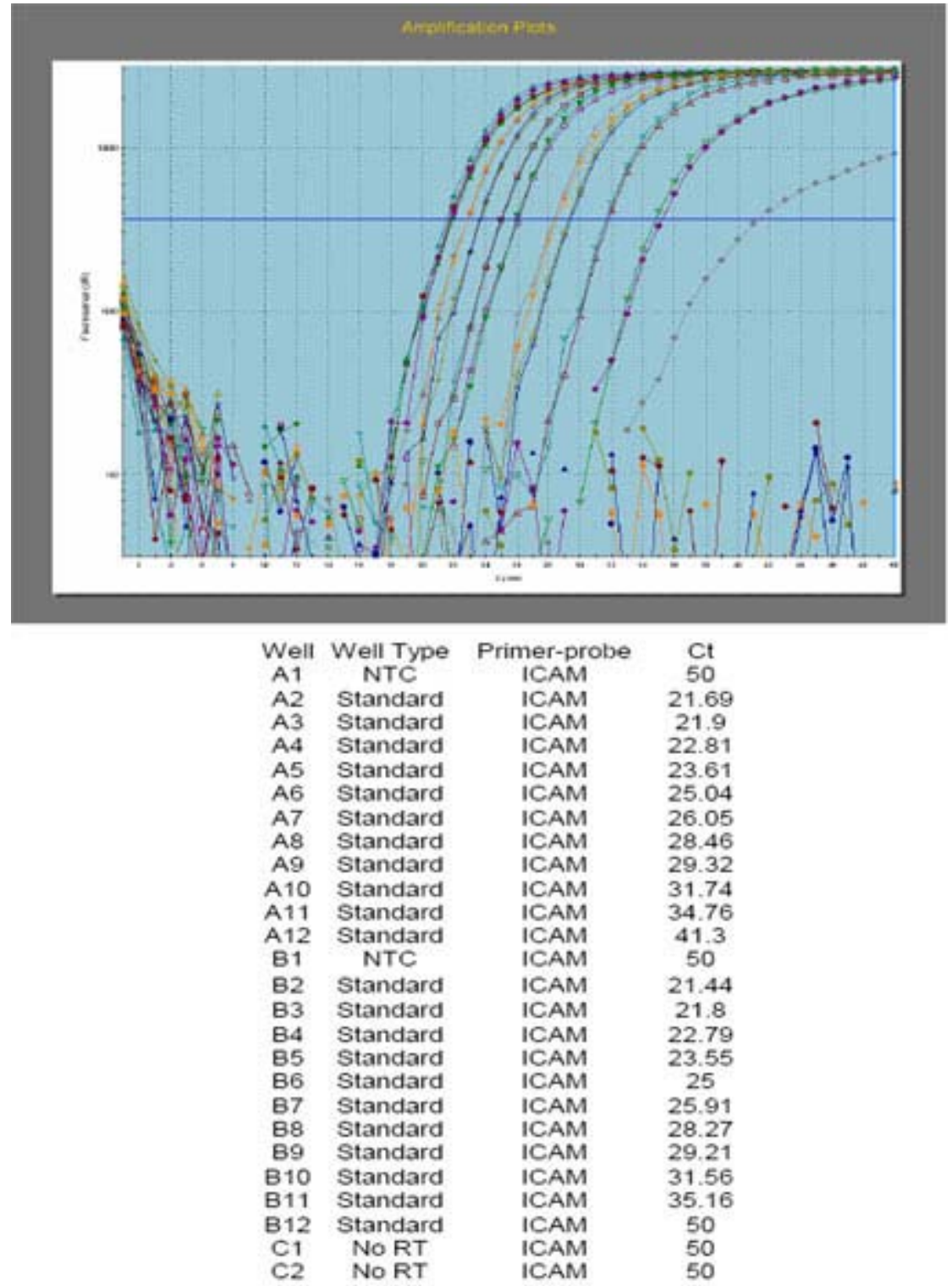

Fig. 10: Amplification plots of the same samples (as in Fig. 9 above) run on a Stratagene Mx3005P real-time qPCR machine. Note the consistency in relative $\mathrm{C}_{\mathrm{T}}$ values between results from the two different machines referred to in Figure 9 and this Figure. This bodes very well for highly-optimized qPCR in general. ABI Cat. No. 4309169, TaqMan ${ }^{\circledR}$ One-Step RT-PCR Master Mix Reagents Kit was used. 


\begin{tabular}{|c|c|c|c|c|}
\hline \multicolumn{5}{|c|}{ OPTIMIZED qPCR PRIMERS AND PROBES MASTER PASTE AREA } \\
\hline species & & Fwd primer & $\underline{\text { Rev primer }}$ & Probe \\
\hline ovine & SBD-1 & 1000 & 1000 & 150 \\
\hline ovine & SBD-2 & 900 & 900 & 175 \\
\hline ovine & SP-A & 500 & 500 & 50 \\
\hline ovine & SP-D & 500 & 500 & 100 \\
\hline ovine & TNF-a & 900 & 900 & 75 \\
\hline porcine & PCV2 & 400 & 400 & 200 \\
\hline ovine & MCP-1a & 900 & 400 & 100 \\
\hline ovine & IL -8 & 900 & 400 & 150 \\
\hline ovine & TTF-1 & 1000 & 1000 & 150 \\
\hline murine & SNAP 25 & 900 & 300 & 100 \\
\hline murine & SNAP 25A & 1000 & 1000 & 25 \\
\hline equine & elL-12p35 & 1000 & 1000 & 150 \\
\hline human & HBD-6 & 800 & 800 & 25 \\
\hline bovine & BPIV-3 & 50 & 1000 & 200 \\
\hline human & hRSV & 1000 & 1000 & 150 \\
\hline human & hSP-D & 900 & 900 & 150 \\
\hline human & hSPA1:A2 & 900 & 900 & 150 \\
\hline human & RIBO18S & 50 & 50 & 200 \\
\hline equine & INF-g & 1000 & 1000 & 150 \\
\hline ovine & SMAP29 & 700 & 700 & 75 \\
\hline equine & elL-12p40 & 1000 & 1000 & 150 \\
\hline equine & elL-10 & 1000 & 1000 & 150 \\
\hline equine & EGA3PDH & 1000 & 1000 & 150 \\
\hline bovine/ovine & TLR4 & 1000 & 1000 & 100 \\
\hline ovine & RIBOS15 & 1000 & 1000 & 150 \\
\hline bovine/ovine & bRSV & 1000 & 1000 & 150 \\
\hline
\end{tabular}

Fig. 11: Portion of FF2-6-001 qPCR set-up tool MasterEntrySheet.xls file (Sheet 1) which the user fills out to tell the system target and housekeeper names and what concentrations of primers and probes will be used for each different target. Extra room is provided here (and elsewhere in the MasterEntrySheet.xls file) for additional targets. 


\begin{tabular}{|c|c|c|c|c|}
\hline Sample & $20.260 \mathrm{~nm}$ & $260 / 280$ & Used in stockin? & (used) \\
\hline 1 & 0.22001 & $1 . \mathrm{mm}$ & $\bar{T}$ & 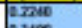 \\
\hline 2 & Q.3050 & 1.mu & 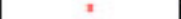 & 03900 \\
\hline 2 & 0.2130 & 1.630 & $=$ & pand \\
\hline 4 & attso & 1.605 & I & 2.1130 \\
\hline s & a.s5o & $1.6 \mathrm{non}$ & $=$ & 2.1520 \\
\hline$\varepsilon$ & atron & 1.6328 & $\approx$ & $0.17 \pi$ \\
\hline y & atan & 1. nos & $\therefore$ & D.19n \\
\hline $\mathbf{E}$ & a.2460 & 1..500 & $\approx$ & orate \\
\hline 5 & 0.5217 & 1.0018 & $=$ & |0.83 \\
\hline to & a.20m & $2 \mathrm{mon}$ & $\approx$ & 03000 \\
\hline $\mathrm{H}$ & a)ต & 1. $m 9 n$ & $\approx$ & osece \\
\hline 12 & a.2sen & 1. & 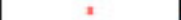 & pais \\
\hline 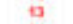 & อมอง & $1.6 \mathrm{n}$ & $=$ & $=0018$ \\
\hline s4 & a.1323 & $1 . \mathrm{mun}$ & $x$ & 2.138 \\
\hline is & atses & $1 . m s$ & $=$ & 2.135 \\
\hline 16 & atross & $1 . \cos 0$ & $=$ & a.17ue \\
\hline 77 & $0220 n$ & 1.6230 & $\approx$ & lome \\
\hline a & ams & 1.320 & $=$ & $0.300 x$ \\
\hline$a$ & atm & $1 . \mathrm{tan}$ & $\approx$ & a.1m \\
\hline 20 & $\operatorname{arns} 7$ & 1.5230 & a & D.200 \\
\hline 21 & 0.245 & 1. $n o n$ & $=$ & p.2atr \\
\hline$n$ & aovin & 1.9670 & $=$ & poever \\
\hline 23 & atani & 1.enn & 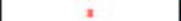 & 2.10000 \\
\hline 24 & a.13:7 & 1. .35 & 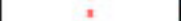 & 0.1317 \\
\hline 25 & a.son & $1.2 n 50$ & $x$ & 2.1514 \\
\hline 25 & atan & $1.5 \mathrm{mn}$ & $x$ & 2.197 \\
\hline$n z$ & a.sis & $1 . m m$ & 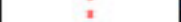 & 0.3rs \\
\hline 21 & atses & 1. $\pi 44$ & 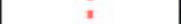 & a.1sit \\
\hline 23 & a.27vis & 1.6231 & 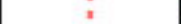 & 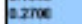 \\
\hline 3 & a.2113 & 1..mm & 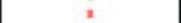 & baxk \\
\hline$\pi$ & aasss & 1.9620 & 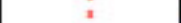 & coise \\
\hline 32 & aans & 1. $1.0 \mathrm{n}$ & 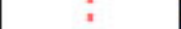 & 20000 \\
\hline$x$ & atas & 20000 & $=$ & 2.100x \\
\hline 36 & atzas & $1 . \mathrm{mu}$ & $x$ & 2.1300 \\
\hline 35 & atres & 1.632! & $x$ & a.17at \\
\hline 35 & a.3523 & 1.5234 & I & 0.360 \\
\hline 37 & Q.1015 & 1.t.eno & $\pi$ & 0.1315 \\
\hline 31 & $0.24 \pi 5$ & 1. $\mathrm{mus}$ & $\pi$ & pars \\
\hline 33 & atass & 1.530 & I & 2.1208 \\
\hline 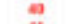 & agm & 1.6270 & s & learn \\
\hline st & anto & t.ronon & x & p.1110 \\
\hline$a z$ & aans & 1.6322 & $=$ & 20008 \\
\hline 0 & $\operatorname{atas} 2$ & 1. & I & 2.1000 \\
\hline 4 & atsis & 1.500 & $=$ & 2.1515 \\
\hline is & $\operatorname{arm}$ & 1.5628 & 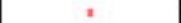 & basece \\
\hline es & atan & 2.0000 & $=$ & 0.1000 \\
\hline \& 7 & a.220s & 1. $\mathrm{nsp}$ & . & 0.2013 \\
\hline a & $Q_{1}+723$ & סנמת. & $=$ & $2.17 n$ \\
\hline $\boldsymbol{n}$ & assin & $1.6 \mathrm{Fm}$ & 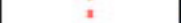 & 20000 \\
\hline 30 & aมm & $1 . \mathrm{m3n}$ & 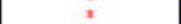 & 0.000 \\
\hline & 02200 & $1 . \mathrm{mso}$ & : & 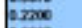 \\
\hline 52 & aan & $1 . \mathrm{mov}$ & 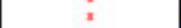 & 20000 \\
\hline 53 & atzon & t.k230 & : & 2.1200 \\
\hline s4 & a335s & 1. $x 220$ & : & 0.3000 \\
\hline ss & aass & 1.tmn & " & 00000 \\
\hline$\$ 4$ & a.2012 & 1. &. & 0.0012 \\
\hline & asmz & 1. $\mathrm{ngs}$ & & a.14x \\
\hline 3ี1 & axto & 1.900 & ; & iate \\
\hline 33 & a.san & 1.enn & i & 20000 \\
\hline ๓ & a.min & 1.nse & 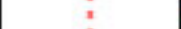 & 2.1000 \\
\hline 69 & a.soss & 1.2n日e & : & 20050 \\
\hline$a 2$ & a.tas2 & $1.5 \mathrm{~g} 2$ & 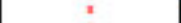 & 2.1050 \\
\hline อง & a.2m & $1 . m n$ & I & bars \\
\hline su & asazs & 1. n44 & I & $=00021$ \\
\hline as & a1230 & 1.673 & 8 & $2-1200$ \\
\hline s & a.136s & 1.tun & x & 2.1980 \\
\hline 67 & a.tros & 1.9022 & 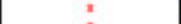 & D.1nes \\
\hline a1 & a.2103 & 1.9000 & I & 03700 \\
\hline 3 & Q.1523 & 2.000 & I & D.100s \\
\hline 节 & a.0323 & 1.mon & : & $=000$ \\
\hline 72 & & $\begin{array}{l}1.1324 \\
\text { 1. }\end{array}$ & 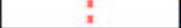 & 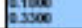 \\
\hline
\end{tabular}

Fig. 12: Portion of FF2-6-001 qPCR set-up tool MasterEntrySheet.xls file (Sheet 1) where the user enters all sample 0.d.260nm readings and selects (using an " $x$ ") which samples are to be used in the creating the Stock I solution for the entire study.

Gallup and Ackermann - Addressing fluorogenic real-time qPCR inhibition using the novel custom Excel file system 'FocusField2-6GallupqPCRSet-upTool001 ' to attain consistently high fidelity qPCR reactions

www.biologicalprocedures.com 


\begin{tabular}{|c|c|c|}
\hline 72 & Stock I parts & Stock / calculated o.d. 260 and ng/uL \\
\hline 25.0000 & एach & $22.685 \mathrm{ng} / \mathrm{uL}$ \\
\hline $5 p e 0260$ & 501280 readings t2 & keen initially at 1: 50 \\
\hline Stoek I made & Stock Ileft after & the Test Plate Stoek I after Sample 8 NRC Plates \\
\hline $1800 \mathrm{uL}$ & Foousfide26.001 & 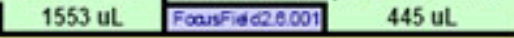 \\
\hline Other Stoek I & OK & \\
\hline $\begin{array}{l}\text { used pr lost? } \\
\text { QuL. }\end{array}$ & Final safe amo & unt of each RNA/target dilution needed: \\
\hline Foasfide2.0001 & adjust here: & 0 problem samples \\
\hline & Totalimar UNas & ETXuvolumes: $170 \mathrm{uL}$ \\
\hline & Amount of RNA & DNase treated: $70.00 \mathrm{uL}$ \\
\hline Amot & unt recovered: & (post DNase) \\
\hline & Stock I par & is prediluted 1: 10 \\
\hline Pestovinse & Unkinowns 2 & Iso prediluted 1: 10 \\
\hline Total rin size & Fortinalse & mple plates (wells per taraet): \\
\hline prepared & 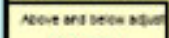 & Number of unknowns: \\
\hline $30.00 \mathrm{uL}$ & $25.00 \% \mathrm{w}$ & Points in standard curves: \\
\hline RNA asded & No. of time & is Target std. curves repeated: \\
\hline $7.80 \mathrm{uL}$ & Corr Shis X keset & NTCs used?: \\
\hline Used in wells & Ctri Shim Q Test F & Interplate Calibrtr?: \\
\hline $25.00 \mathrm{uL}$ & Ctril Shim M Final & Fine Sample Adjust: \\
\hline of simples & For Final & INRC Plates (wells per taraet): \\
\hline with degrees & Samples & tested for DNA contamination: \\
\hline of inhibition & Ctril ShifizRur & NTCs used?: \\
\hline & Final Stnds. & and Calibrator volumes made: $30000 \mathrm{~L}$ \\
\hline Rough amou & unt of each RIN/ & Teft aifter used for Stock etc. $\rightarrow-755 \mathrm{uL}$ \\
\hline Your One-Ste! & epMM & 1st-Tier target no/ul starts at: 0.36295 \\
\hline $\begin{array}{l}\text { Parameter Adju } \\
\text { (Based initially }\end{array}$ & $\begin{array}{l}\text { ustments: } \\
\text { y on } A B I\end{array}$ & $\begin{array}{l}\text { Enter [ two-step qPCR]-determined optimal } \\
\text { primer and probe concentrations (if known) }\end{array}$ \\
\hline One-Step Mast & ster Mix) & Endpriets \\
\hline & $2.0 x$ & 3000 \\
\hline RT solution: & & \\
\hline Important Me & tessage: & 300 \\
\hline$\$ 150 K$ & & 300 \\
\hline Ctrismiti $x$ & Resetfile & \\
\hline $\begin{array}{l}\text { Ctrl Shift Q } \\
\text { Ctrl Shift M }\end{array}$ & $\begin{array}{l}\text { Test Plate } \\
\text { Final Plates }\end{array}$ & \\
\hline Fousfiel & 2.6 .001 & \\
\hline Universa & al qPCR & \\
\hline Set-up & p Tœd & \\
\hline Lmeng $0.035 \mathrm{sm}$ & 0.0570 & \\
\hline & AEl $1=0$ & \\
\hline & ABI $2-9 t_{\mathrm{P}}$ & \\
\hline & Eppenosert 10tp & \\
\hline & strabouen ins & \\
\hline & 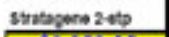 & \\
\hline Approx, oost: & $58,353.35$ & \\
\hline How many reac & ction plates? & \\
\hline & & \\
\hline & & \\
\hline & & \\
\hline & & \\
\hline
\end{tabular}

Fig. 13: Key portion of FF2-6-001 qPCR set-up tool MasterEntrySheet.xls file (Sheet 1) wherein the user enters numerous other numerically descriptive parameters which define the particular qPCR set-up and/or approach being pursued.

Gallup and Ackermann - Addressing fluorogenic real-time qPCR inhibition using the novel custom Excel file system 'FocusField2-6GallupqPCRSet-upTool001 ' to attain consistently high fidelity qPCR reactions

www.biologicalprocedures.com 


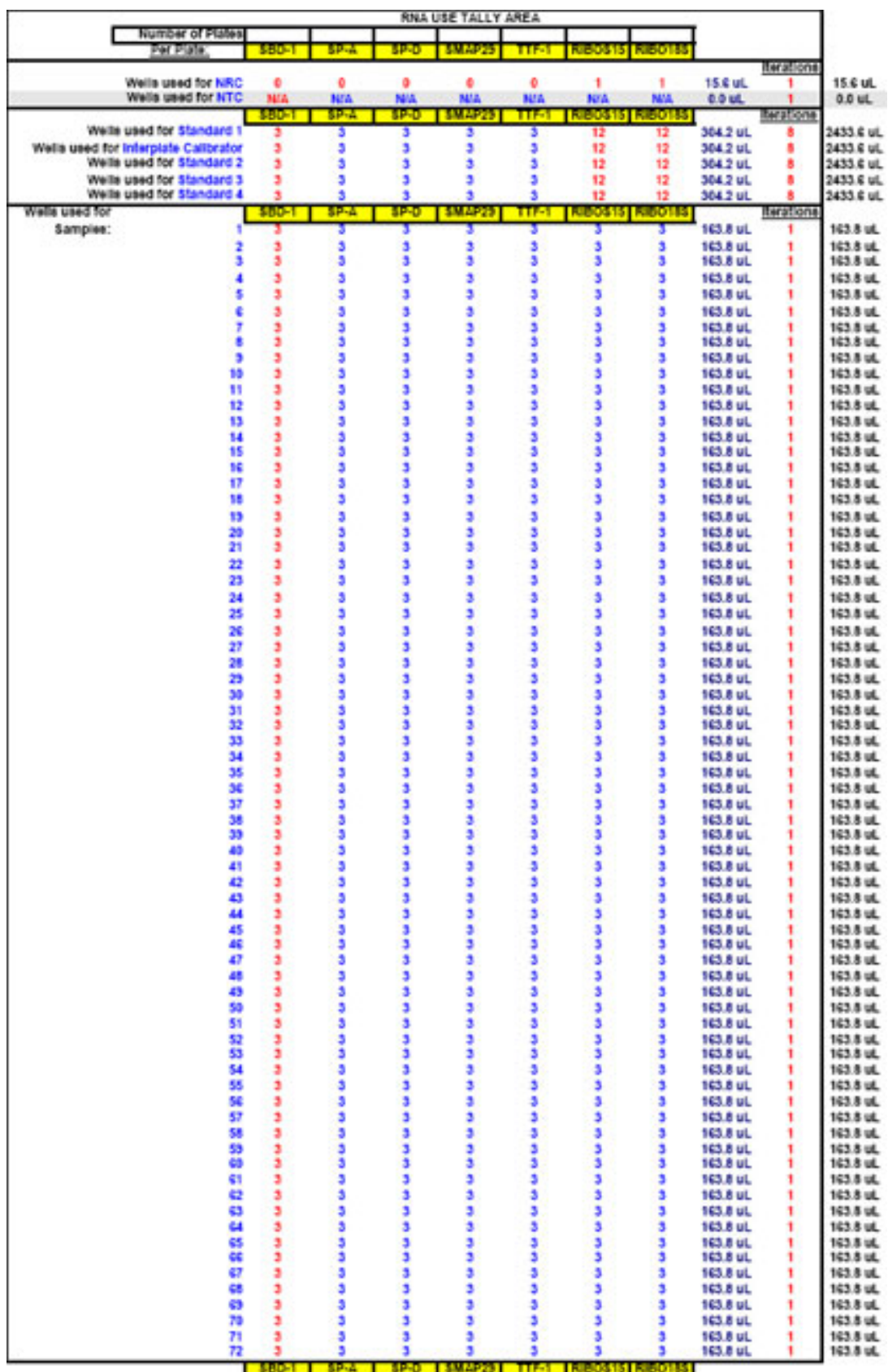

Fig. 14: Portion of FF2-6-001 qPCR set-up tool MasterEntrySheet.xls file (Sheet 2) wherein the file system can be used to help the user calculate how much of each standard, inter-plate calibrator and sample will be needed to successfully complete the entire study at hand without running out of one, some or all of them. 


\begin{tabular}{|c|c|c|c|c|c|c|c|}
\hline RNA Usāge Tally Área & $\mathrm{cn}$ & & [NRC Use? & Stnds and & alit & ators needed & íterations \\
\hline & Total samples: & 72 & & $187.20 \mathrm{uL}$ & A & 1: 400 & 1 \\
\hline Wells not used per plate & Sample wells total: & 1296 & & $187.20 \mathrm{uL}$ & B & 1: 693.2424 & 1 \\
\hline 0 & Replicates/sample: & 3 & & $187.20 \mathrm{uL}$ & C & 1: 800 & 1 \\
\hline Replicates/S & s, NTC and Calibr samples: & 3 & & $187.20 \mathrm{uL}$ & D & 1: 986.4848 & 1 \\
\hline \# of Wells used $f$ & NTC, Stds \& Calibr/Target: & 18 & & $187.20 \mathrm{uL}$ & $\mathrm{E}$ & 1: 2086.865 & 1 \\
\hline \# of Wells used & or NTC, Stds \& Calibr/Plate: & 36 & & $187.20 \mathrm{uL}$ & $\mathrm{F}$ & 1: 2432.881 & 1 \\
\hline & \# of Housekeepers/Plate: & 1 & & $187.20 \mathrm{uL}$ & G & 1: 3373.731 & 1 \\
\hline & ells used for Samples/Plate: & 60 & & $187.20 \mathrm{uL}$ & $\mathrm{H}$ & 1: 4034.241 & 1 \\
\hline \# of Sampl & allowable per Target/Plate: & 10 & & $187.20 \mathrm{uL}$ & I & 1: 6000 & 1 \\
\hline & \# of Plates estimate: & 7.2 & & $187.20 \mathrm{uL}$ & $\mathrm{J}$ & 1: 7268.482 & 1 \\
\hline & Round \# of Plates/Target: & 8 & $x$ & $2823.60 \mathrm{uL}$ & $\mathrm{K}$ & 1: 8000 & 15 \\
\hline & \# of Targets per plate: & 2 & & $187.20 \mathrm{uL}$ & $\mathrm{L}$ & 1: 8229.735 & 1 \\
\hline \# of Targets total ( & t including housekeepers): & 5 & & $187.20 \mathrm{uL}$ & M & 1: 14227.57 & 1 \\
\hline Number of & ousekeepers Tested Alone: & 0 & & $187.20 \mathrm{uL}$ & $\mathrm{N}$ & 1: 15659.47 & 1 \\
\hline & RNA used/well: & $7.80 \mathrm{uL}$ & & $187.20 \mathrm{uL}$ & $\mathrm{O}$ & 1: 40342.41 & 1 \\
\hline Total & eded of each Sample RNA: & $163.8 \mathrm{uL}$ & & $187.20 \mathrm{uL}$ & $\mathbf{P}$ & 1: 60000 & 1 \\
\hline & Manually chosen by user: & $250 \mathrm{uL}$ & & $187.20 \mathrm{uL}$ & $Q$ & 1: 66038.54 & 1 \\
\hline & NRC sample RNA usage: & & $x$ & $577.20 \mathrm{uL}$ & $\mathbf{R}$ & 1: 72684.82 & 3 \\
\hline & $\overline{\text { samples to check for NRC: }}$ & 77 & & $187.20 \mathrm{uL}$ & $\mathbf{S}$ & 1: 306523.8 & 1 \\
\hline & Sample wells total needed: & 154 & & $187.20 \mathrm{uL}$ & $\mathrm{T}$ & 1: 600000 & 1 \\
\hline & Replicates/sample: & 1 & $x$ & $577.20 \mathrm{uL}$ & $\mathbf{U}$ & 1: 660385.4 & 3 \\
\hline & \# of Housekeepers Tested: & 2 & $x$ & $577.20 \mathrm{uL}$ & V & 1: 6000000 & 3 \\
\hline Well & available for samples/Plate: & 96 & & $187.20 \mathrm{uL}$ & & & 1 \\
\hline \# of Sampl & allowable per Target/Plate: & 96 & & $187.20 \mathrm{uL}$ & & & 1 \\
\hline & \# of Plates estimate: & 2 & & $187.20 \mathrm{uL}$ & & & 1 \\
\hline & \# of Plates: & 2 & & $187.20 \mathrm{uL}$ & & & 1 \\
\hline & \# of Targets per plate: & 1 & & $187.20 \mathrm{uL}$ & & & 1 \\
\hline & RNA used/well: & $7.80 \mathrm{uL}$ & & $\begin{array}{l}187.20 \mathrm{uL} \\
187.20 \mathrm{uL}\end{array}$ & & & $\begin{array}{l}1 \\
1\end{array}$ \\
\hline Total & eded of each Sample RNA: & $15.6 \mathrm{uL}$ & & $187.20 \mathrm{uL}$ & & & 1 \\
\hline & & & & $187.20 \mathrm{uL}$ & & & 1 \\
\hline & & & & $187.20 \mathrm{uL}$ & & & 1 \\
\hline & & & & $187.20 \mathrm{uL}$ & & & 1 \\
\hline Override Sample RNA Amout: & & & & $187.20 \mathrm{uL}$ & & & 1 \\
\hline $250 \mathrm{uL}$ & & & & $187.20 \mathrm{uL}$ & & & 1 \\
\hline Master Control Settings & & Largest A & t Needed: & $2823.60 \mathrm{uL}$ & & & \\
\hline Override Stnd RNA Amounts: & & & en by user: & $3000 \mathrm{uL}$ & & & \\
\hline $3000 \mathrm{uL}$ & & & Other Tally: & $2433.60 \mathrm{uL}$ & & & \\
\hline
\end{tabular}

Fig. 15: Portion of FF2-6-001 qPCR set-up tool MasterEntrySheet.xls file (Sheet 3) which automatically calculates the required amounts needed of all samples, standards and inter-plate calibrators based on what the user has already entered in the portions of the MasterEntrySheet.xls file depicted in Figures 12, 13, and 14.
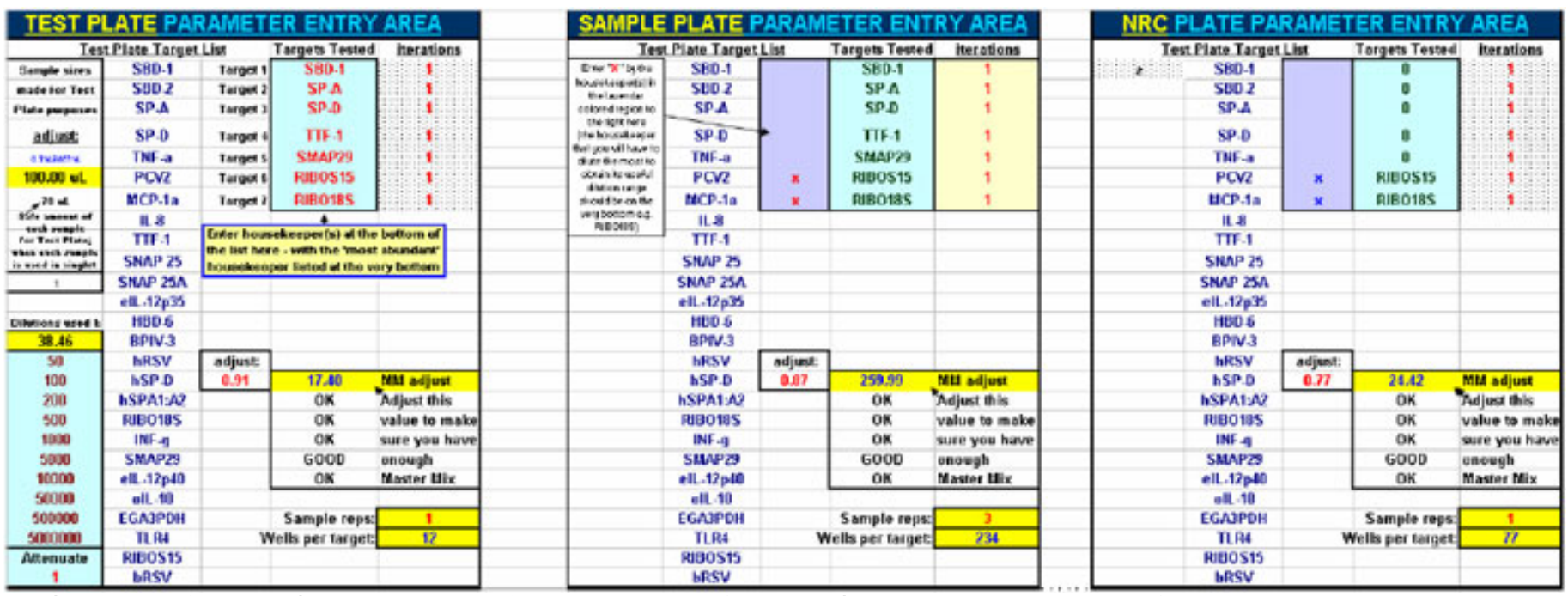

Fig. 16: Portion of FF2-6-001 qPCR set-up tool MasterEntrySheet.xls file (Sheet 1) which allows the user to define Test Plate parameters (and correct master mix usage), Sample Plate parameters (and correct master mix usage), and NRC Plate parameters (and correct master mix usage). 


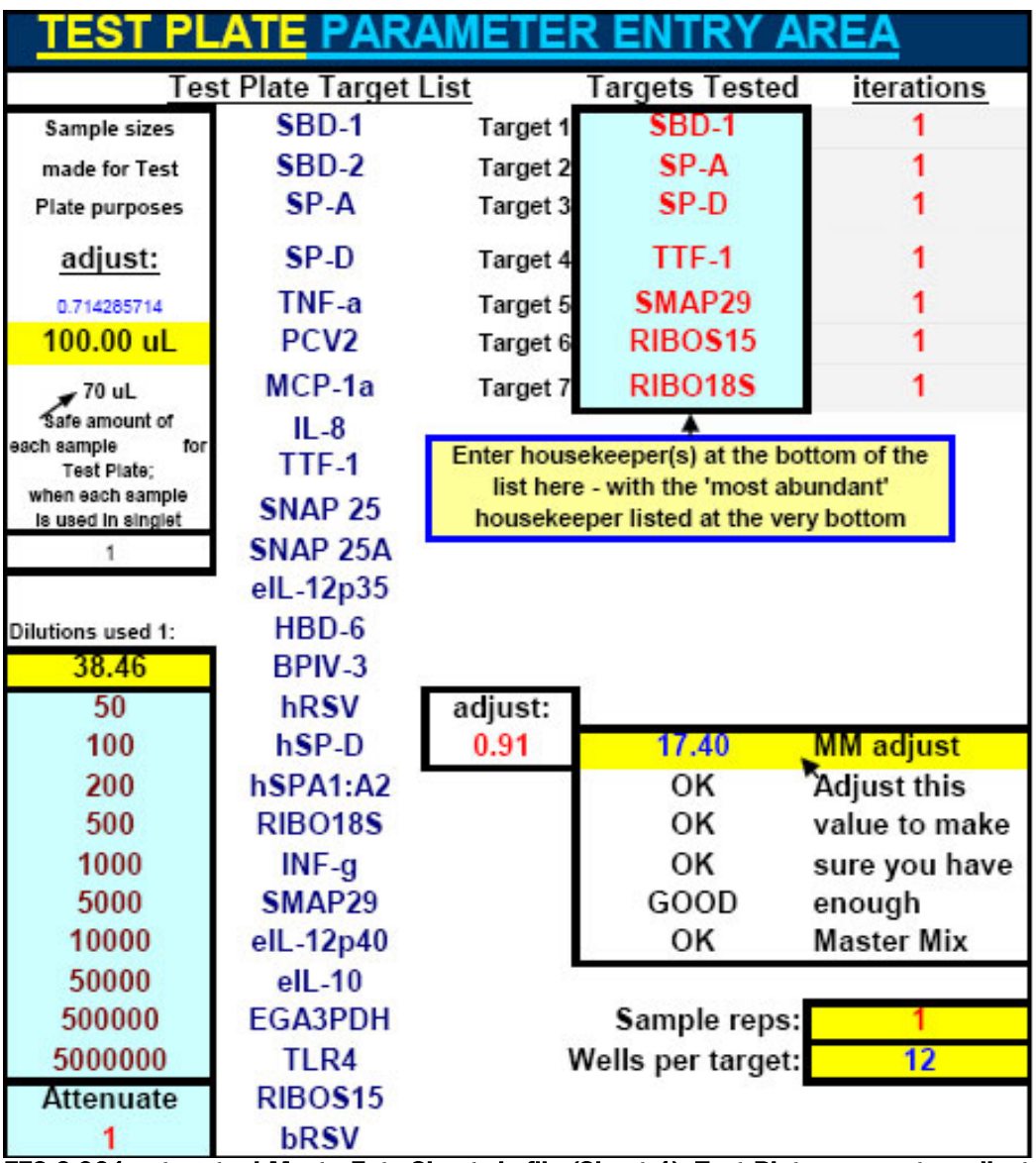

Fig. 17: Close-up of a portion of FF2-6-001 set-up tool MasterEntrySheet.xls file (Sheet 1): Test Plate parameter adjustment area (as also shown in Fig. 16).

\begin{tabular}{|c|c|c|c|c|c|c|c|c|c|c|c|c|c|c|c|}
\hline \multicolumn{16}{|c|}{ TEST PLATE DEPICTION: } \\
\hline \multirow{2}{*}{\multicolumn{2}{|c|}{$\begin{array}{l}\text { Machine Faotors: } \\
\text { Scientific notation: }\end{array}$}} & 0.026 & 0.02 & 0.01 & 0.005 & 0.002 & 0.001 & 0.0002 & 0.0001 & 0.00002 & 0.000002 & \multirow{2}{*}{\multicolumn{2}{|c|}{$\begin{array}{c}0.0000002 \\
2.00 \mathrm{E}-07\end{array}$}} & \multirow{2}{*}{\multicolumn{2}{|c|}{ (The Null-strength" dilution) }} \\
\hline & & $2.60 E-02$ & $200 \mathrm{E}-02$ & $1.00 E-02$ & $5.00 E-03$ & $2.00 \mathrm{E}-03$ & $1.00 E-03$ & $2.00 \mathrm{E}-04$ & $1.00 E-04$ & $200 \mathrm{E} \cdot 05$ & $2.00 €-06$ & & & & \\
\hline & 1 & 2 & 3 & 4 & 5 & 6 & 7 & 8 & 3 & 10 & 11 & \multicolumn{2}{|l|}{12} & \multirow{2}{*}{\begin{tabular}{c|}
38.46 \\
50
\end{tabular}} & \multirow{2}{*}{ n-wel achived, post CNbse diuson } \\
\hline A & Nete & 130,4 & 152 & +100 & $\operatorname{casc}$ & 1900 & 41000 & 15250 & tostos & $130 t 5$ & 100000 & 10500000 & SBD-1 & & \\
\hline B & $m$ & 130.4 & 169 & ter & $12 a$ & +100 & +1000 & $\operatorname{tans}$ & tiens & taces & toseces & -1500000 & SP.A & 100 & In wel ashived, post CNbse dlusion \\
\hline c & NTo & t3a.se & 105 & tien & $t 200$ & 1900 & 101000 & +5000 & tuevos & taccon & 1300000 & $\pm=500000$ & SP.D & 200 & 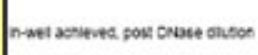 \\
\hline D & sese & 134.44 & 16 & जाही & 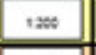 & +100 & $t+10 x$ & $+6 a x$ & t10 & tacest & tososs & 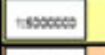 & $\pi T F=1$ & 500 & numel asnived, post CNase diuson \\
\hline E & NTo & 131..4 & 152 & twen & 1200 & 1100 & $4: 1000$ & +5200 & t10000 & tsocen & t:s00000 & 50500000 & \multirow{2}{*}{ SMAP29 } & 1000 & \multirow{2}{*}{ In-wel ashieved, post DNose olluson } \\
\hline$F$ & Noto & tat.4t & 100 & tesen & 1900 & 1900 & \pm 1000 & 15200 & t10000 & sacten & socosen & $=5000000$ & & 5000 & \\
\hline G & NTO & tas.at & 100 & ten & 1300 & 1300 & \pm 1000 & 15000 & tretos & 190000 & 1050000 & 105000000 & \multirow[t]{2}{*}{ RIB0185 } & 10000 & 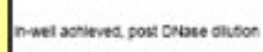 \\
\hline$H$ & & & & & & & & & & & & & & 50000 & 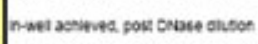 \\
\hline & & & & & & & & & & & & & & $\begin{array}{r}500000 \\
5000000\end{array}$ & 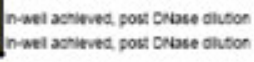 \\
\hline
\end{tabular}

This Test Plate dilution series thus represents the following RNA concentrations:

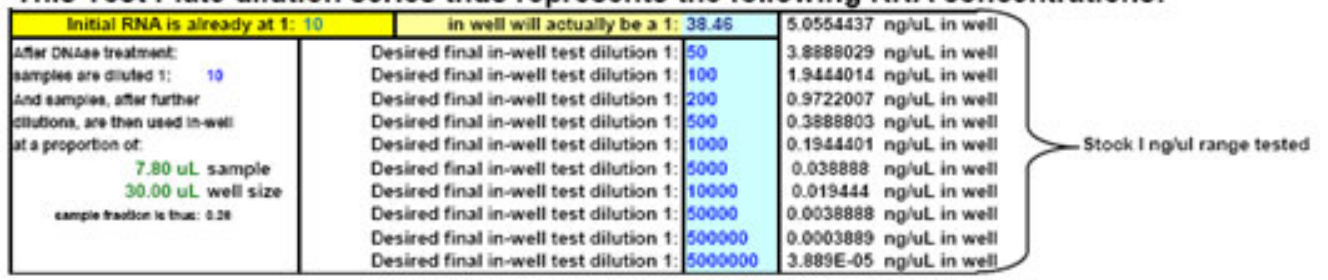

Fig. 18: The FF2-6-001 qPCR set-up tool TestPlateDepiction.xls file - used to show the general Test Plate parameters and which is equationally linked to other key FF2-6-001 qPCR set-up tool files.

Gallup and Ackermann - Addressing fluorogenic real-time qPCR inhibition using the novel custom Excel file system 'FocusField2-6GallupqPCRSet-upTool001 ' to attain consistently high fidelity qPCR reactions

www.biologicalprocedures.com 


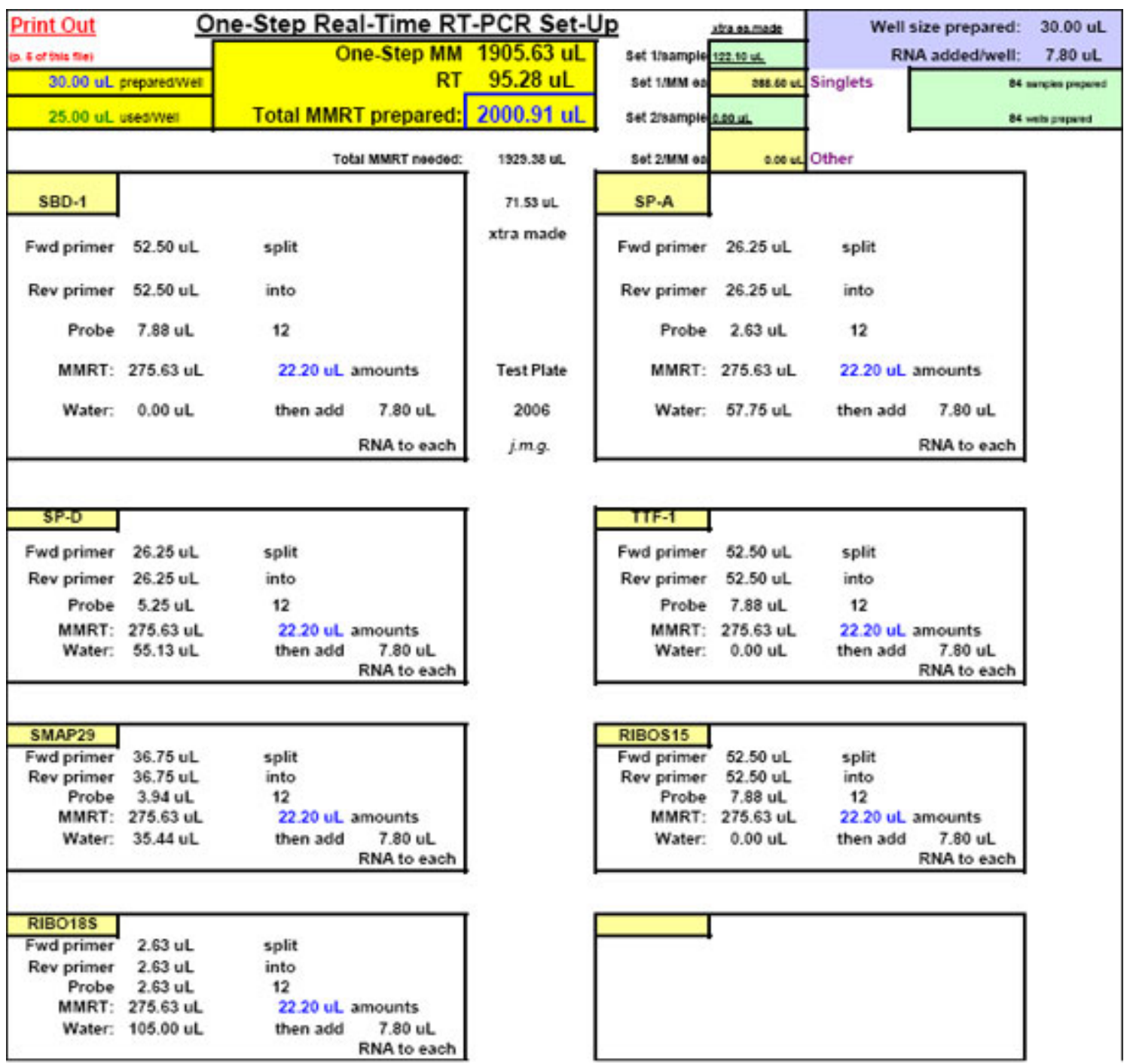

Fig. 19: Portion of FF2-6-001 qPCR set-up tool MasterEntrySheet.xls file (Sheet 2) which shows the automatically-calculated master mix preparations needed to perform the user-designed Test Plate. All master mix calculation files automatically figure in safe extra preparative amounts to safeguard the user from running short on final volumes or running into bubbles at the bottom of time-intensive sample preparation tubes. 


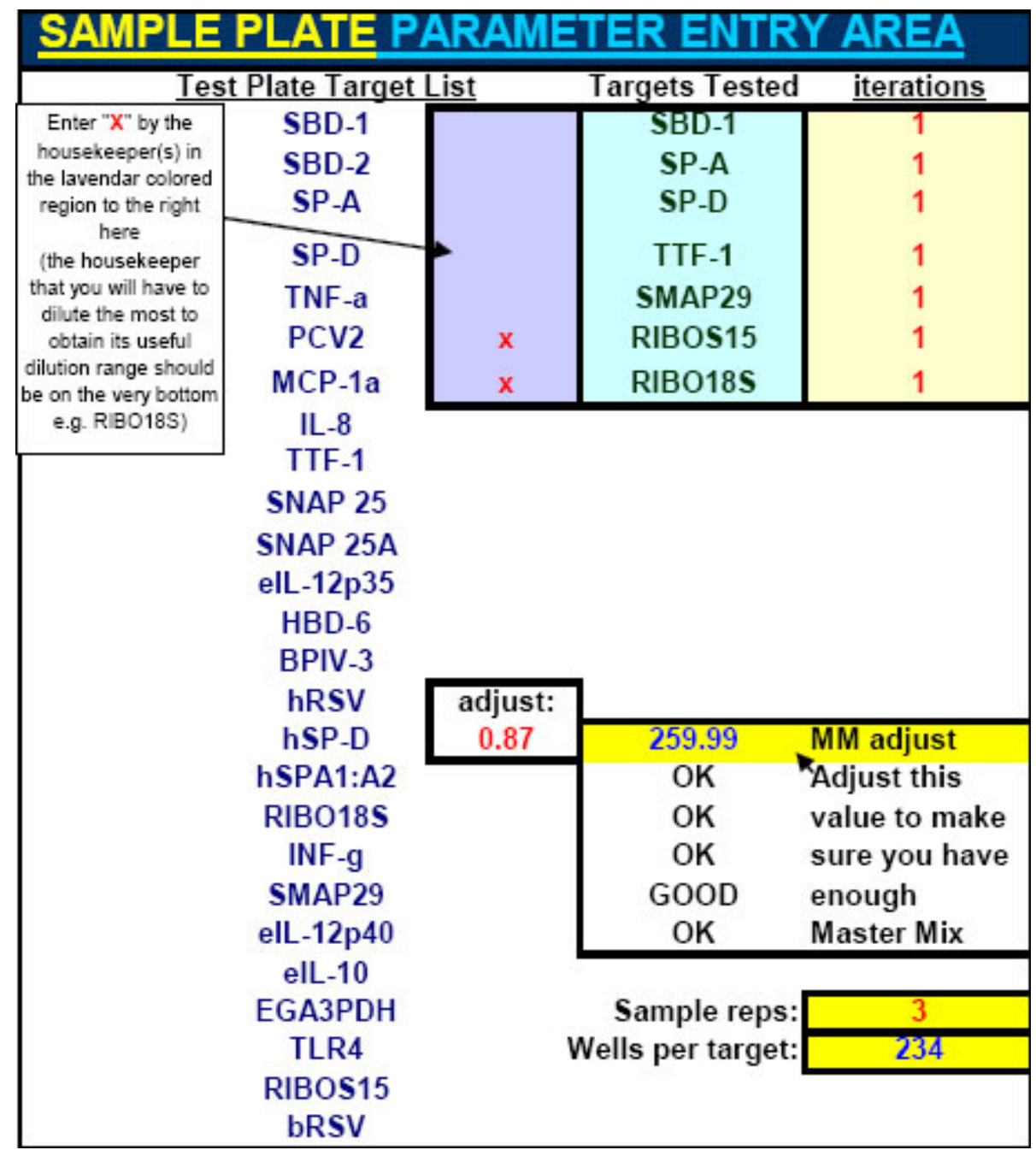

Fig. 20: Close up of the portion of FF2-6-001 qPCR set-up tool MasterEntrySheet.xls file (Sheet 1) used for adjusting final Sample Plate parameters (as also shown in Fig. 16). 


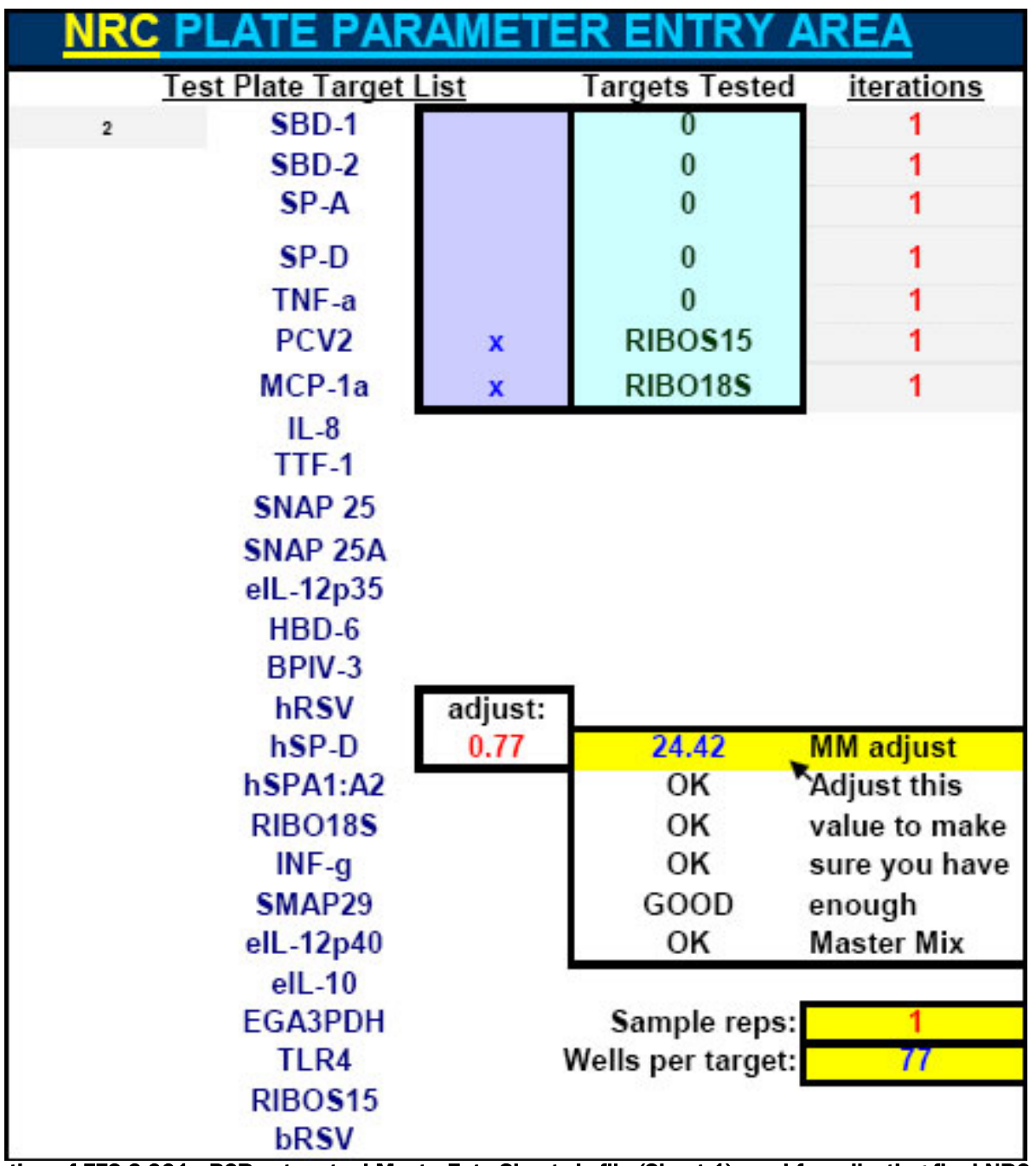

Fig. 21: Close up of the portion of FF2-6-001 qPCR set-up tool MasterEntrySheet.xls file (Sheet 1) used for adjusting final NRC Plate parameters (as also shown in Fig. 16). 


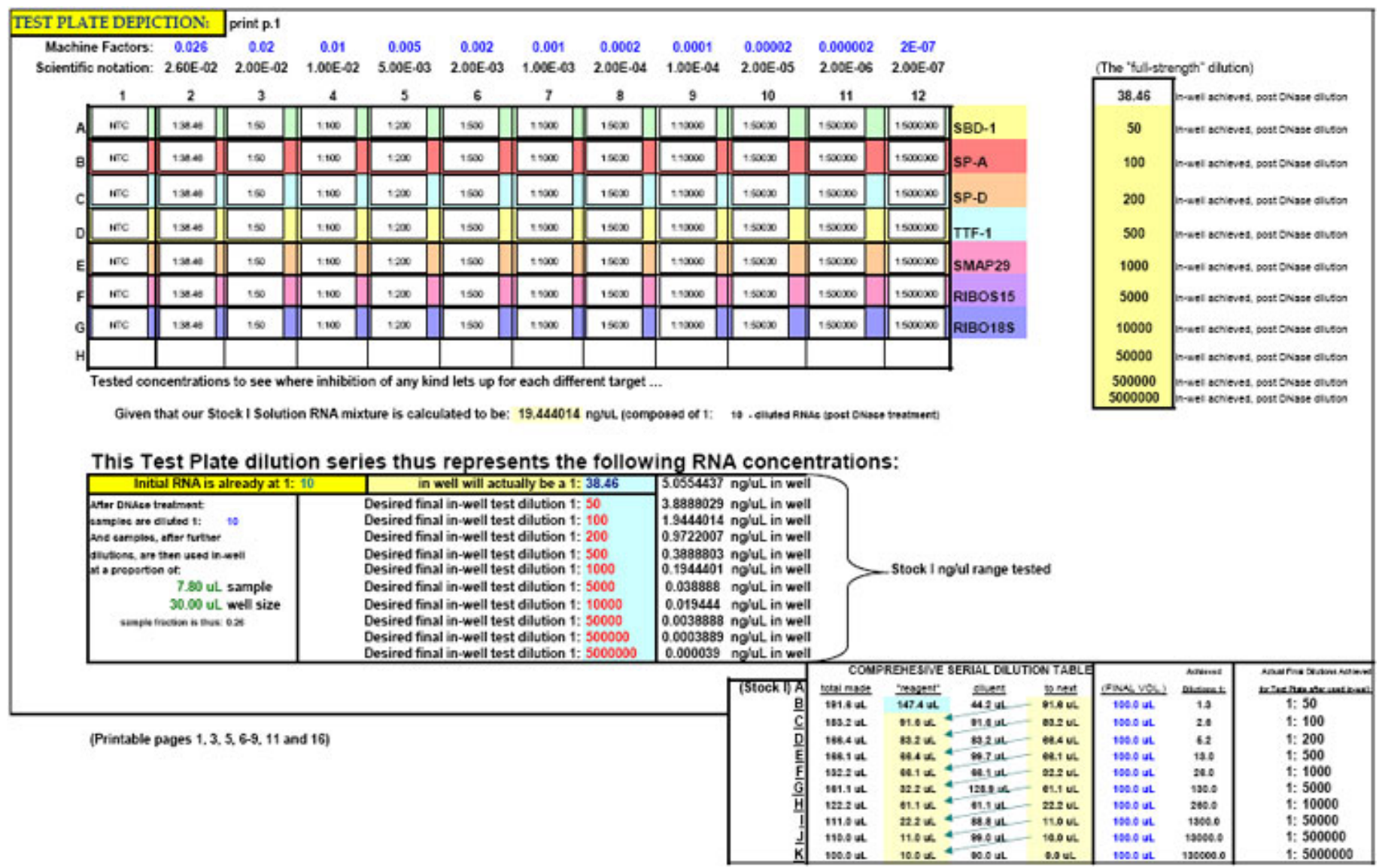

Fig. 22: FF2-6-001 qPCR set-up tool MasterEntrySheet.xls file (Sheet 2) showing the final automatically-calculated Test Plate parameters and set up for seven targets. This page is printed out and used as a guide for machine programming and Stock I sample dilutions. The term "reagent" in the dilution table above connotes Stock I as the solution used in the light blue-highlighted cell. 


\begin{tabular}{|c|c|c|c|c|c|c|}
\hline Well & Type & Name & Primer/Probe & Paste Cts & Not98: & Cty \\
\hline AT & tic & SEV-1 & SED-1 & 50 & \multirow{3}{*}{$\begin{array}{c}\text { Ideal Cts: } \\
50.38\end{array}$} & \\
\hline A2 & UNKN & 38.46154 & SBD-1 & 50 & & $T$ \\
\hline$A_{3}$ & UNKN & 50 & SBD-1 & 50 & & 0.2 \\
\hline A4 & UNKN & 100 & SBD-1 & 37.82 & 51.00 & 0.004 \\
\hline A5 & UNKN & 200 & SBD-1 & 32.95 & 38.82 & 0.00004 \\
\hline AS & UNKN & 500 & SBD-1 & 33.87 & 34.27 & $9.81 \mathrm{E}-05$ \\
\hline A7 & UNKN & 1000 & SBD-1 & 34.6 & 35.27 & $9.81 \mathrm{E}-05$ \\
\hline$A B$ & UNKN & 5000 & SBD-1 & 36.93 & 37.59 & 0.07956 \\
\hline As & UNKN & 10000 & SBD-1 & 39.27 & 38.59 & 0.698345 \\
\hline A10 & UNKN & 50000 & SBD-1 & 46.7 & 40.92 & 0.129793 \\
\hline A11 & UNKN & 500000 & SBD-1 & 50 & 44.24 & 0.035842 \\
\hline A12 & UNIKN & 5000000 & SBD-1 & 50 & 47.56 & $9.81 E-05$ \\
\hline B1 & NTIC & SPR-A & SP-A & 50 & \multirow[b]{2}{*}{ Ideal Cts: } & \\
\hline B2 & UNKN & 38.46154 & SP-A & 25.03 & & $T$ \\
\hline B3 & UNKN & 50 & SP-A & 24.64 & 25.41 & 0.2 \\
\hline B4 & UNKN & 100 & SP-A & 25.55 & 25.64 & 0.004 \\
\hline B5 & UNKN & 200 & SP-A & 26.54 & 26.55 & 0.00004 \\
\hline B6 & UNKN & 500 & SP-A & 27.86 & 27.86 & 2.2006 \\
\hline 87 & UNKN & 1000 & SP-A & 28.76 & 28.86 & 2.813517 \\
\hline $\mathrm{B} 8$ & UNKN & 5000 & SP-A & 35.57 & 31.18 & 1.585854 \\
\hline B9 & UNKN & 10000 & SP-A & 32.24 & 32.18 & 0.370016 \\
\hline B10 & UNKN & 50000 & SP-A & 34.62 & 34.51 & 0.035737 \\
\hline B11 & UNKN & 500000 & SP-A & 38.46 & 37.83 & 0.023432 \\
\hline B12 & UNIKN & 5000000 & SP-A & 42.6 & 41.15 & 0.000466 \\
\hline Cा & TIC & SPR-D & SP-D & 50 & \multirow{3}{*}{$\begin{array}{c}\text { Ideal Cts: } \\
45.39\end{array}$} & \\
\hline C2 & UNKN & 38.46154 & SP-D & 45.01 & & 1 \\
\hline c3 & UNKN & 50 & SP-D & 46.98 & & 0.2 \\
\hline C4 & UNKN & 100 & SP-D & 29.48 & 47.98 & 0.004 \\
\hline C5 & UNKN & 200 & SP-D & 25.39 & 30.48 & 0.00004 \\
\hline C6 & UNKN & 500 & SP-D & 25.3 & 26.71 & 2.99E-07 \\
\hline c7 & UNKN & 1000 & SP-D & 26.1 & 27.71 & 7.03E-08 \\
\hline $\mathrm{C}_{8}$ & UNKN & 5000 & SP-D & 27.28 & 30.03 & 0.02719 \\
\hline C9 & UNKN & 10000 & SP-D & 29.06 & 31.03 & 0.587586 \\
\hline C10 & UNKN & 50000 & SP-D & 31.53 & 33.36 & 0.137045 \\
\hline C11 & UNKN & 500000 & SP-D & 35.11 & 36.68 & 0.037027 \\
\hline C12 & UNIKN & 5000000 & SP-D & 38.76 & 40.00 & 0.000433 \\
\hline णT & TIC & Ttr-1 & Tाr-1 & 50 & & \\
\hline D2 & UNKN & 38.46154 & TTF-1 & 29.64 & Ideal Cts: & $\overline{1}$ \\
\hline D3 & UNKN & 50 & TTF-1 & 28.73 & 30.02 & 0.2 \\
\hline D4 & UNKN & 100 & TTF-1 & 22.18 & 29.73 & 0.004 \\
\hline D5 & UNKN & 200 & TTF-1 & 19.8 & 23.18 & 0.00004 \\
\hline DG & UNKN & 500 & TTF-1 & 28.7 & 21.12 & 0.000432 \\
\hline D7 & UNKN & 1000 & TTF-1 & 22 & 22.12 & 0.000568 \\
\hline D8 & UNKN & 5000 & TTF-1 & 22.32 & 24.44 & 0.147305 \\
\hline D9 & $\begin{array}{l}\text { UNKNN } \\
\text { UNKN }\end{array}$ & $\frac{10000}{50000}$ & $\begin{array}{l}\text { TTF-1 } \\
\text { TTF-1 }\end{array}$ & $\frac{23.9}{25.22}$ & $\begin{array}{l}25.44 \\
27.77\end{array}$ & $\begin{array}{l}0.000591 \\
0.132305\end{array}$ \\
\hline $\begin{array}{l}\text { D10 } \\
\text { D11 }\end{array}$ & NKN & $\frac{50000}{500000}$ & $\begin{array}{l}\text { TTF-1 } \\
\text { TTF-1 }\end{array}$ & $\frac{26.22}{25.7}$ & 27.77 & 0.132305 \\
\hline D11 & NKN & 500000 & TTF-1 & 29.7 & 31.09 & 0.039373 \\
\hline D12 & UNKNN & 5000000 & TTF-1 & 33.21 & 41 & 0.00046 \\
\hline D1 & NTC & SMAP2S & SMAPZ9 & 50 & & 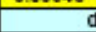 \\
\hline D2 & UNKN & 38.46154 & SMAP29 & 29.29 & Ideal Ctr: & $T$ \\
\hline D3 & UNKN & 50 & SMAP29 & 29.62 & 29.67 & 0.2 \\
\hline D4 & NKN & 100 & 229 & 22.38 & 30.62 & 0.004 \\
\hline D5 & UNKN & 200 & SMAP29 & 21.73 & 23.38 & 0.00004 \\
\hline D6 & NKN & 500 & SMAP29 & 22 & 23.05 & 0.002129 \\
\hline D7 & UNKN & 1000 & SMAP29 & 22.45 & 24.05 & 0.001667 \\
\hline D8 & UNKN & 5000 & SMAP29 & 24.64 & 26.37 & 0.358254 \\
\hline D9 & IKN & 10000 & 29 & 25.43 & 37 & 0.474904 \\
\hline D10 & NKN & 50000 & 29 & 28.15 & 29.70 & 0.067011 \\
\hline D11 & UNKN & 500000 & SMAP29 & 31.5 & 33.02 & 0.037295 \\
\hline D12 & UNKN & 5000000 & SMAP29 & 34.92 & 36.34 & 0.000413 \\
\hline ET & NTTC & RIBOST5 & RाBOS15 & 50 & & \\
\hline E2 & UNKN & 38.46154 & $\$ 15$ & 50 & Ideal Cts: & $\overline{1}$ \\
\hline E3 & NKN & 50 & RIB & 50 & 50.38 & 0.2 \\
\hline E4 & UNKN & 100 & RIBOS15 & 25.07 & 51.00 & 0.004 \\
\hline E5 & JNKN & 200 & RIBOS15 & 30.73 & 26.07 & 0.00004 \\
\hline E6 & UNKN & 500 & RIBOS15 & 20.95 & 32.05 & $1.4 \mathrm{E}+179$ \\
\hline E7 & NKN & 1000 & RIBOS15 & 22.1 & 33.05 & $1.4 \mathrm{E}+179$ \\
\hline E8 & NKN & 5000 & $\$ 15$ & 18.63 & 35.37 & 2.4E-05 \\
\hline E9 & UNKN & 10000 & RIBOS15 & 19.4 & 36.37 & $1.03 E-35$ \\
\hline E10 & UNKN & 50000 & RIBOS15 & 20.78 & 38.70 & 8.19E-53 \\
\hline E11 & NKN & 500000 & $\$ 15$ & 24.42 & 42.02 & 3.88E-47 \\
\hline E12 & UNKNN & 50000000 & RIBOS15 & 28.16 & 45.34 & 3.89E-10 \\
\hline$\overline{E 1}$ & NTC & RIBO18S & RाBO18S & 50 & & \\
\hline E2 & UNKN & 38.46154 & RIBO18S & 50 & Ideal Ct8: & $T$ \\
\hline E3 & UNKN & 50 & RIBO18S & 50 & 50.38 & 0.2 \\
\hline E4 & UNKNN & 100 & RIBO18S & 25.07 & 51.00 & 0.004 \\
\hline E5 & WNKN & 200 & RIBO18S & 30.73 & 26.07 & 0.00004 \\
\hline ES & JNKN & 500 & RIBO18S & 20.95 & 32.05 & $1.4 E+179$ \\
\hline E7 & NKN & 1000 & RIBO18S & 22.1 & 33.05 & $1.4 E+179$ \\
\hline E8 & UNKN & 5000 & RIBO18S & 18.63 & 35.37 & 2.4E-05 \\
\hline E9 & UNKN & 10000 & RIBO18S & 19.4 & 36.37 & \\
\hline E10 & NKNN & 50000 & RIBO18S & 20.78 & 38.70 & 8.19E-53 \\
\hline E11 & UNKN & 500000 & RIBO18S & 24.42 & 42.02 & $3.88 E-47$ \\
\hline E12 & UNKN & 5000000 & RIBO18S & 28.16 & 45.34 & $3.89 \mathrm{E}-10$ \\
\hline
\end{tabular}

Fig. 23: FF2-6-001 qPCR set-up tool TestPlateResultsAnalysis2006.xls file; Test Plate final $C_{T}$ entry area (shown in red font).

Gallup and Ackermann - Addressing fluorogenic real-time qPCR inhibition using the novel custom Excel file system 'FocusField2-6GallupqPCRSet-upTool001 ' to attain consistently high fidelity qPCR reactions

www.biologicalprocedures.com 


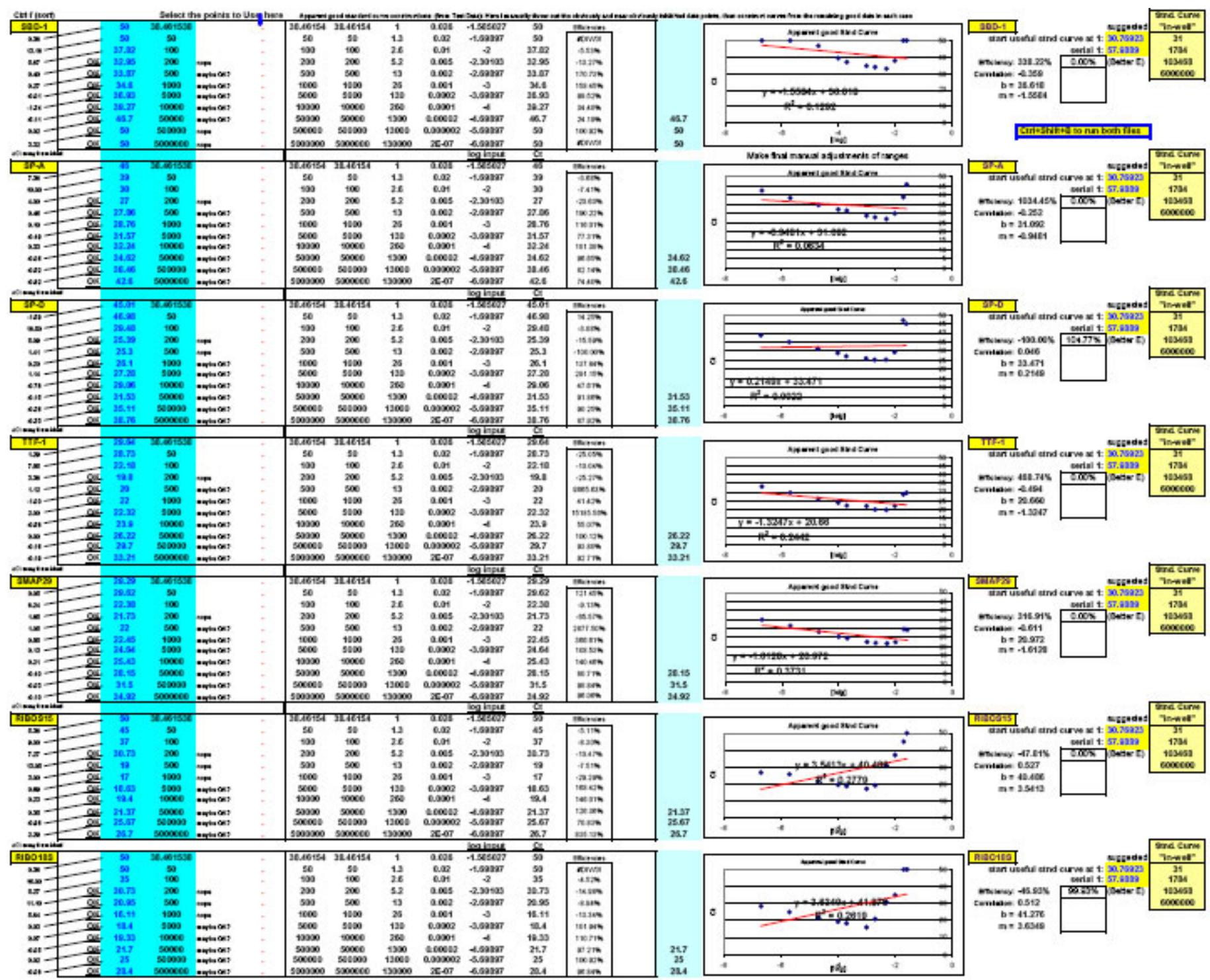

Fig. 24: FF2-6-001 qPCR set-up tool TestPlateResultsAnalysis2006.xIs file just after Test Plate $C_{T}$ values have been entered and preliminary macros have been run. Notice how the regions of QPCR inhibition are clearly exposed for each qPCR target at the right hand side of each target's dilution profile (LOG 10 of Stock I dilution vs. $\mathrm{C}_{\mathrm{T}}$ ) graph. The most concentrated RNA samples in each case are the samples which exhibit the most qPCR inhibitory phenomena.

Gallup and Ackermann - Addressing fluorogenic real-time qPCR inhibition using the novel custom Excel file system 'FocusField2-6GallupqPCRSet-upTool001 ' to attain consistently high fidelity qPCR reactions

www.biologicalprocedures.com 


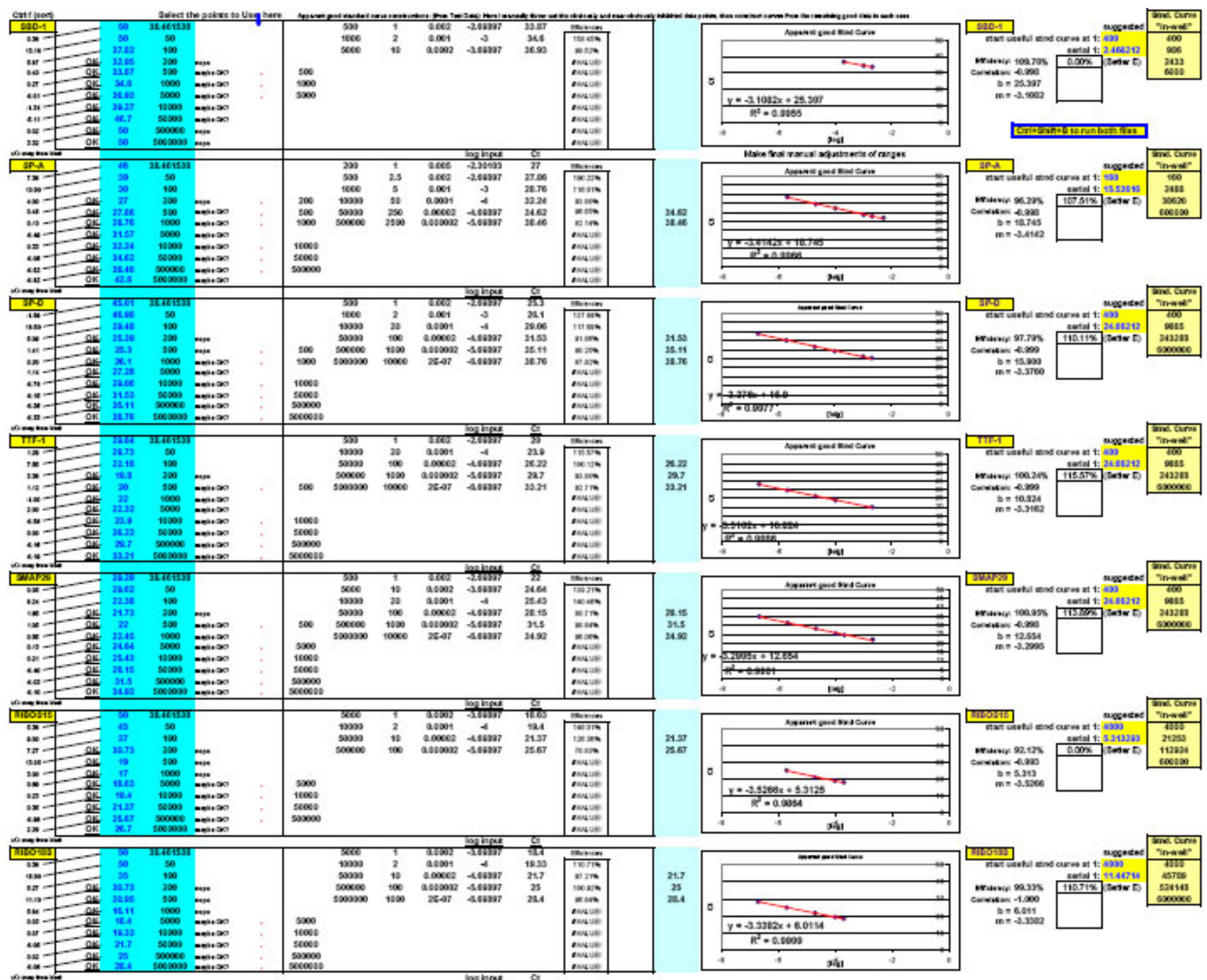

Fig. 25: Optimal ranges identified for all targets using the FF2-6-001 qPCR set-up tool TestPlateResultsAnalysis2006.xls file (which is connected by Visual Basic macros and equations to its "twin" file, TestPlateResultsAnalysis2006b.xls, which is used to fine-tune the parameters revealed by this file). Efficiencies and slopes for each target are calculated from Test Plate $C_{T}$ values for each qPCR target as the user manually selects different points on each graph in effort to ascertain the optimal RNA dilution ranges for each target.

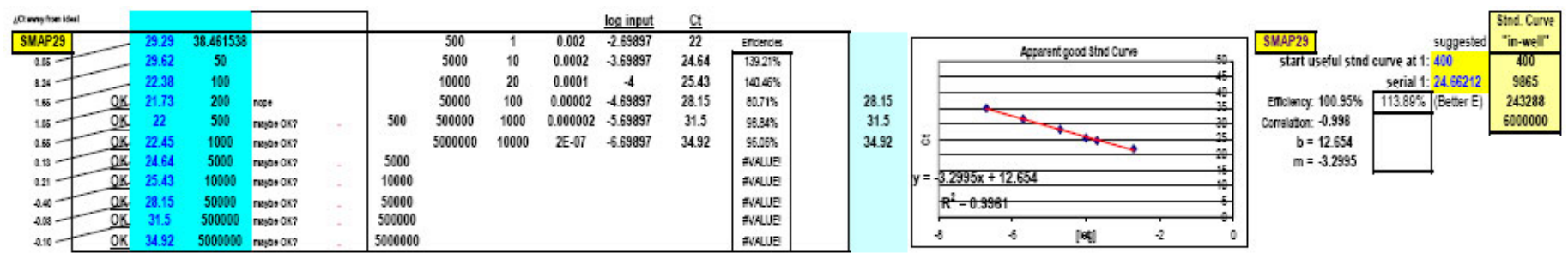

Fig. 26: Close up of a region of the FF2-6-001 qPCR set-up tool TestPlateAnalysis2006.xls file which is used to detect qPCR inhibition, dial in a target's optimal RNA dilution range, and find the Stock I RNA dilution range which yields the highest efficiency reaction for each qPCR target. Here, qPCR target SMAP29 has been assessed. 


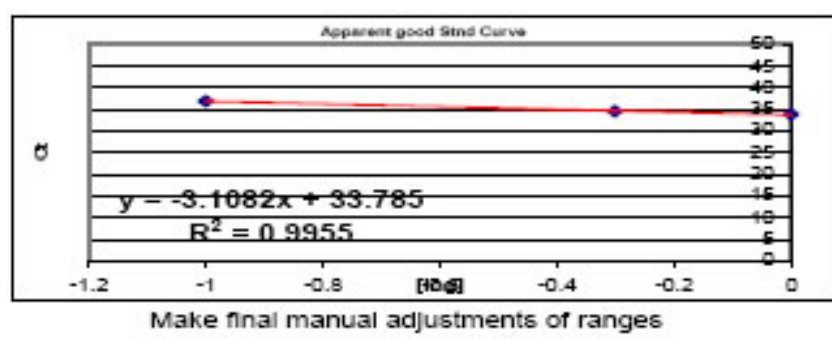

\begin{tabular}{cc} 
SBD-1 & "In-well" \\
\hline start useful stnd curve at $1: 250$ & 250 \\
serlal $1: 3$ & 750 \\
Efnolenoy: $109.76 \%$ & 2250 \\
Corrolation: -0.998 & 6750 \\
$b=33.785$ & \\
$m=-3.1082$ &
\end{tabular}

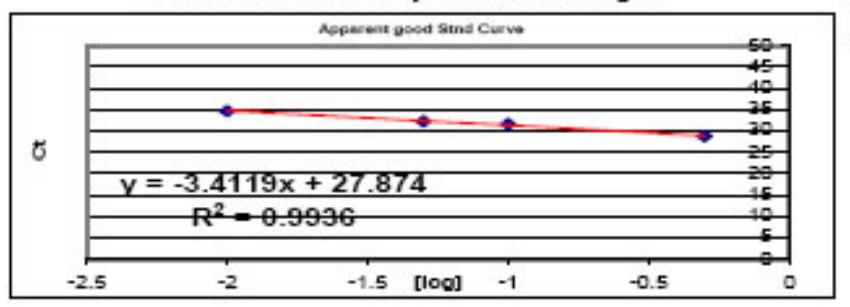

\begin{tabular}{|c|c|}
\hline TTF-1 & "In-weII" \\
\hline $\begin{array}{r}\text { start userul stnd curve at 1: } 1000 \\
\text { serlal 1: } 4\end{array}$ & $\begin{array}{l}1000 \\
4000\end{array}$ \\
\hline Efrolenoy: $96.38 \%$ & 16000 \\
\hline $\begin{aligned} \text { Corrolation: }-0.997 \\
b=27.874\end{aligned}$ & 64000 \\
\hline
\end{tabular}

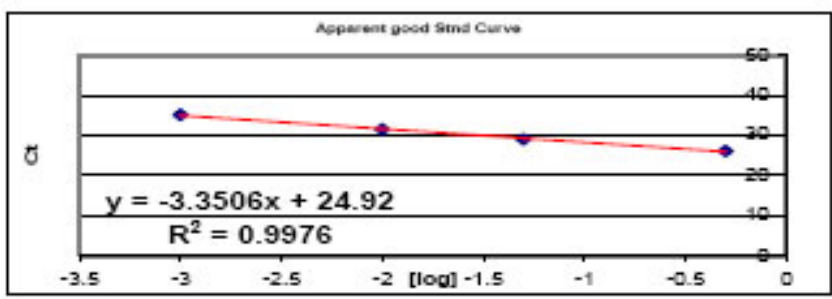

\section{SP-D}

start userul stnd curve at 1: 1500

$$
\begin{aligned}
& \text { "In-weII" } \\
& 1500 \\
& 7500 \\
& 37500 \\
& 187500
\end{aligned}
$$

Efrlolenoy: $98.82 \%$

serial 1: 5

$\mathrm{m}=-3.3506$

$m=-3.3506$

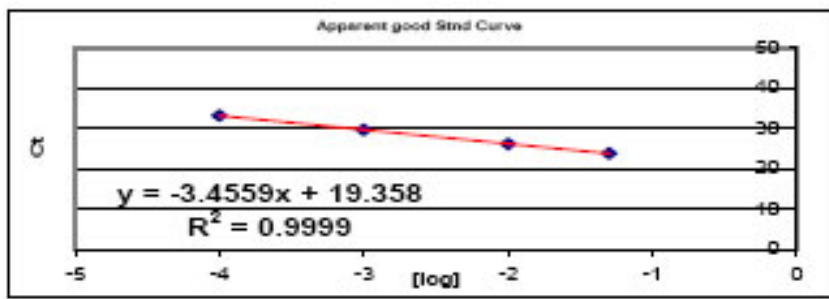

\section{SP-A}

start useful atnd curve at 1: 1500

serial 1: 5

$$
\begin{aligned}
& \text { "In-weII" } \\
& 1500 \\
& 7500 \\
& 37500 \\
& 187500
\end{aligned}
$$

Correlation: -1.000

$\mathrm{b}=19.358$

$m=-3.4559$

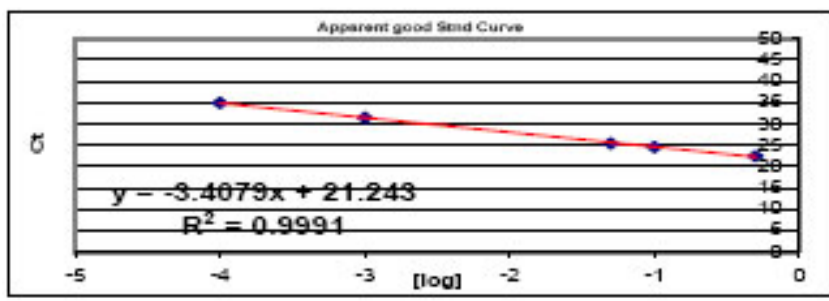

\section{RPST5}

start useful atnd curve at 1: 3000

"In-well"

3000

30000

300000

Efrlolenoy: $96.53 \%$

serial 1: 10

Corrolation: -1.000

$\mathrm{b}=21.243$

3000000

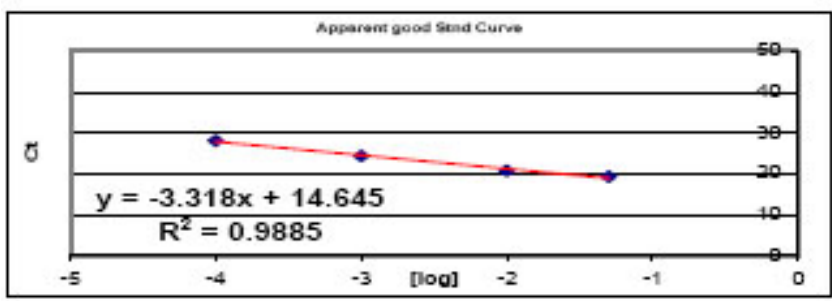

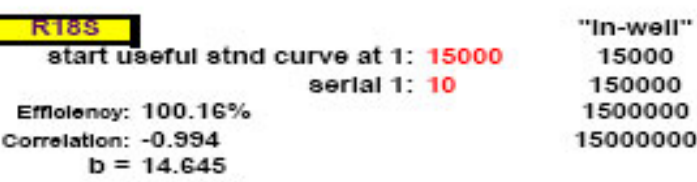

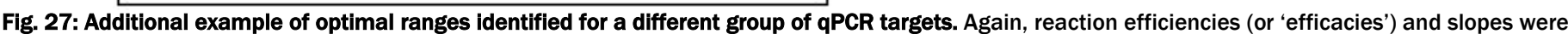

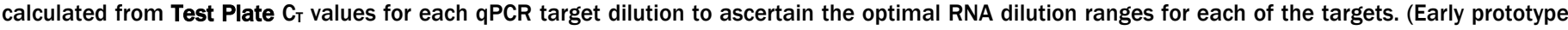

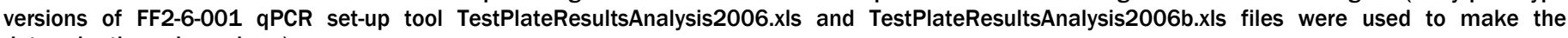
determinations shown here). 


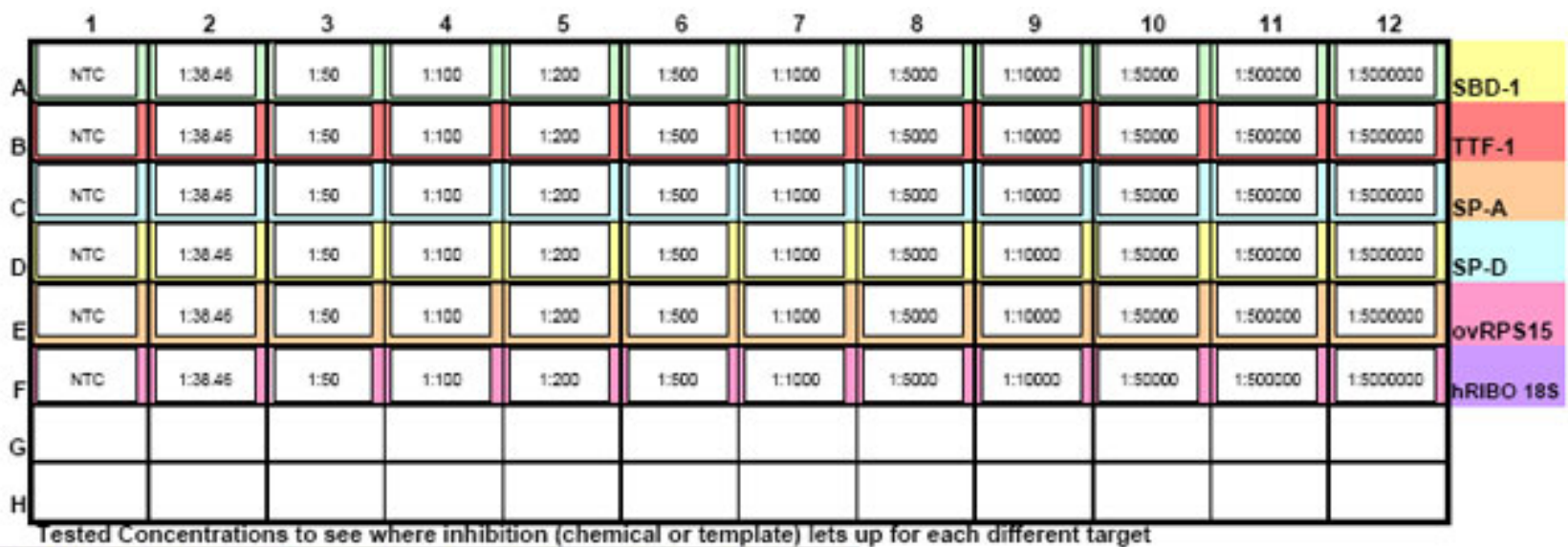

Initial RNA is already at 1: $10 \longrightarrow$ in well will actually be a 1: 38.46

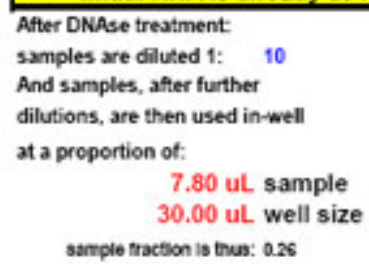

Desired final in-well test dilution 1: 50

Desired final in-well test dilution 1: 100

Desired final in-well test dilution 1: 200

Desired final in-well test dilution 1: 500

Desired final in-well test dilution 1: 1000

Desired final in-well test dilution 1: 5000

Given that our StockTSolution RIIA mixture is calculated to be: $38.68471 \mathrm{ng} / \mathrm{uL}$ (oomprised of 1:10 RNAs)

This Test Plate dilution series thus represents: $10.05802 \mathrm{ng} / \mathrm{uL}$ in well

$7.736941 \mathrm{ng} / \mathrm{uL}$ in well

$3.868471 \mathrm{ng} / \mathrm{uL}$ in well

$1.934235 \mathrm{ng} / \mathrm{uL}$ in well

$0.773694 \mathrm{ng} / \mathrm{uL}$ in well

$0.386847 \mathrm{ng} / \mathrm{uL}$ in well

$0.077369 \mathrm{ng} / \mathrm{uL}$ in well

$0.038685 \mathrm{ng} / \mathrm{uL}$ in well

$0.007737 \mathrm{ng} / \mathrm{uL}$ in well

$0.000774 \mathrm{ng} / \mathrm{uL}$ in well

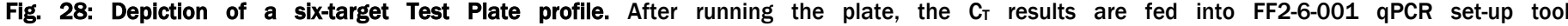

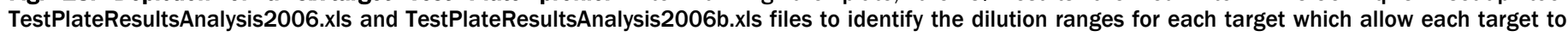

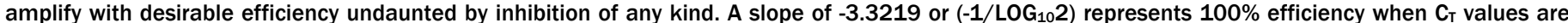

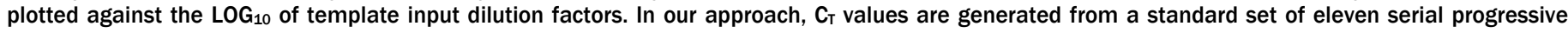

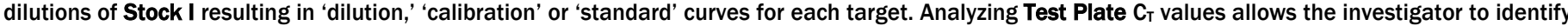

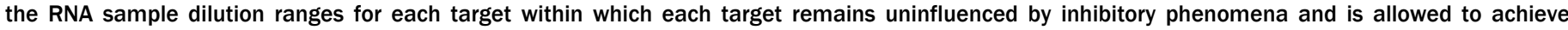

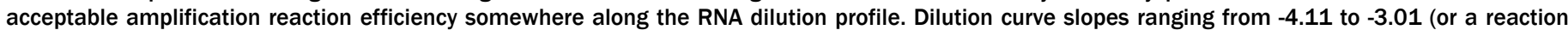

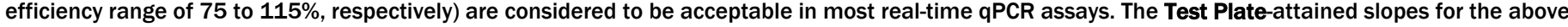
six targets are shown in Figure 27. 


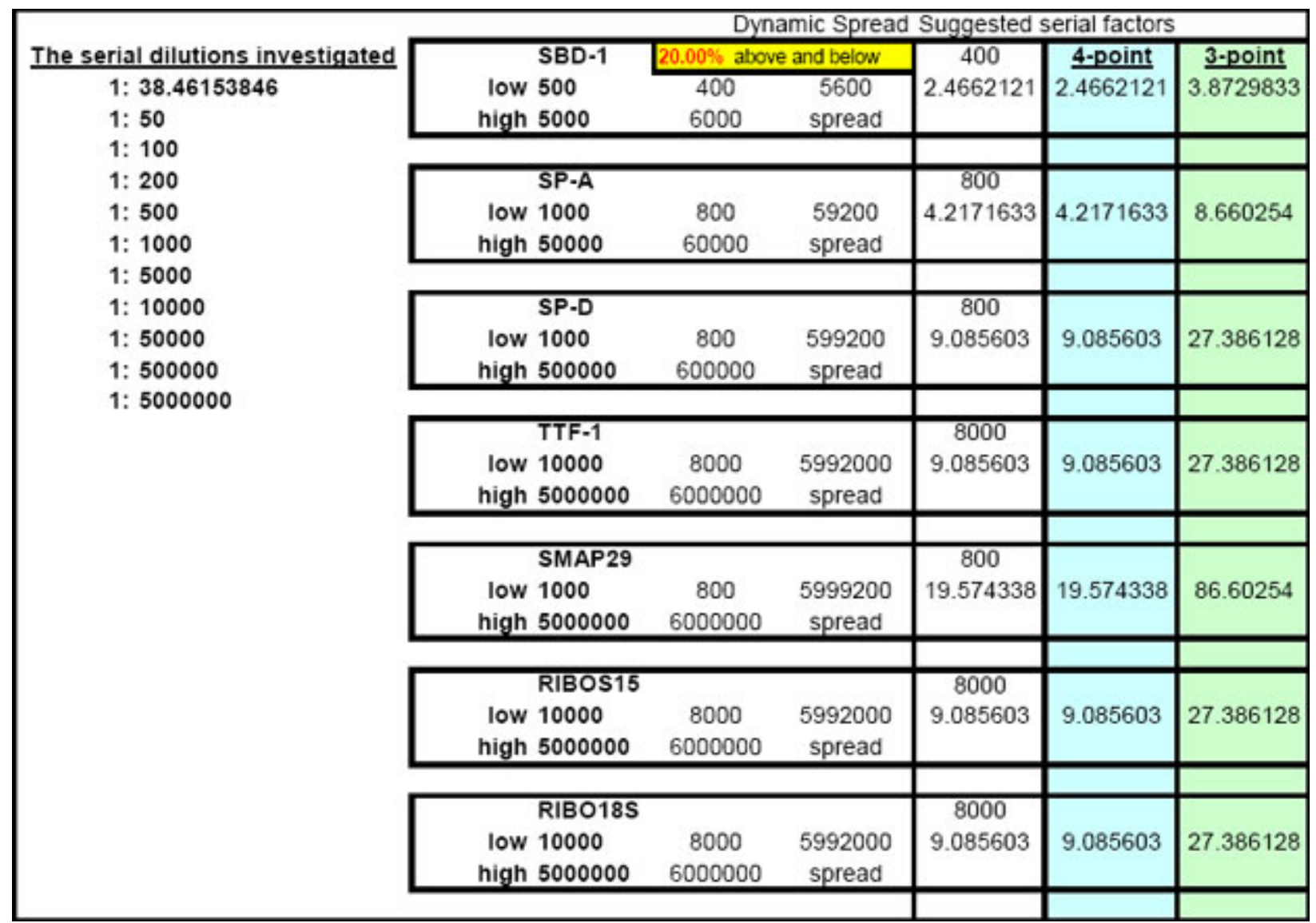

Fig. 29: Portion of the FF2-6-001 qPCR set-up tool TestPlateResultsAnalysis2006b file which the user can manually adjust to determine how far above and below the proven LOG-linear range one wishes the standard curve for each target to include. The file default is set at $20 \%$ above and $20 \%$ below the highest and lowest points of the proven target LOG-linear range in each case. User-access to this parameter is useful in cases where one is confident that the qPCR targets studied exhibit linearity further than the default $20 \%$ above and $20 \%$ below the calculated optimal dilution profile/range for each target. Elongation of the dynamic range of qPCR target standard curves serves to provide more room within which sample unknowns can appear and therefore be assessed with greater confidence. 


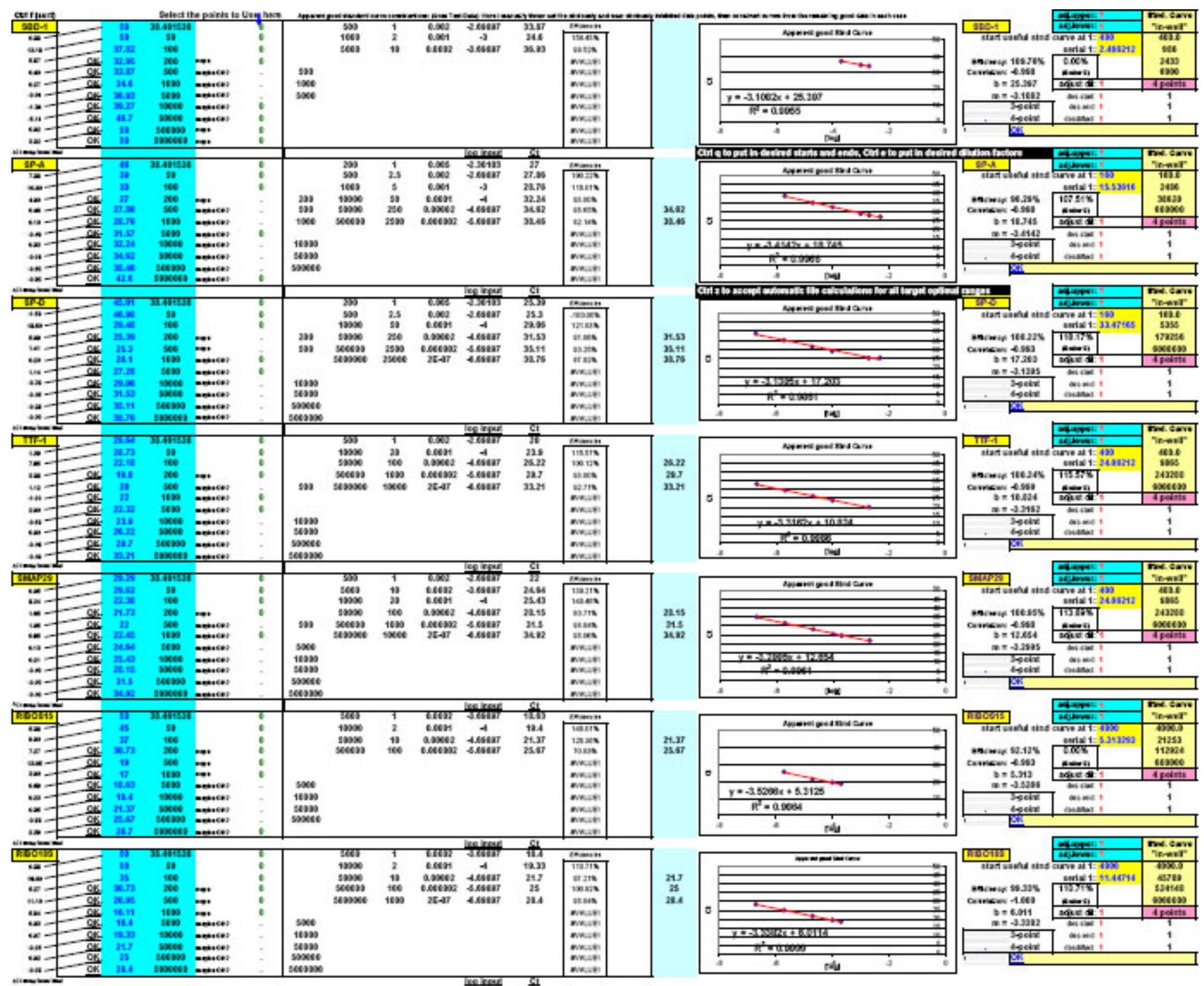

Fig. 30: Portion of the FF2-6-001 qPCR set-up tool TestPlateResultsAnalysis2006b file which allows the user to fine-tune the parameters already established by "twin" file TestPlateResultsAnalysis2006. In this file, the user manually adjusts standard curve dilution factors, standard curve start and end points (or chooses to accept file default calculations for those parameters), and activates pre-programmed macros to quickly hone in on the final optimal RNA dilution range to be used for each target - all of which exhibit LOG-linear behavior, lack of qPCR inhibition and high amplification reaction efficiencies; all based on Test Plate $\mathrm{C}_{\mathrm{T}}$ analyses. 
Tier 1 dilutions

\begin{tabular}{|c|c|c|c|c|c|c|c|c|c|c|c|c|c|c|c|}
\hline & 900. & & & D.A & & $9 n-0$ & & suspe & & $\pi F-1$ & & Aldosis & & niootie & \\
\hline 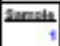 & 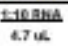 & 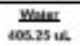 & 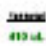 & 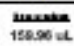 & ${ }_{22196 \mathrm{ut}}$ & $\frac{1}{21.51+1}$ & $\frac{\text { Whatr }}{216 \cdot 2 \mathrm{at}}$ & ת & $\operatorname{mins}_{2 \min }$ & 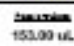 & $\lim _{20000}^{\min }$ & 50200 & $\begin{array}{l}\text { maver } \\
\text { aceoul }\end{array}$ & 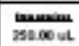 & $\begin{array}{l}\text { Wour } \\
0.000 \mathrm{~L}\end{array}$ \\
\hline & $2.4 \mathrm{~K}$ & $\cos 203$ is & ma & $100000 \mathrm{dt}$ & 2218sut & zat.st at & reas at & 177.58 & mens $x$ & $\sin 20$ & $200000 \mathrm{c}$ & sonatur & aceur & sonocout & 200 ut \\
\hline & 2746 & $\cos 30$ is & mas & $180000 \mathrm{ct}$ & maseut & ntstact & Meas Ch & 177.:s8 4 & rees at & 150000 & $200000 \mathrm{cc}$ & 500000 u. & acoul & sanos ut & ane ut \\
\hline & $22 \mathrm{kK}$ & conara is & mas & 1800000 & m218se oc & nt.st ut & Heas ac & 127.88 & reesst & $\sin \alpha$ & $=200000 \mathrm{ut}$ & snoous & aceul & sonow ut & aesul \\
\hline & abus & $\cos 200 \mathrm{us}$ & ase & 1000000 & $3258 \mathrm{at}$ & 2n1.st a & reas a & t77.58 & reens & $\sin 20$ & $=200000$ & $\sin 00$ ut & 2000 & 250000 ot & 200 uh \\
\hline & sons & 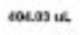 & mou & $150000 \mathrm{ct}$ & 32188uL & zatst at & Measuch & 177.ss 4. & mest ut & $\operatorname{tscos} 0$ & $200000 \mathrm{cc}$ & $500000 \mathrm{ul}$ & acoul & savoout & $200 u \mathrm{t}$ \\
\hline & asus & cot.as is & asu & $180000 \mathrm{ct}$ & maseut & nt.st ac & reas ch & 197.ss u. & rese.45 & $\operatorname{tscos} u$ & 200000 o c & $\sin 000 \mathrm{ut}$ & acoul & monout & ane ut \\
\hline & .s. us & masen is & mus & 1800000 & mase at & nt.stact & reas ac & nzseu. & reens ac & $\operatorname{tscos} 0$. & 200000 o th & $\sin 00 \mathrm{ur}$ & acoul & $280000 \mathrm{ot}$ & $200 u t$ \\
\hline & $2.8 \mathrm{k}$ & $\cos 205$ is & asu & $150000 \mathrm{cc}$ & mese at & nt.st ac & Mesas LC & 177.586 & mees dL & 152000 u. & $\operatorname{sen} 000$ o & $\operatorname{sensoub}$ & aceul & 250.00 ot & ane ut \\
\hline$\infty$ & szok & col.7n us & mas & $1800000 \mathrm{ct}$ & mase at & nt.st ac & He.and & 7.884. & meens ac & $\sin \alpha$ & 200000 o t & masu un & aceout & 3000 of & ane ut \\
\hline 74 & $\begin{array}{l}2.34 \mathrm{k} \\
.1 .04\end{array}$ & 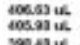 & mu & 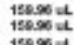 & 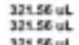 & 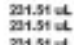 & 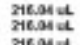 & sou & 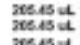 & 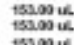 & 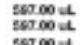 & $\begin{array}{l}\text { sonucu } \\
\text { smonou }\end{array}$ & $\begin{array}{l}\text { aceut } \\
\text { aneo ut }\end{array}$ & 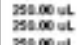 & $\begin{array}{l}200 u \text { uh } \\
\text { ane ut ut }\end{array}$ \\
\hline & 11.sut & 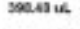 & 134 & 19. & & 4 & & & & & & & & & \\
\hline 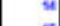 & 7.210 & coran us & A3u & 1500006 & $22+8 \pi \mathrm{L}$ & ret.stat & reasch & 177.85 u. & rese.15. & 1520040 & 300000 & smas ub & ace ul & $9000 \mathrm{GL}$ & 000 ul \\
\hline & $\begin{array}{l}\text { alduk } \\
\text { aodus }\end{array}$ & 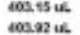 & 19u & 200 & $23180 \mathrm{ut}$ & 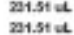 & $\begin{array}{l}\text { resand } \\
\text { Treast }\end{array}$ & uit & 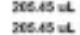 & 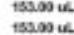 & $\operatorname{ses} 00$ & $s n$ & $\begin{array}{l}\text { aceut } \\
\text { aneout }\end{array}$ & & out \\
\hline & S. W & masta 4 & $m u$ & 100 & ise at & 21.51 & TeSA & & & $\operatorname{tsans} \alpha$ & & & aceoul & & ou \\
\hline & $\begin{array}{l}284 k \\
3904\end{array}$ & 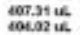 & ${ }_{m a}^{m a u}$ & 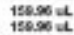 & $\begin{array}{l}32180 \mathrm{ut} \\
\text { mise }\end{array}$ & natstat & 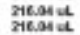 & 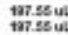 & 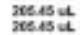 & $\begin{array}{l}\operatorname{sen} 0 \\
15000\end{array}$ & 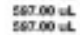 & s. & $\begin{array}{l}\text { aceur } \\
\text { anesur }\end{array}$ & $\begin{array}{ll}0000 \mathrm{ot} \\
0.000 \mathrm{ut}\end{array}$ & $\begin{array}{c}a x u L \\
\text { ane un un }\end{array}$ \\
\hline 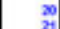 & $28 \mathrm{k}$ & $\cos _{0}$ & 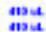 & 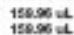 & 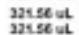 & mast.st & resas a & 77.880 & greess & $\operatorname{sen} 4$ & $\operatorname{sos}_{0000}$ & smouch & aceout & 0000 ut & ane ut \\
\hline & 15sut & satas us & 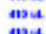 & $\$ 4$ & iseut & $n$ & reas & 8 u. & metosu & $152000 \mathrm{ac}$ & $=0$ & out & acoul & 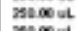 & ouk \\
\hline${ }_{2}^{2}$ & ands & col.s5 ut & $\begin{array}{l}130 \\
\ldots a u\end{array}$ & 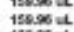 & $\begin{array}{l}212 x=\mathrm{ut} \\
22\end{array}$ & mistat & resest & $\begin{array}{l}\text { thess } \\
\text { 17.se }\end{array}$ & zesosut & 152000 & $=50000 \mathrm{ot}$ & smout & aceout & 280 & $2000 \mathrm{uL}$ \\
\hline & 7.046 & 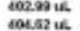 & mu & $\begin{array}{l}15000000 \\
1500 x\end{array}$ & 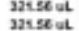 & 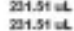 & 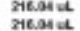 & 197984 & 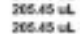 & 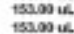 & 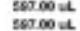 & $\begin{array}{l}\text { snoub } \\
\text { smoto }\end{array}$ & $\begin{array}{l}\text { ane un } \\
\text { aneoun }\end{array}$ & & uh \\
\hline & $2.1 \mathrm{uk}$ & $200.45 \%$ & mus & 180060 & mase ut & nestst ut & Heasc & 177.ss & 206est & $1 \sin 20$ & $=000000$ & $\sin$ & aceout & & 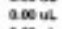 \\
\hline & 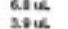 & 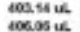 & A3u & 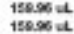 & 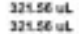 & $\begin{array}{l}z=1.51 \\
m\end{array}$ & reseand & 3785 & 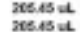 & $15 \operatorname{sen} 4$ & $=057$ & sonedu & ar & & \\
\hline & Aok & tostou & $m u$ & $150000 \mathrm{ct}$ & 22180 of & & Meas C & & meetsu & 150000 & & of & aceoul & & ane ut \\
\hline & $\begin{array}{l}221.10 \mathrm{LL} \\
1280 \mathrm{~L}\end{array}$ & 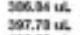 & $\begin{array}{l}m u \\
m a n\end{array}$ & $\begin{array}{l}18000000 \\
1500\end{array}$ & 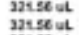 & 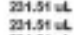 & 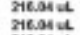 & sevit: & 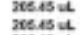 & $\begin{array}{l}1350004 \\
152004\end{array}$ & 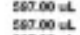 & 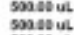 & $\begin{array}{l}\text { ane un } \\
\text { anotut }\end{array}$ & a & a \\
\hline & 27 & 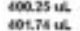 & $\mathrm{mu}$ & 1505 & 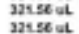 & antsida & Treasc & wit & roess a & $\sin \alpha$ & $=000000$ & smous & ace ut & & andut \\
\hline & a.u. & cosic & $\begin{array}{l}\text { mus } \\
\text { anu }\end{array}$ & $\begin{array}{ll}18 \\
18\end{array}$ & 2324 & at & xit & . & $\frac{\pi}{\pi x}$ & wa & 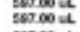 & 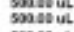 & 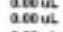 & ut & 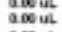 \\
\hline & a.tuk & 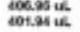 & $\begin{array}{l}m a \\
\ldots u\end{array}$ & $\begin{array}{l}150000 \mathrm{du} \\
10000\end{array}$ & $\begin{array}{l}212 \pi s e \mathrm{uu} \\
22\end{array}$ & $\begin{array}{l}2 \\
\text { nat. }\end{array}$ & Fesas & tivi & 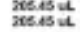 & $\begin{array}{l}152000 \\
1500\end{array}$ & $\frac{58}{56}$ & 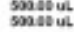 & $\begin{array}{l}\text { anou ut } \\
\text { aceour }\end{array}$ & $\mathrm{t}$ & a \\
\hline & Sas & & was & 6000 & & tict & & & & 3500 & & Hevos & 0.6 & & 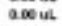 \\
\hline & sals & & mas & & & & & & & & & & & & \\
\hline & $\begin{array}{l}125 \mathrm{uL} \\
2 \mathrm{sik}\end{array}$ & 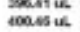 & $\begin{array}{l}m u \\
\text { and }\end{array}$ & 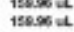 & $\mathrm{t}$ & $\begin{array}{l}n \\
z \\
z\end{array}$ & 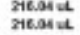 & & 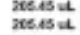 & $\begin{array}{l}18000 \\
15000\end{array}$ & & of & $\begin{array}{l}\text { aceout } \\
\text { aceout }\end{array}$ & & \\
\hline & $\begin{array}{l}1230 \mathrm{ut} \\
\text { 1000 }\end{array}$ & 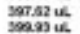 & $m_{m u}^{m u}$ & 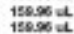 & 2224 & $\begin{array}{l}n \\
m \\
m 1\end{array}$ & Fench & & 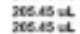 & 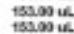 & & & at & & $a t$ \\
\hline & 7.046 & in & Mad & 18 & 224 & 烈 & rat & & we & & & & & & \\
\hline & $2.2 \mathrm{kK}$ & 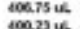 & mus & ${ }^{11000060}$ & 3215 & $\begin{array}{l}n+1 . \\
n=1\end{array}$ & resos C & & reens at & stanu & & & & & \\
\hline & $8.74 k$ & 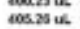 & mau & 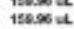 & 2018 & 21. & resen a & & zesesos d & 152000 & & of & & & \\
\hline & alic. & сово и & $m u$ & 1800060 & 2210 & and & सesare & & zes & 13 & & u. & & & $a$. \\
\hline & $\begin{array}{l}\text { tesut } \\
1200 \mathrm{~L}\end{array}$ & 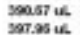 & ${ }_{134}^{m u}$ & 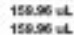 & 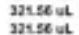 & 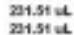 & reasu & 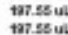 & 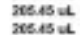 & 155000 & $=$ & 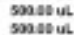 & $\begin{array}{l}\text { aecout } \\
\text { aneoun }\end{array}$ & rasoo ot & \\
\hline & 24 us & astiu & mu & $18000 \mathrm{at}$ & mase ot & massut & reast & 177.ses & zinesest & 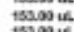 & $=0000 \mathrm{t}$ & smose of & geve ut & & we ut \\
\hline & $\begin{array}{l}1104 \\
0.24\end{array}$ & 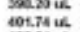 & $\begin{array}{l}\text { mus } \\
\text { anu }\end{array}$ & $\begin{array}{l}1500 \\
1500 \\
100\end{array}$ & 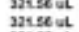 & & Teas d & & & & & & & & \\
\hline & $\begin{array}{l}24,4 \\
12404\end{array}$ & 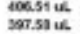 & $\begin{array}{l}m u s \\
\text { anu }\end{array}$ & $\begin{array}{l}150000000 \\
15000\end{array}$ & 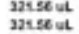 & & 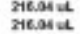 & & & 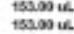 & & & $2000 \mathrm{ul}$ & & 20 \\
\hline & $\begin{array}{l}5240 \\
7.14\end{array}$ & 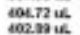 & 184 & 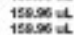 & 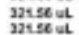 & rats.s & ress & & 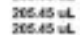 & 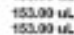 & & & & & - \\
\hline & 28.7 & $50.25 \mathrm{uL}$ & mas & 1500 & 221 & 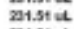 & resal a & & 20ens d & $\sin 20$ & & & & & \\
\hline & 109 & 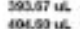 & man & 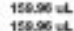 & 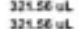 & $\begin{array}{l}\text { sat.st a } \\
\text { nastst }\end{array}$ & reseasc & $\underset{m 7}{m 7}$ & 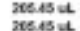 & $\operatorname{sen} u$ & $\operatorname{sen}_{000}$ & & & & anut \\
\hline & 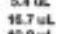 & sonsou u & aud & $\begin{array}{l}150000 \\
1904\end{array}$ & mase ot & a1stut & reose & ta7.seu & 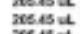 & 152000 & $00000 \mathrm{u}$ & sonout & & & ane ut \\
\hline & $\begin{array}{l}1000 \\
27.4\end{array}$ & 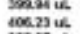 & $\begin{array}{l}m u \\
\text { and }\end{array}$ & 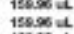 & $\begin{array}{l}23280 \mathrm{ut} \\
2218 \mathrm{ut}\end{array}$ & 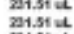 & $\begin{array}{l}\text { Meard } \\
\text { resosd }\end{array}$ & 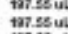 & 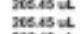 & $\begin{array}{l}150000 \\
15000\end{array}$ & $\operatorname{sen}_{200}$ & of & $\begin{array}{l}2060 \mathrm{uL} \\
\text { ano un }\end{array}$ & 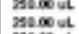 & 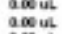 \\
\hline & 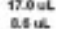 & 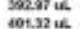 & $\begin{array}{l}m u \\
\ldots u \\
104\end{array}$ & $\begin{array}{l}13000 \\
1150 x\end{array}$ & 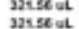 & 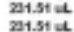 & $\begin{array}{l}\text { Mat } \\
\text { Xite }\end{array}$ & & $\begin{array}{l}\mathrm{x} e \\
\mathrm{me}\end{array}$ & & & & & & ax ul \\
\hline & 7.84 & 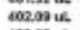 & 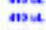 & 150006 & 2218s ut & m1.st at & zesa d & m7.8s u. & zxe.015 & $15 \operatorname{sen} \alpha$ & $=050000$ & snos us & & ravoout & a we ut \\
\hline & $\begin{array}{l}\text { ande } \\
\text { solus }\end{array}$ & $\begin{array}{l}\cos 20 \\
\text { cotax }\end{array}$ & 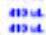 & 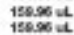 & 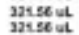 & 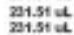 & Fesch & 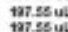 & 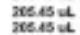 & & $\operatorname{sev}_{000000}$ & $\begin{array}{c}\sin \\
\text { son }\end{array}$ & aceou & & 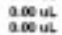 \\
\hline & $\begin{array}{c}\text { tosut } \\
\text { incus }\end{array}$ & sos us & $m_{m u}^{m u}$ & 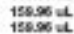 & 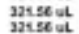 & tistiot & resesch & t7 & $\begin{array}{l}\frac{\pi}{3} \\
\pi\end{array}$ & 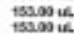 & sevoou & 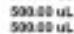 & $\begin{array}{l}20004 \\
\text { aceou }\end{array}$ & 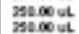 & 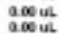 \\
\hline & $\begin{array}{l}\text { son } \\
\text { azu }\end{array}$ & 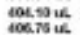 & $\mathbb{m a n}_{104}$ & $1500 \%$ & 1804 & ista & Feas: & 77.584 & 245 & $\begin{array}{l}15000 \\
1500\end{array}$ & 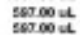 & monou un & acoin & 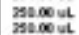 & $\begin{array}{l}200 u \text { uh } \\
\text { ane un una }\end{array}$ \\
\hline
\end{tabular}

Fig. 31: Portion of the FF2-6-001 qPCR set-up tool MasterEntrySheet.xls file (Sheet 2) which shows the automatically-calculated serial dilutions the user will perform to obtain the appropriately and differentially diluted RNA samples that have already been calculated to be optimal for each qPCR target (seventy-two RNA samples are shown here). Notice how (after the Tier 1 dilutions have been performed) all subsequent sample volume transfers from row to row are repetitive and therefore directly amenable to liquid-handling robot technologies (see Fig. 45). 


\begin{tabular}{|c|c|c|c|c|c|c|c|}
\hline \multirow[t]{2}{*}{\begin{tabular}{|l|} 
Eample \\
\end{tabular}} & $\begin{array}{c}\text { optmal for Twose } 1 \\
\text { seo-1 }\end{array}$ & $\begin{array}{c}\text { optemal far Turpot } 2 \\
\text { gpa }\end{array}$ & $\begin{array}{c}\text { opemal for Targes } 3 \\
\text { ap. }\end{array}$ & $\begin{array}{c}\text { asiand for Twasget } 4 \\
\text { syapzz }\end{array}$ & $\begin{array}{c}\text { aptind for Tresels } \\
\pi \text { Tr-1. }\end{array}$ & $\begin{array}{c}\text { opdmes far Tarpen } 6 \\
\text { seosis }\end{array}$ & $\begin{array}{c}\text { aptind foe Twget } 7 \\
\text { mpoins }\end{array}$ \\
\hline & soast ul & 250.03 us & $250.00 \mathrm{ul}$ & $25080 u L$ & $255000 \mathrm{uL}$ & 250.030 & $25060 \mathrm{uL}$ \\
\hline 2 & zsaso ut & $250.03 \mathrm{uL}$ & 250.00 ut & soseovut & $250.00 \mathrm{ut}$ & 250.00 us & $25300 \mathrm{uL}$ \\
\hline 3 & seaso ul. & $2 \sec 00 \mathrm{us}$ & $250.00 \mathrm{uL}$ & sooseut & $290.00 \mathrm{ul}$ & 250.00 us & 25300 ut \\
\hline$A$ & zsasoul & $2 \operatorname{sen} u$ & $250.00 \mathrm{uL}$ & 250soul & $250000 \mathrm{uL}$ & $250.03 \mathrm{~L}$ & $25 a c 0 u t$ \\
\hline 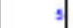 & zasas ul & $2 \sec 00 \mathrm{u}$ & $250.00 \mathrm{uL}$ & ssoseut & $250.00 \mathrm{ul}$ & $250.000 \mathrm{~L}$ & $25300 u t$ \\
\hline of & sasos ut & $250.03 \mathrm{u}$ & 250.00 ul & soseoul & $290.00 \mathrm{ulc}$ & $250.03 \times$ & $250.00 \mathrm{uL}$ \\
\hline 7 & zsaso ut & 280.03 is & $280.000 \mathrm{uL}$ & soseout & $298000 \mathrm{uL}$ & $250.03 \mathrm{~L}$ & $25000 \mathrm{ut}$ \\
\hline 1 & sanoul & 250.030 & 250.00 uL & soseul & $250.000 \mathrm{at}$ & 25000 us & 2saceut \\
\hline 3) & sooso ut & $250.03 \mathrm{u}$. & 250.00 ul & zsoseul & 290.000 us & 290.03 us & 25000 ut \\
\hline 50 & rsaso ut & $250.00 \mathrm{uk}$ & $280.00 \mathrm{uL}$ & zsaseut & $250.000 \mathrm{at}$ & $250.00 \mathrm{us}$ & $2 s a c 0 u t$ \\
\hline $\begin{array}{l}13 \\
12 \\
13\end{array}$ & 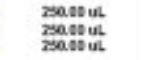 & 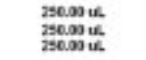 & $\begin{array}{l}250.00 \text { uL } \\
258.00 \text { uL } \\
250.00 \text { uL }\end{array}$ & 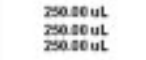 & $\begin{array}{l}250000 \mathrm{ut} \\
250000 \mathrm{u} \\
252000 \text { ut }\end{array}$ & 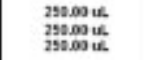 & $\begin{array}{l}25000 \text { ut } \\
25300 \text { ot } \\
25000 \text { ot }\end{array}$ \\
\hline 4 & zsano uL & $250.03 \mathrm{u}$ & 250.00 uL & zSOSEuL & $290000 \mathrm{~A}$ & $29000 \mathrm{u}$ & $25000 \mathrm{ut}$ \\
\hline is & sano ul & 250.03 us & 250.00 uL & sonoul & $258000 \mathrm{ut}$ & 250.000 & $25000 \mathrm{dL}$ \\
\hline * & ssaso ul & $250.030 \mathrm{u}$ & 250.00 ul & sogosul & $250000 \mathrm{ut}$ & 2500030 & 25000 ut \\
\hline 17] & $\begin{array}{l}\text { zsages ol } \\
\text { Tsang of }\end{array}$ & $\begin{array}{l}250.030 \text { us } \\
250.03 \text { u }\end{array}$ & $\begin{array}{l}250.00 \text { uL } \\
250.00 \text { of }\end{array}$ & $\begin{array}{l}\text { Sogeout } \\
\text { Tsogeut }\end{array}$ & 295000 ut & $\begin{array}{l}290.03 \\
29000\end{array}$ & $\begin{array}{l}25000 \text { ut } \\
33000 \text {. }\end{array}$ \\
\hline 19 & sano ut & $280.00 \mathrm{u}$ u & 280.00 ut & $25000 u t$ & $290000 \mathrm{at}$ & 250.00 u & 25000 ot \\
\hline 2 & zaso ul & 250.03 us & $250.00 \mathrm{uL}$ & zsosoul & 258000 ot & 250.00 us & 25000 oL \\
\hline 23 & zsaso ul & 250.03 is. & $250.90 \mathrm{uL}$ & zsosoul & $250000 \mathrm{at}$ & 290.0346 & $25 a c 0$ ot \\
\hline 22 & zasos ul & $250.03 \mathrm{u}$ & $250.00 \mathrm{uL}$ & zsoseul & $290.000 \mathrm{ut}$ & 2500046 & 25000 uL \\
\hline 23 & zea.00 ul & 280.030 & $250.00 \mathrm{uL}$ & sosoul & $295000 \mathrm{uL}$ & 250.03 us & 25000 ut \\
\hline 24 & zaso ul & 250.03 u & $250.00 \mathrm{uL}$ & zosout & 25000 ot & 290.03 us & $25 a c e$ ot \\
\hline 23: & Trano uL & 250.034 & 250.00 ul & rsogeut & $25000 \mathrm{at}$ & 250.004 & 25ange ot \\
\hline 27 & zsanul. & $\begin{array}{l}250.030 \text { u. } \\
250.93 \text {. }\end{array}$ & $\begin{array}{l}250.00 \text { uL } \\
250.000 \text { uL }\end{array}$ & $\begin{array}{l}75000 \mathrm{uL} \\
75000 \mathrm{~L}\end{array}$ & $\begin{array}{l}290000 \text { of } \\
290000 \text { u }\end{array}$ & $\begin{array}{l}250.003 \text { u } \\
250.03 \text { us }\end{array}$ & $\begin{array}{l}25300 \text { uL } \\
25000 \text { o }\end{array}$ \\
\hline 20 & sacto ut & 250.0016 & 250.00 ut & 3000 ut & $290000 \mathrm{uL}$ & $250.004 \mathrm{~K}$ & $25000 \backsim \mathrm{L}$ \\
\hline 23 & zans ul & 280.03 u & $250.00 \mathrm{uL}$ & ssoseul & $290000 \mathrm{uL}$ & $250.00 \mathrm{u}$ & $25 a c 0$ ut \\
\hline 30 & rsase ul & 250.030 & $250.00 \mathrm{uL}$ & 25000 uL & $298.00 \mathrm{uL}$ & 290003 u. & $25 a c 0 u t$ \\
\hline 3 & zooso ut & 250.034. & $250.00 \mathrm{uL}$ & $250000 \mathrm{LL}$ & $250000 \mathrm{ul}$ & 250.000 & 25000 ut \\
\hline 32 & 200.00 uL & $250.03 \mathrm{uk}$ & $250.00 \mathrm{uL}$ & sonoul & 250000 ot & $250.000 \mathrm{uk}$ & 25000 ut \\
\hline 크 & zeasoul & 250.030 & 250.000 ul & zogoul & 25000 at & 290.03 is & 25000 ot \\
\hline in & 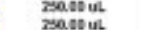 & $\begin{array}{l}250.030 \mathrm{u} \\
250.03 \mathrm{~K}\end{array}$ & $\begin{array}{l}230.000 \\
250.00\end{array}$ & ronoul & $250000 \mathrm{du}$ & 250.034 & 25000 ut \\
\hline and & 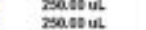 & $\begin{array}{l}250.030 \mathrm{uk} \\
250.03 \mathrm{~K}\end{array}$ & $\begin{array}{l}258.000 \text { uL } \\
250.00 \text { uL }\end{array}$ & $\begin{array}{l}\text { zoseut } \\
\text { zosesout }\end{array}$ & & 250.03 u & 25000 ut \\
\hline 37 & zacos ul & $\begin{array}{l}250.03016 \\
250.03 \text { us }\end{array}$ & $\begin{array}{l}230.000 \mathrm{uL} \\
250.00 \mathrm{u}\end{array}$ & 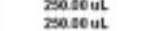 & $\begin{array}{l}25000 \text { ut } \\
250.000 \text { u }\end{array}$ & $\begin{array}{l}250.000 \text { u } \\
250.003 \text { u }\end{array}$ & 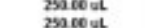 \\
\hline 교 & sasp ut & 280.034 & $2 s e .00$ ut & 750 seut & $\begin{array}{l}250000 \mathrm{ut} \\
29000 \mathrm{u}\end{array}$ & $\begin{array}{l}250.03 \text { u } \\
798094\end{array}$ & 25000 ut \\
\hline 3日 & saobot & 250.030 & 250.00 ut & $25000 u \mathrm{~L}$ & $25000 \mathrm{u}$ & $\begin{array}{l}250.0004 \\
250.03\end{array}$ & 25000 ut \\
\hline An & zasos uL & 250.03 us & 250.00 ul & $75000 \mathrm{uL}$ & $250000 \mathrm{ul}$ & 250.00346 & 25000 ut \\
\hline A & rsage ut & 258003 us & $\begin{array}{lll}250.000 \\
\text { un }\end{array}$ & zoogut & 290004 & 290.034 . & 23000 ut \\
\hline $\begin{array}{l}42 \\
43\end{array}$ & 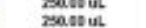 & $\begin{array}{l}2580.0004 \\
250.03\end{array}$ & $\begin{array}{l}250.000 \text { uL } \\
250.0\end{array}$ & Snogeut & $\begin{array}{l}250.000 \mathrm{u} \\
290000\end{array}$ & $\begin{array}{l}290.000 \mathrm{u} \\
290.003 \mathrm{u}\end{array}$ & 2500 ut \\
\hline 4 & Tsaos ut & 250.03 us & $2 s 8.00$ ut & $>0000$ ut & 290000 us & $\begin{array}{l}2500000 \\
29000\end{array}$ & $\begin{array}{l}250600 \mathrm{LL} \\
25000 \mathrm{~L}\end{array}$ \\
\hline 45 & 7sa.00 uL & 250.93 u & 250.00 uL & s5oosut & $295000 \mathrm{uL}$ & $250.004 \mathrm{u}$ & $\begin{array}{l}25000 \text { ot } \\
25000 \text { ot }\end{array}$ \\
\hline in & zsaso ut & 250.00 us & 250.00 ul. & sogeut & 250000 ut & 250.0004 & 25000 ut \\
\hline 47 & zsano ul & $250.03 \mathrm{u}$ & $250.00 \mathrm{ul}$ & $25000 \mathrm{uL}$ & $29800 \mathrm{uL}$ & $250.00 \mathrm{~L}$ & 25000 ul \\
\hline 41 & rsaso ul & 280.03 u & $280.00 \mathrm{uL}$ & Psoseul & $295000 \mathrm{ut}$ & $250.004 \mathrm{~K}$ & $25 a c 0$ ut \\
\hline 4al & za.00 ul & 250.03 u & $280.00 \mathrm{uL}$ & Fosoul & $290000 \mathrm{ul}$ & $250.03 \mathrm{uL}$ & 25000 ul \\
\hline 20 & zeaso uL & 250.03 $4 \mathrm{~K}$ & 250.00 ut & Fosout & 2900004 & 290.03 us & 25000 ut \\
\hline 50 & 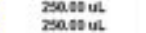 & $\begin{array}{l}250.030 \\
25034\end{array}$ & $\begin{array}{l}250.000 \text { uL } \\
250.04\end{array}$ & zonoul & 250000 o & 250.034 & 25000 ut \\
\hline s] & 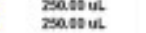 & 258.030 u & $\begin{array}{l}250.00 \text { uL } \\
250.00 \text { uL }\end{array}$ & $\begin{array}{l}25000 \text { uL } \\
\text { s5000uL }\end{array}$ & $\begin{array}{l}290.000 \\
25100\end{array}$ & 290.03 u & 25000 ut \\
\hline 54 & ravoul ut & $\begin{array}{l}250.030 \\
2850\end{array}$ & $\begin{array}{l}250.000 \text { uL } \\
250.00 \text { ul }\end{array}$ & rasout & 2900004 & 250.034 & 2500 ut \\
\hline is & sado ut & 2s0.00u & 250.00 of & $\begin{array}{l}3006 \mathrm{uL} \\
z 30.00 \mathrm{u}\end{array}$ & $250.000 \mathrm{ut}$ & 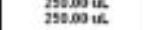 & $\begin{array}{l}2300 \mathrm{uL} \\
2500 \mathrm{~L}\end{array}$ \\
\hline sol & rsage ol & 250.03 ok & $2 s e .00$ ut & Fonoul & $295000 \mathrm{ut}$ & 29000 \& & $25 a c 0$ ul \\
\hline 52] & zaso ul & 250.0316 & 250.00 ul & sonoul & 290.000 ut & 290.03 uL & $25000 \mathrm{uL}$ \\
\hline sn & zaso ul & $280.034 \mathrm{~L}$ & 250.00 ul & zosoul & 2900004 & $290.03 \mathrm{~L}$ & 23000 ut \\
\hline 5n & zano ul & 280.0314 & $250.00 \mathrm{uL}$ & zonout & 2900004 & $290.00 \mathrm{u}$ & $25000 \mathrm{uL}$ \\
\hline : & zaso ul & 250.030 & 250.00 ul & sosout & $290.00 \mathrm{u}$ & $250.004 \mathrm{~K}$ & $25 a c 0$ ul \\
\hline 01 & zaso ul & 250.03 u & $250.00 \mathrm{uL}$ & soseul & $290000 \mathrm{uL}$ & $250.03 \mathrm{u}$ & $25000 \mathrm{uL}$ \\
\hline 哉 & ragoul out & $\begin{array}{l}250.030 \\
250.034\end{array}$ & $\begin{array}{lll}250.000 & \text { uL } \\
250.00 & 0\end{array}$ & 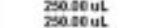 & $\begin{array}{l}295000 \mathrm{ut} \\
29000 \mathrm{u}\end{array}$ & 250.03 u & $\begin{array}{l}35000 \mathrm{~L} \\
25000 \mathrm{~L}\end{array}$ \\
\hline 4 & T2000 ut & 250.03 u & $2 s 0.00$ ut & 30000 ut & 25800 o & $290000 \mathrm{u}$ < & 25000 ot \\
\hline of & z5a.0 ul & 250.9304 & 250.00 uL. & s50.0 uL & $250.00 \mathrm{uL}$ & $290.004 \mathrm{~L}$ & $25 a c 0$ of \\
\hline$m$ & seaso ul & $250.03 \mathrm{uL}$ & 250.00 uL & soneul & $250.00 \mathrm{uc}$ & 250.0046 & 25000 ul \\
\hline a) & z50.00 ul & 250.0304 & 250.00 uL & $25000 \mathrm{uL}$ & $250000 \mathrm{C}$ & $250.00 \mathrm{u}$ & $25000 \mathrm{ut}$ \\
\hline 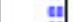 & zsaso ul & 250.03 us & $250.00 \mathrm{uL}$ & sogeou & $29500 \mathrm{ut}$ & 290.034 & $25000 \mathrm{uL}$ \\
\hline แ & 250.60 ut & $250.00 \mathrm{u}$ & 250.00 u. & $250000 \mathrm{LL}$ & $250000 \mathrm{c}$ & $290000 \mathrm{uk}$ & $235000 \mathrm{ut}$ \\
\hline$n$ & 200.00 uL & $250.03 \mathrm{uL}$ & $250.00 \mathrm{uL}$ & zsoseut & $290000 \mathrm{ac}$ & $250.00 \mathrm{u}$ \& & 25300 ut \\
\hline 23 & rsage ul & 250.030 & $250.00 \mathrm{uL}$ & Fonoul & 250004 & 290003 \& & 25300 ot \\
\hline 721 & zass ul & $250.034 \mathrm{~K}$ & $250.00 \mathrm{ul}$ & ZS0.00uL & $25000 \mathrm{LL}$ & $250.03 \times$ & $25060 \mathrm{uL}$ \\
\hline
\end{tabular}

Fig. 32: Portion of FF2-6-001 qPCR set-up tool MasterEntrySheet.xls file (Sheet 2) which confirms for the user how much of each RNA dilution will be prepared for each optimal dilution range for each target investigated. 


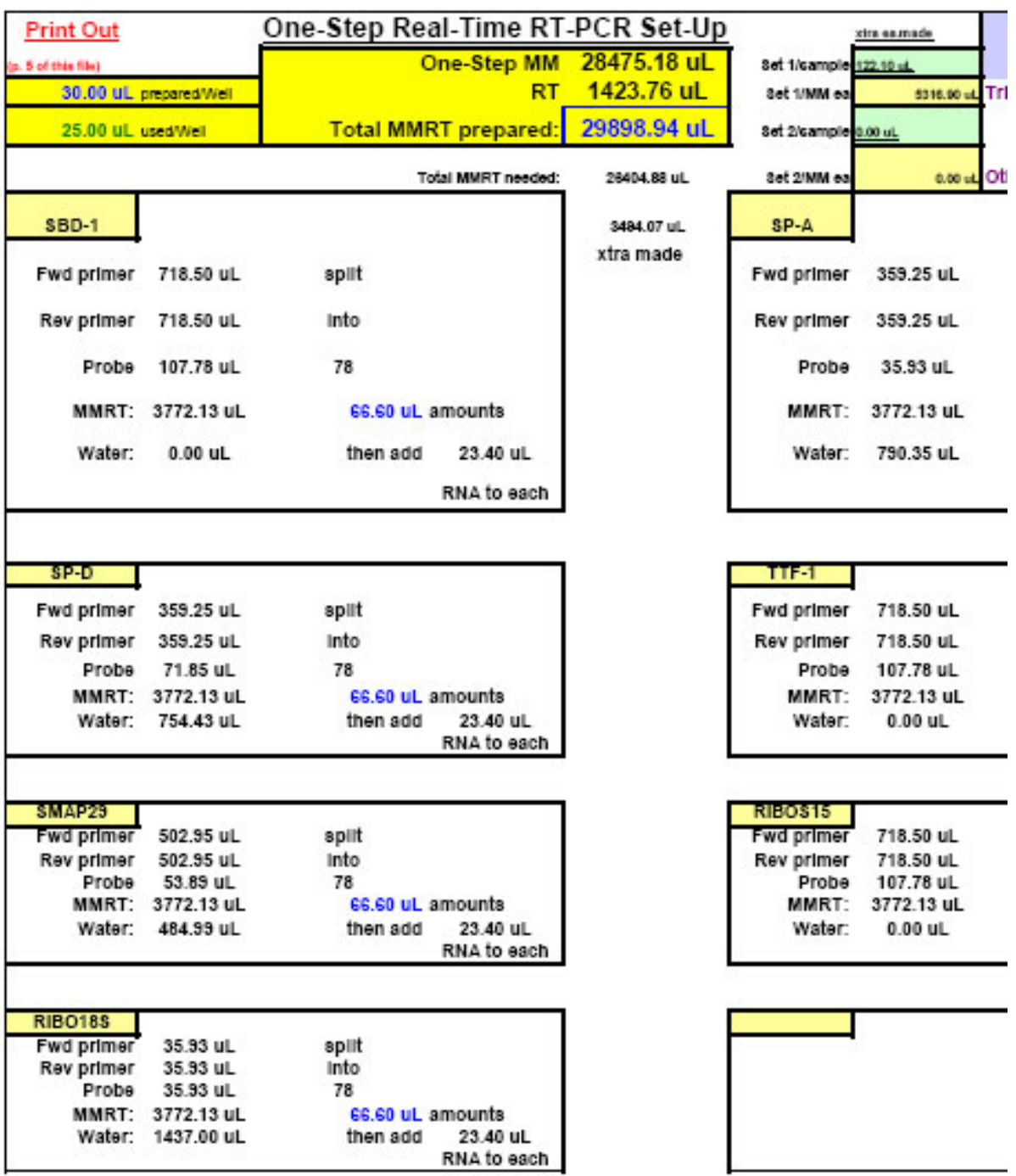

Fig. 33: Portion of FF2-6-001 qPCR set-up tool MasterEntrySheet.xls file (Sheet 2) which shows the automatically-calculated master mix set-ups for all final target Sample Plates. ABI Cat. No. 4309169, TaqMan ${ }^{\circledR}$ One-Step RT-PCR Master Mix Reagents Kit and the ABI GeneAmp ${ }^{\circledR} 5700$ Sequence Detection System were used here. All master mix calculation files automatically figure in safe extra preparative amounts so the user will not run short on final volumes or run into bubbles at the bottom of sample tubes. 


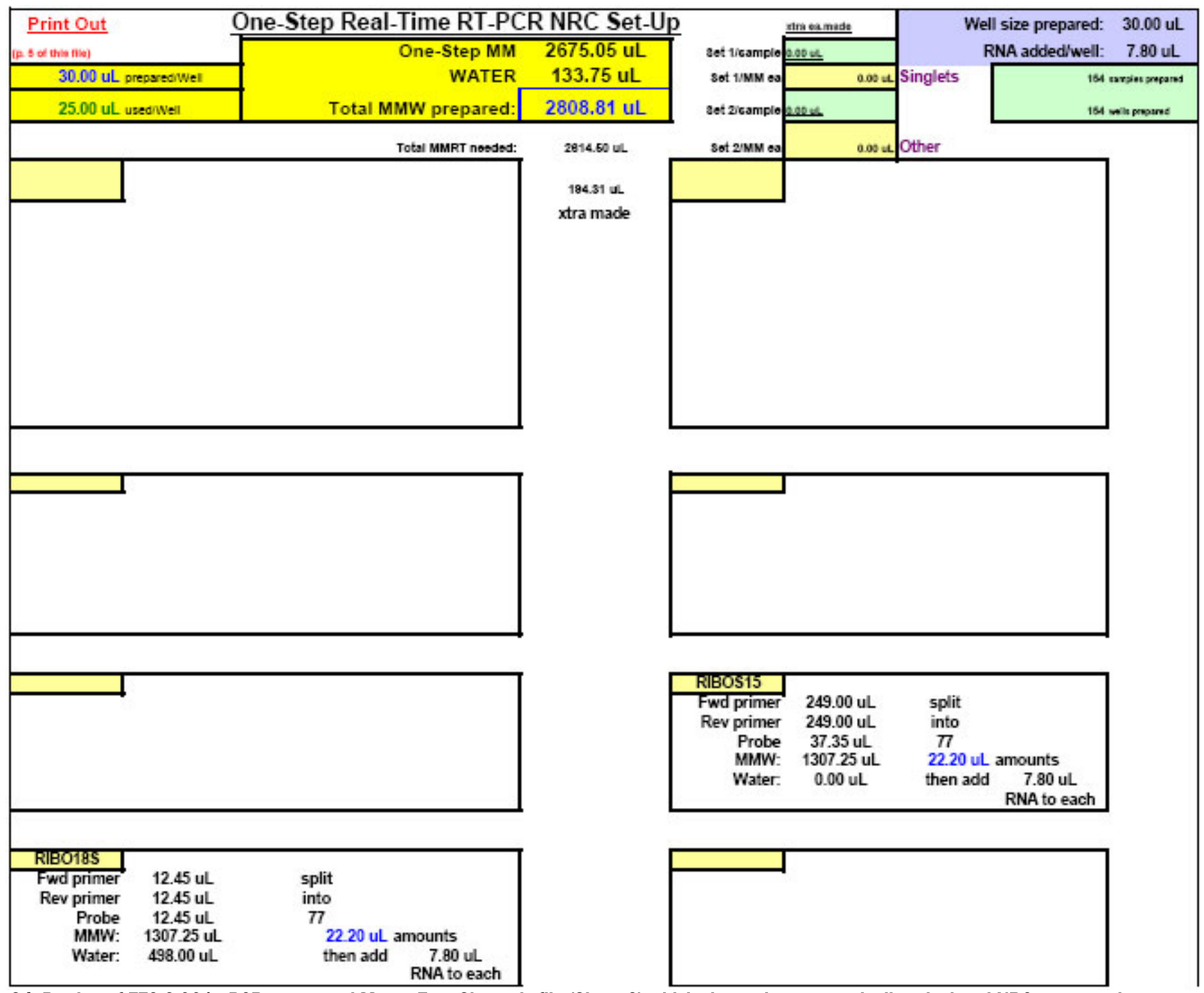

Fig. 34: Portion of FF2-6-001 qPCR set-up tool MasterEntrySheet.xls file (Sheet 2) which shows the automatically-calculated NRC master mix set-ups. ABI Cat. No. 4309169, TaqMan ${ }^{\circledR}$ One-Step RT-PCR Master Mix Reagents Kit and the ABI GeneAmp ${ }^{\circledR} 5700$ Sequence Detection System were used here. Note that only housekeeper targets are tested for DNA contamination by NRC (no reverse transcription) analyses since they are the targets which will most likely reveal whether or not DNA contamination exists - given their endogenous genetic abundance in most samples. All master mix calculation files automatically figure in safe extra amounts so the user will not run short on final volumes or run into bubbles at the bottom of sample preparation tubes. 
gPCR aample dynamic range of thls set-up: ACcepted userul rangr or kiNATn one-gtep real-time qPCR: 5 to 50,000 pg/25 UL rxn

We'reat: उ13 pgr25 uL well
PRINT THIS OUT (P.16)

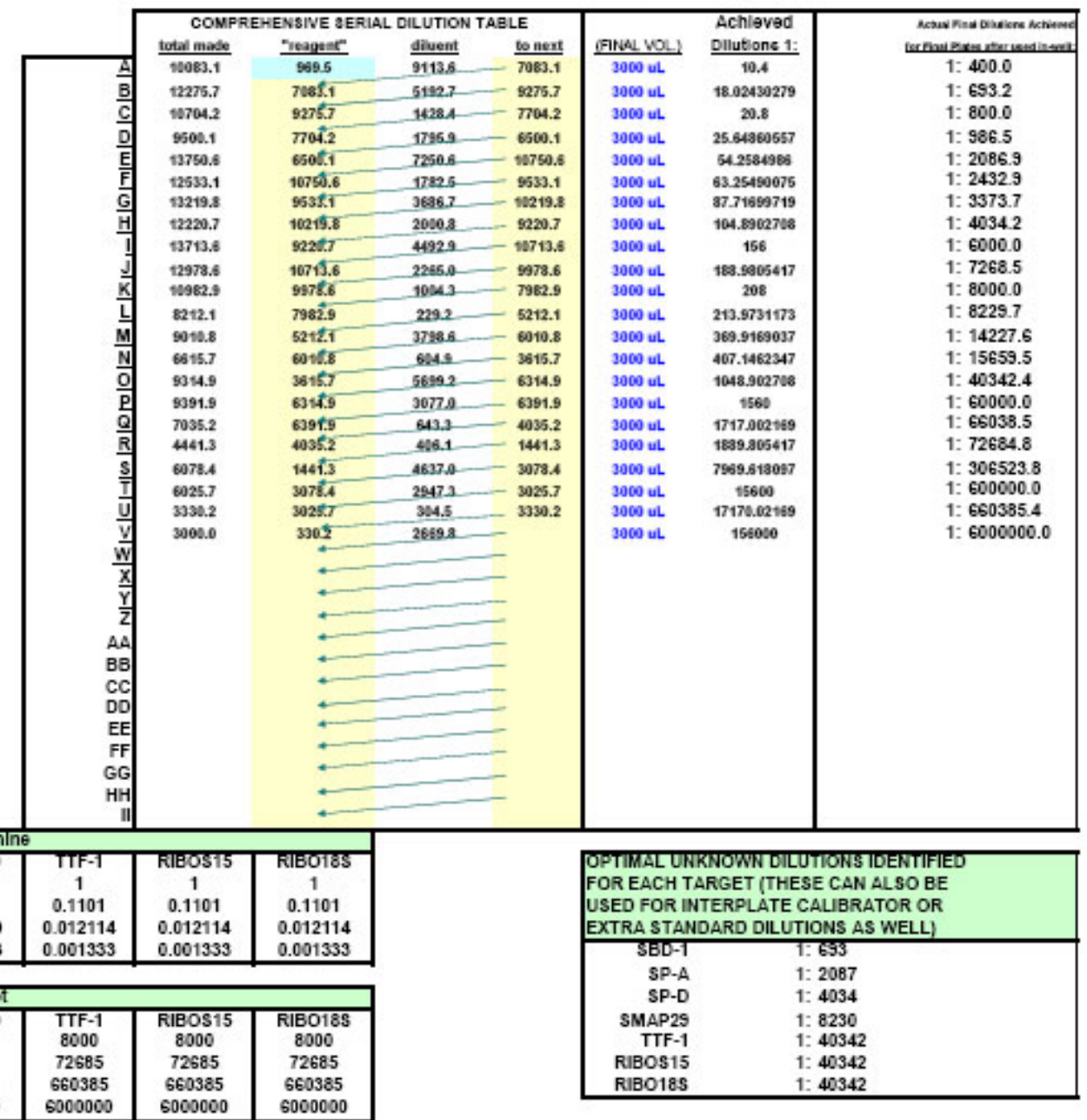

\begin{tabular}{|c|c|c|c|c|c|c|}
\hline \multicolumn{7}{|c|}{ Stind. Curve serlar dilution ractors to enter Into qPCle Machine } \\
\hline SBO-1 & SPF-A & SPR-0 & SIMAP25 & TTF-1 & RIEOST5 & FIBOTES \\
\hline 1 & 1 & 1 & 1 & 1 & 1 & 1 \\
\hline 0.4055 & 0.2371 & 0.1101 & 0.0511 & 0.1101 & 0.1101 & 0.1101 \\
\hline 0.164414 & 0.056229 & 0.012114 & 0.002610 & 0.012114 & 0.012114 & 0.012114 \\
\hline 0.066667 & 0.013333 & 0.001333 & 0.000133 & 0.001333 & 0.001333 & 0.001333 \\
\hline \multicolumn{7}{|c|}{ Optimal Standard curve kanges calculated for alch Target } \\
\hline SBD-1 & SP-A & SP-D & SMAP29 & TTF-1 & RIBOS15 & RाBO18S \\
\hline 400 & 800 & 800 & 800 & 8000 & 8000 & 8000 \\
\hline 986 & 3374 & 7268 & 15659 & 72685 & 72685 & 72685 \\
\hline 2433 & 14228 & 66039 & 306524 & 660385 & 660385 & 660385 \\
\hline 6000 & 60000 & 600000 & 6000000 & 6000000 & 5000000 & 6000000 \\
\hline
\end{tabular}

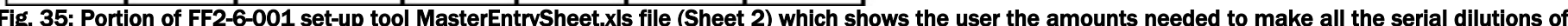

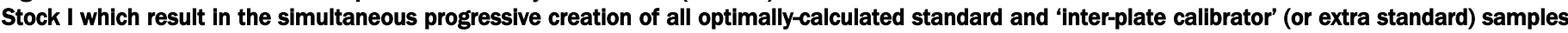
for all qPCR targets tested in any given study. 


\begin{tabular}{|c|c|c|c|c|}
\hline \multicolumn{2}{|l|}{ QPCR sample dynamic range of thls set-up: } & \multicolumn{2}{|c|}{ Sample pestowase 1 : } & \multirow{2}{*}{$\frac{\text { Inhlultion Repert }}{O K}$} \\
\hline Accəpted useful range of RNA In one-step & & 1 & 3351 & \\
\hline real-tIme qPCR: 5 to $50,000 \mathrm{pg} / 25 \mathrm{uL} \mathrm{rXn}$ & & 2 & 5086 & OK \\
\hline We're at: $\quad 36.5 \mathrm{pg} / 25$ uL well & & 3 & 4308 & OK \\
\hline \multicolumn{2}{|l|}{ To: $\quad 2127.0 \mathrm{pg} / 25$ uL well } & 4 & 1720 & OK \\
\hline & & 5 & 2334 & oK \\
\hline \multicolumn{2}{|l|}{0 samples with Inhlbition posalbilitles } & 6 & 2663 & OK \\
\hline \multicolumn{2}{|l|}{ 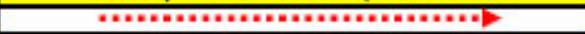 } & 7 & 2957 & OK \\
\hline Are you performing 2-step? $\left(" y^{\prime}\right.$ or "n"): & $\bar{n}$ & 8 & 3650 & oK \\
\hline \multicolumn{2}{|l|}{ Seg Tabatha for ad uatments of thes $\theta$ values: } & 9 & 6308 & oK \\
\hline \multicolumn{2}{|l|}{ aggressive RT? ("Y" or "n"): } & 10 & 3005 & oK \\
\hline \multirow{3}{*}{$\begin{array}{l}\text { If uaing cDNA Instaad of RNA In 2-step method } \\
\text { TWO-STEP NOT IN USE } \\
\text { for all aample o.d.260nm readings } \\
\end{array}$} & Sarte Detass at & 11 & 4740 & OK \\
\hline & Tabstra $\left(x^{\top}\right):$ & 12 & 3962 & OK \\
\hline & $x^{2}$ & 13 & 1374 & OK \\
\hline \multicolumn{2}{|l|}{ Ad]ust cDNA concentration parameter: 1} & 14 & 1988 & oK \\
\hline 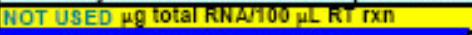 & & 15 & 2317 & oK \\
\hline Two-step well parameters: & aglum ug & 16 & 2611 & OK \\
\hline Well-gize prepared:NNOT INUSE & newioo us & 17 & 3304 & OK \\
\hline CDNA added: NOT IN USE & Dhase py: & 18 & 5962 & oK \\
\hline Flnal used In-well: NOT IN USE & & 19 & 2659 & OK \\
\hline 600 uL Tabatha RNA epeo. reosding volume propare & & 20 & 4394 & oK \\
\hline 10 uL RNA port of that volumb & & 21 & 3616 & oK \\
\hline 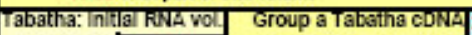 & $\sqrt{2}$ & 22 & 1028 & OK \\
\hline made ad: 170 uL Group b Tabatha cDNA & 2 & 23 & 1642 & oK \\
\hline Group c Tabatha cDNA & & 24 & 1971 & oK \\
\hline Group a Tabatha cDNA & & 25 & 2265 & oK \\
\hline Group $e$ Tabatha cDNA & & 26 & 2958 & OK \\
\hline Group $f$ Tabatha cDNA & & 27 & 5616 & OK \\
\hline DNase conditions when all trastments are the & same: & 28 & 2313 & oK \\
\hline 10.00 uL $10 \times$ DNaee Buffer & & 29 & 4048 & oK \\
\hline 0.00 uL nuclesse-free Water & & 30 & 3270 & oK \\
\hline 20.00 UL DNase Enzyme (9.g. Turbo DNas9) & adj: & 31 & 682 & oK \\
\hline 70.00 UL RNA lsolate & 18 & 32 & 1295 & oK \\
\hline 10.00 UL Inactivation Reagant/stop solution & & 33 & 1625 & OK \\
\hline \begin{tabular}{ll|l}
$110.0 \mathrm{uL}$ & \\
\end{tabular} & & 34 & 1919 & oK \\
\hline OK & & 35 & 2612 & oK \\
\hline & & 36 & 5270 & OK \\
\hline & & 37 & 1967 & OK \\
\hline & & 38 & 3702 & OK \\
\hline & & 39 & 2924 & OK \\
\hline & & 40 & 1164 & OK \\
\hline & & 41 & 1660 & OK \\
\hline & & 42 & 1278 & OK \\
\hline & & 43 & 1573 & OK \\
\hline & & 44 & 2266 & OK \\
\hline & & 45 & 4924 & OK \\
\hline & & 46 & 1621 & OK \\
\hline & & 47 & 3356 & OK \\
\hline & & 48 & 2578 & OK \\
\hline & & 49 & 818 & OK \\
\hline & & 50 & 1314 & OK \\
\hline & & 51 & 3291 & OK \\
\hline & & 52 & 1342 & OK \\
\hline & & 53 & 1920 & OK \\
\hline & & 54 & 4578 & OK \\
\hline & & 55 & 1274 & OK \\
\hline & & 56 & 3010 & OK \\
\hline & & 57 & 2232 & OK \\
\hline & & 58 & 613 & OK \\
\hline & & 59 & 968 & OK \\
\hline & & 60 & 2945 & $\mathrm{OK}$ \\
\hline & & 61 & 947 & OK \\
\hline & & 62 & 1574 & OK \\
\hline & & 63 & 4232 & OK \\
\hline & & 64 & 528 & OK \\
\hline & & 65 & 1825 & OK \\
\hline & & 66 & 2005 & OK \\
\hline & & 67 & 2640 & OK \\
\hline & & 68 & 3141 & OK \\
\hline & & 69 & 1530 & OK \\
\hline & & 70 & 1381 & OK \\
\hline & & 71 & 2693 & OK \\
\hline & & 72 & 4937 & OK \\
\hline
\end{tabular}

Fig. 36: Portion of FF2-6-001 qPCR set-up tool MasterEntrySheet.xls file which informs the user of the qPCR dynamic range tested and whether or not inhibition can be expected of RNA samples during amplification. This is also the region where investigators tell the system whether two-step or one-step real-time qPCR is being performed. In two-step real-time qPCR applications, ten other Excel files are activated which all function to correctly handle cDNA preparation and its subsequent use in qPCR as managed by the FF2-6-001 qPCR set-up tool. These ten other files (known collectively as "Tabatha IV") are not discussed in this manuscript.

Gallup and Ackermann - Addressing fluorogenic real-time qPCR inhibition using the novel custom Excel file system 'FocusField2-6GallupqPCRSet-upTool001 ' to attain consistently high fidelity qPCR reactions

www.biologicalprocedures.com 


\begin{tabular}{|c|c|c|}
\hline $\begin{array}{l}\text { FINAL ST } \\
\text { CREATED }\end{array}$ & $\begin{array}{l}\text { D AND CALIE } \\
\text { SE: FINAL "II }\end{array}$ & $\begin{array}{l}\text { RATOR DILUTIONS } \\
\text { WELL" DILUTIONS }\end{array}$ \\
\hline$\underline{A}$ & 1: 400 & $3000 \mathrm{uL}$ \\
\hline$\underline{B}$ & 1: 693 & 3000 uL \\
\hline $\bar{c}$ & 1: 800 & $3000 \mathrm{uL}$ \\
\hline$\underline{\mathrm{D}}$ & 1: 986 & $3000 \mathrm{uL}$ \\
\hline$\underline{E}$ & 1: 2087 & $3000 \mathrm{uL}$ \\
\hline$\underline{\mathbf{F}}$ & 1: 2433 & $3000 \mathrm{uL}$ \\
\hline$\underline{G}$ & 1: 3374 & $3000 \mathrm{uL}$ \\
\hline 븐 & 1: 4034 & $3000 \mathrm{uL}$ \\
\hline 1 & 1: 6000 & $3000 \mathrm{uL}$ \\
\hline$\underline{J}$ & 1: 7268 & $3000 \mathrm{uL}$ \\
\hline$\underline{\mathbf{K}}$ & 1: 8000 & $3000 \mathrm{uL}$ \\
\hline$\underline{L}$ & 1: 8230 & $3000 \mathrm{uL}$ \\
\hline$\underline{M}$ & $1: 14228$ & $3000 \mathrm{uL}$ \\
\hline$\underline{\underline{N}}$ & 1: 15659 & $3000 \mathrm{uL}$ \\
\hline 으 & 1: 40342 & $3000 \mathrm{uL}$ \\
\hline$\overline{\underline{p}}$ & 1: 60000 & $3000 \mathrm{uL}$ \\
\hline$\underline{\overline{\mathrm{a}}}$ & 1: 66039 & $3000 \mathrm{uL}$ \\
\hline$\underline{R}$ & 1: 72685 & $3000 \mathrm{uL}$ \\
\hline$\underline{\underline{\mathbf{s}}}$ & 1: 306524 & $3000 \mathrm{uL}$ \\
\hline I & 1: 600000 & $3000 \mathrm{uL}$ \\
\hline$\underline{u}$ & 1: 660385 & $3000 \mathrm{uL}$ \\
\hline$\underline{v}$ & 1: 6000000 & $3000 \mathrm{uL}$ \\
\hline
\end{tabular}

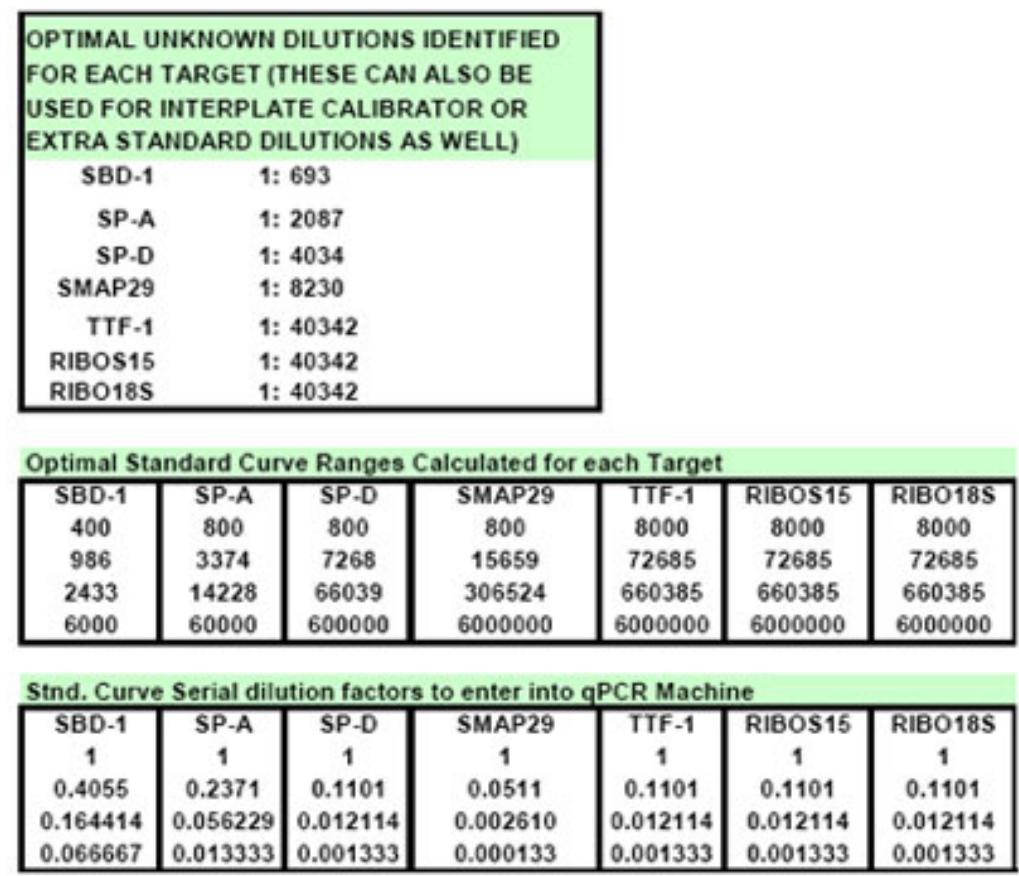

Fig. 37: Portion of FF2-6-001 qPCR set-up tool MasterEntrySheet.xls file which shows the final volumes and relative dilutions achieved for all standards and inter-plate calibrators. Inter-plate calibrator samples serve an added function as additional standards since they are specifically diluted in each case to appear either between the first two points on each target's 3- or 4-point standard curve or at any other place within each standard curve (as can all sample unknowns) by using the 'sample aiming device' shown in Figure 39. This helps to further define each standard curve and lends more credence to final quantitative analyses. Also shown here are the values one enters directly into the qPCR machine so it knows what serial progressive dilution factors are being used to create each different standard curve.

ng/uL RNA achieved in-well for each different qPCR Target:

\begin{tabular}{|lllllll|}
$\frac{\text { SBD-1 }}{0.07292}$ & $\frac{\text { SP-A }}{0.0242251}$ & $\frac{\text { SP-D }}{0.012531}$ & $\frac{\text { SMAP29 }}{0.006143}$ & $\frac{\text { TTF-1 }}{0.001253}$ & $\frac{\text { RIBOS15 }}{0.001253}$ & $\frac{\text { RIB018S }}{0.001253}$ \\
\hline
\end{tabular}

Total pg of RNA per 25.00 uL well:

\begin{tabular}{|c|c|c|c|c|c|c|}
\hline SBD-1 & SP-A & $\underline{\text { SP-D }}$ & SMAP29 & TTF-1 & RIBOS15 & RIB018S \\
\hline 1823.1 & 605.6 & 313.3 & 153.6 & 31.3 & 31.3 & 31.3 \\
\hline
\end{tabular}

Fig. 38: Portion of FF2-6-001 qPCR set-up tool MasterEntrySheet.xls file which shows the final in-well ng/ $\mu$ l total RNA concentrations achieved for each different qPCR target tested and how many picograms of total RNA are present in each final reaction well for each particular target. 
Sample dilution adjust (for theoretic appearance on standard curves) ...

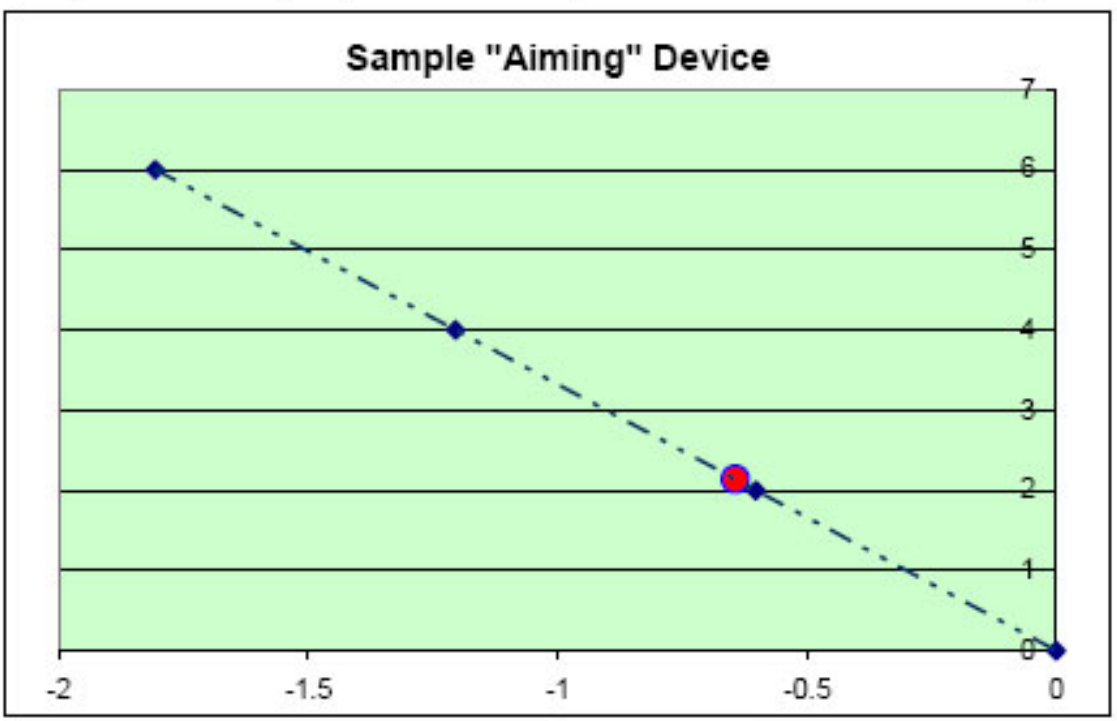

\begin{tabular}{|c|c|c|c|c|}
\hline \multicolumn{2}{|c|}{ Shift Tier 1 and all sample dilutions up?: } & & adjust: & \multirow{2}{*}{$\frac{2.2}{\text { surrogate }}$} \\
\hline & & \multicolumn{2}{|l|}{ (type $x$ if yes) } & \\
\hline \multicolumn{2}{|c|}{ dil factor between samples } & & log input & Ct values \\
\hline 0 & 250 & 1 & 0 & 0 \\
\hline 4.4 & 1100 & 0.227272727 & -0.643452676 & 2.137503524 \\
\hline 0.909090909 & 1000 & 0.25 & -0.602059991 & 2 \\
\hline 4 & 4000 & 0.0625 & -1.204119983 & 4 \\
\hline 4 & 16000 & 0.015625 & -1.806179974 & 6 \\
\hline
\end{tabular}

Fig. 39: 'Sample aiming device' portion of FF2-6-001 qPCR set-up tool MasterEntrySheet.xls file which allows the investigator to manually pre-select where all qPCR signals will most likely appear within the respective Test Plate-determined LOG-linear standard curve ranges for each different target and housekeeper evaluated. 


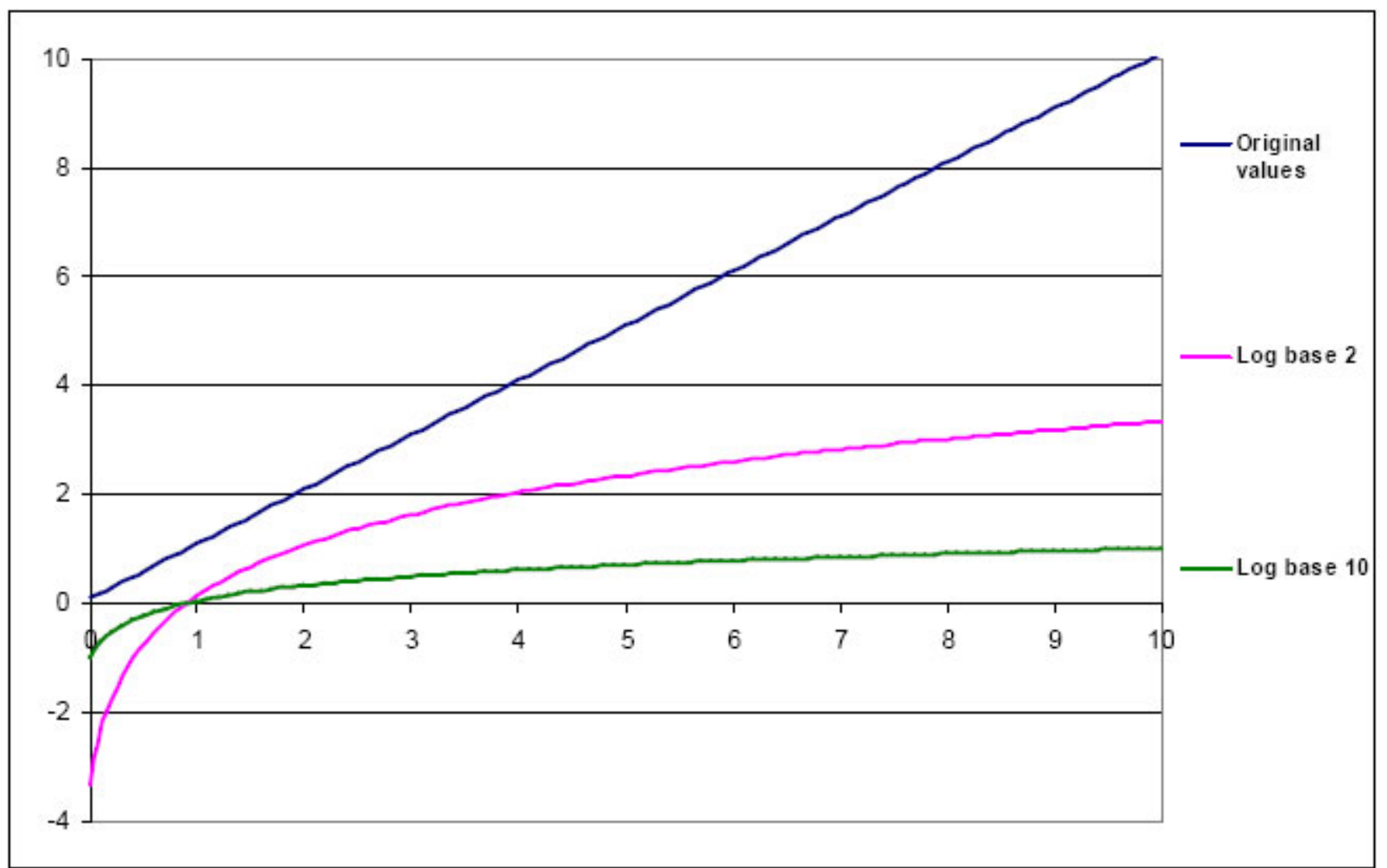

Fig. 40: Graph showing the result of $L O G_{2}$ and $L O G_{10}$ transformation of any data set (original values are shown as the top, dark blue line). For PCR of any variety, it is absolutely necessary to LOG transform the data in order to compress the variance so that relevant parametric and t-test analyses may ensue $(29,30)$. LOG transformation of qPCR data also exposes the Monte-Carlo effect, e.g. low-copy number targets which amplify across threshold after 40 cycles often exhibit statistically-unacceptable variance $(2,37)$. 


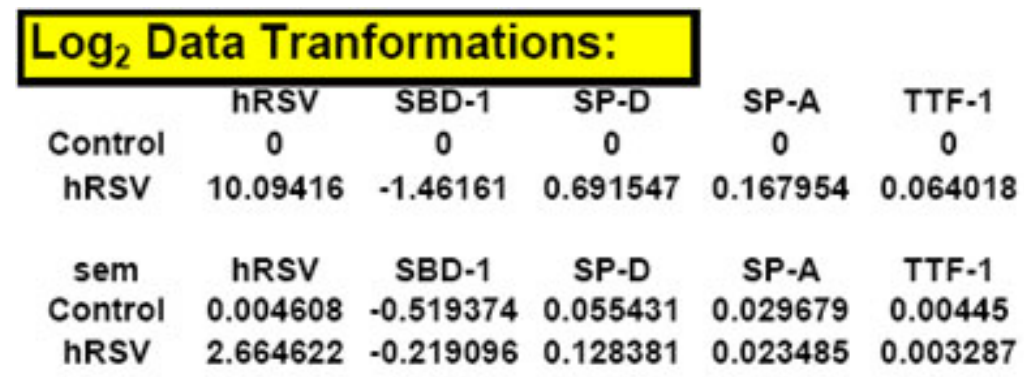

Alicia's 10-lamb study

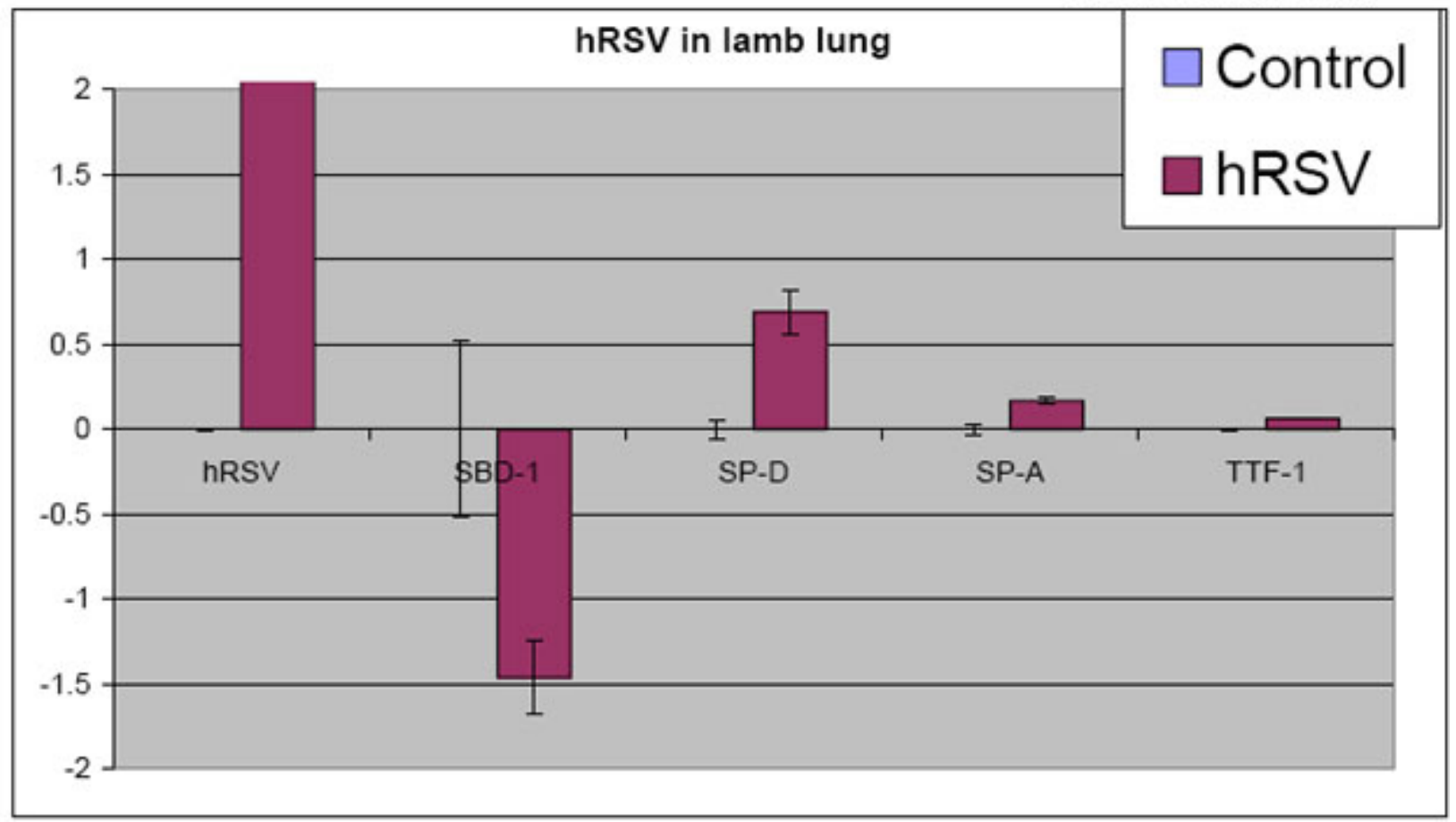

Fig. 41: Graph showing the result of $\mathrm{LOG}_{2}$ transformation of a recent data set. Notice how the "zero" value on the x-axis ends up being where "control" or "calibrator" target expression appears. This is a very user-friendly way to represent final real-time qPCR data as it shows which samples are expressing targets above and below that of control or calibrator levels in a visually easy-to-interpret fashion (Olivier-Gallup-Ackermann, 2006 unpublished results). 
Ct correction file for genomic DNA contamination signals generated during qPCR as revealed by NRC plates Fllo for real-timo Pfam Math

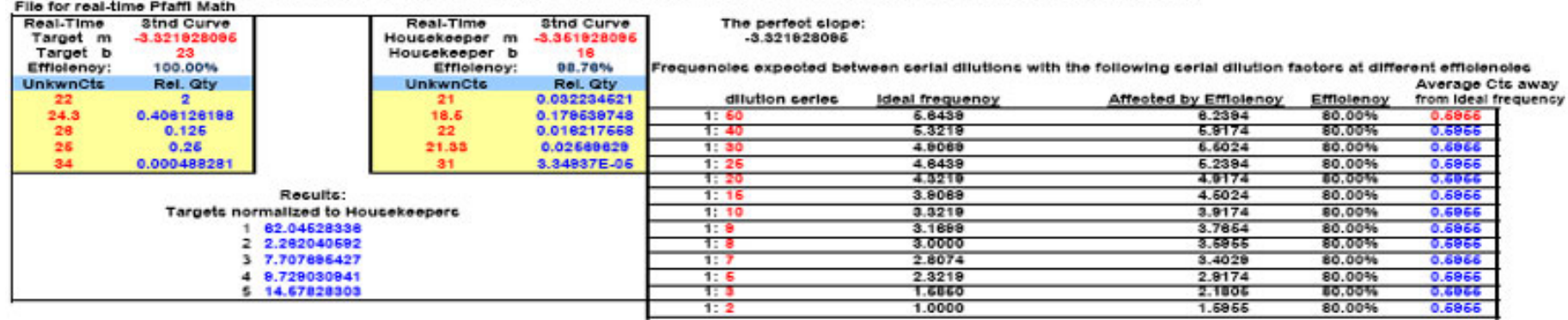

Worried about contaminating signals several Cts away from actual sample (target or housekeeper) signals?

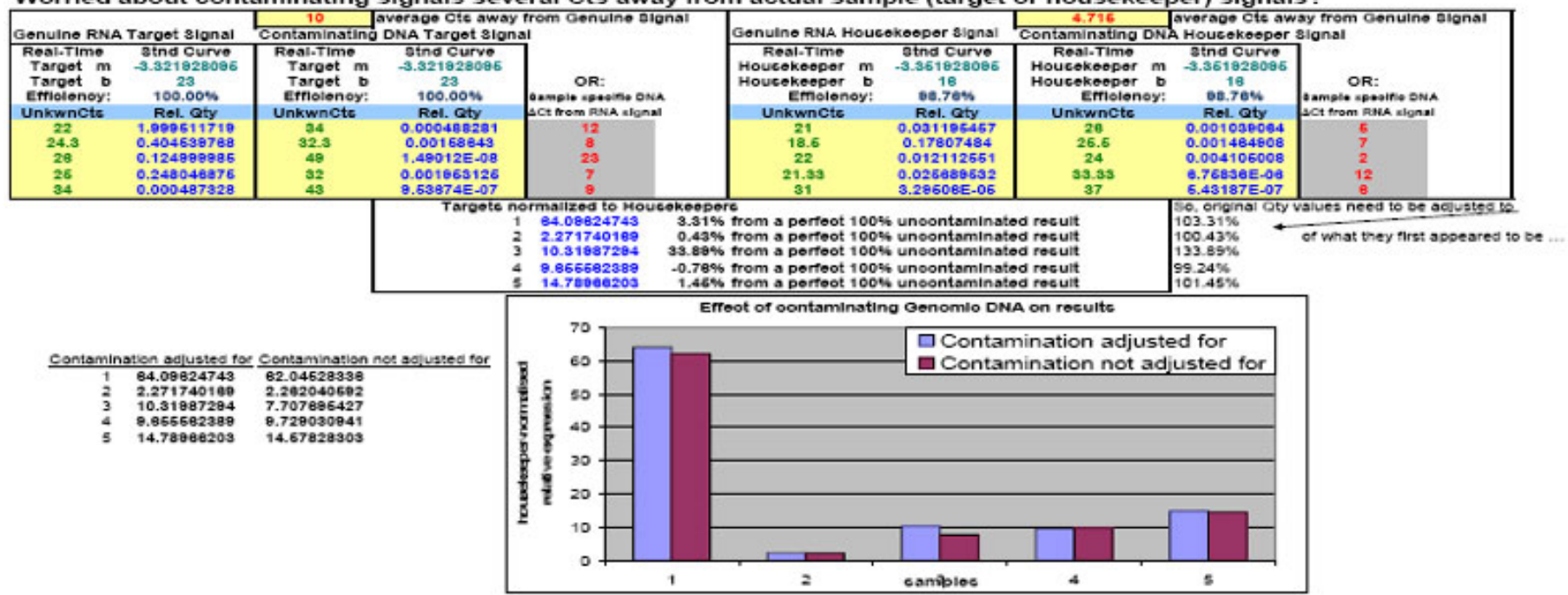

Fig. 42: Depiction of the custom Excel file we use to examine the results of NRC plates to determine whether or not DNA contamination in RNA samples contributes significantly to sample target and/or housekeeper signals and, if they do, this file can be used to mathematically correct for it. Typically, signals elicited from NRC reactions that amplify across threshold greater than 5 cycles away from genuine qPCR signals have very little impact on final qPCR quantitation calculations. In our studies, NRC signals are typically 13 cycles or more away from genuine qPCR signals. 


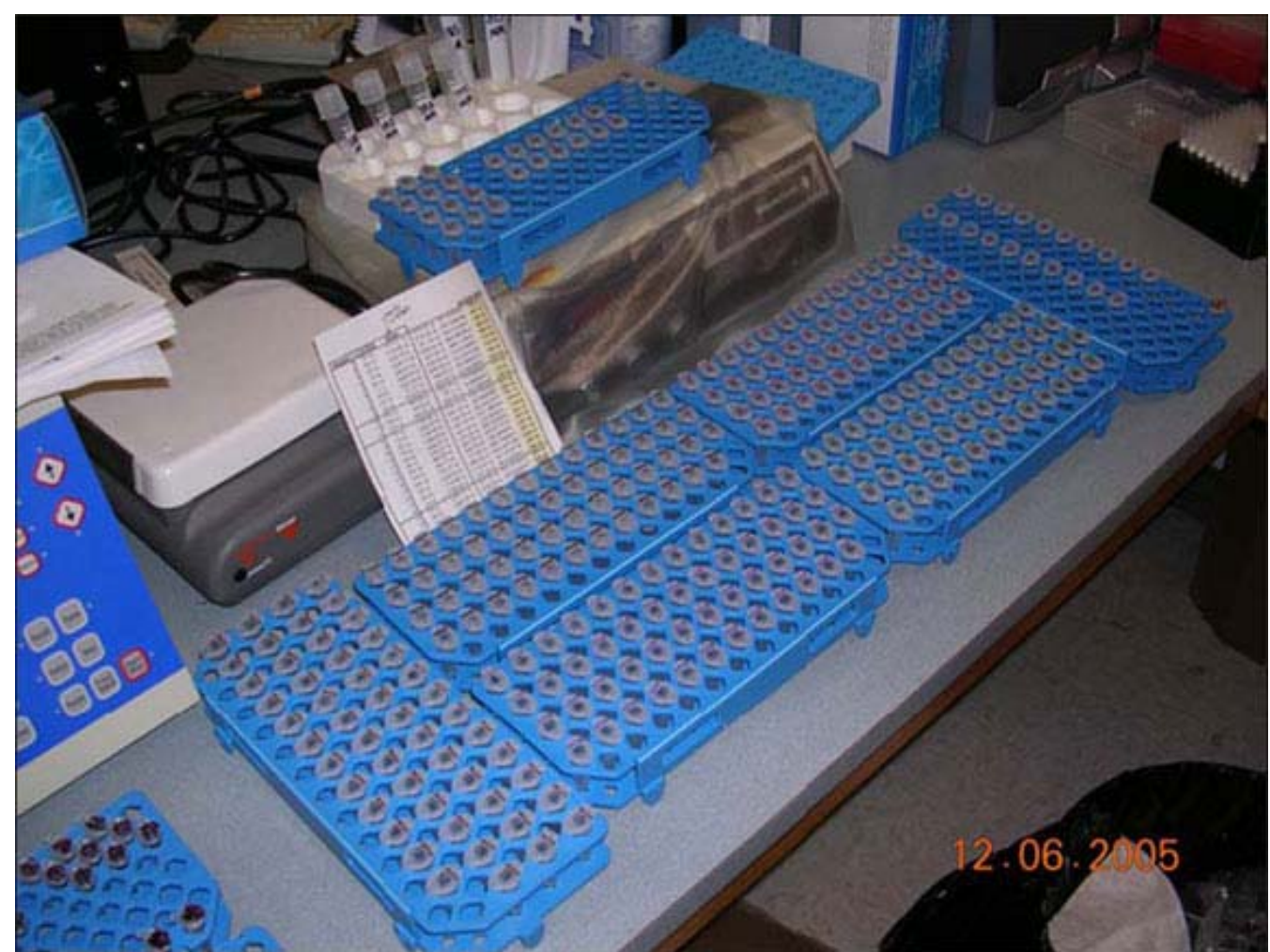

Fig. 43: Typical master mix reaction tube set-up illustrating the often extensive nature of hands-on real-time qPCR. Approximately 260 tubes containing optimally-diluted sample RNAs are not shown here. All tube set-ups were quickly defined by the FF2-6-001 qPCR set-up tool.

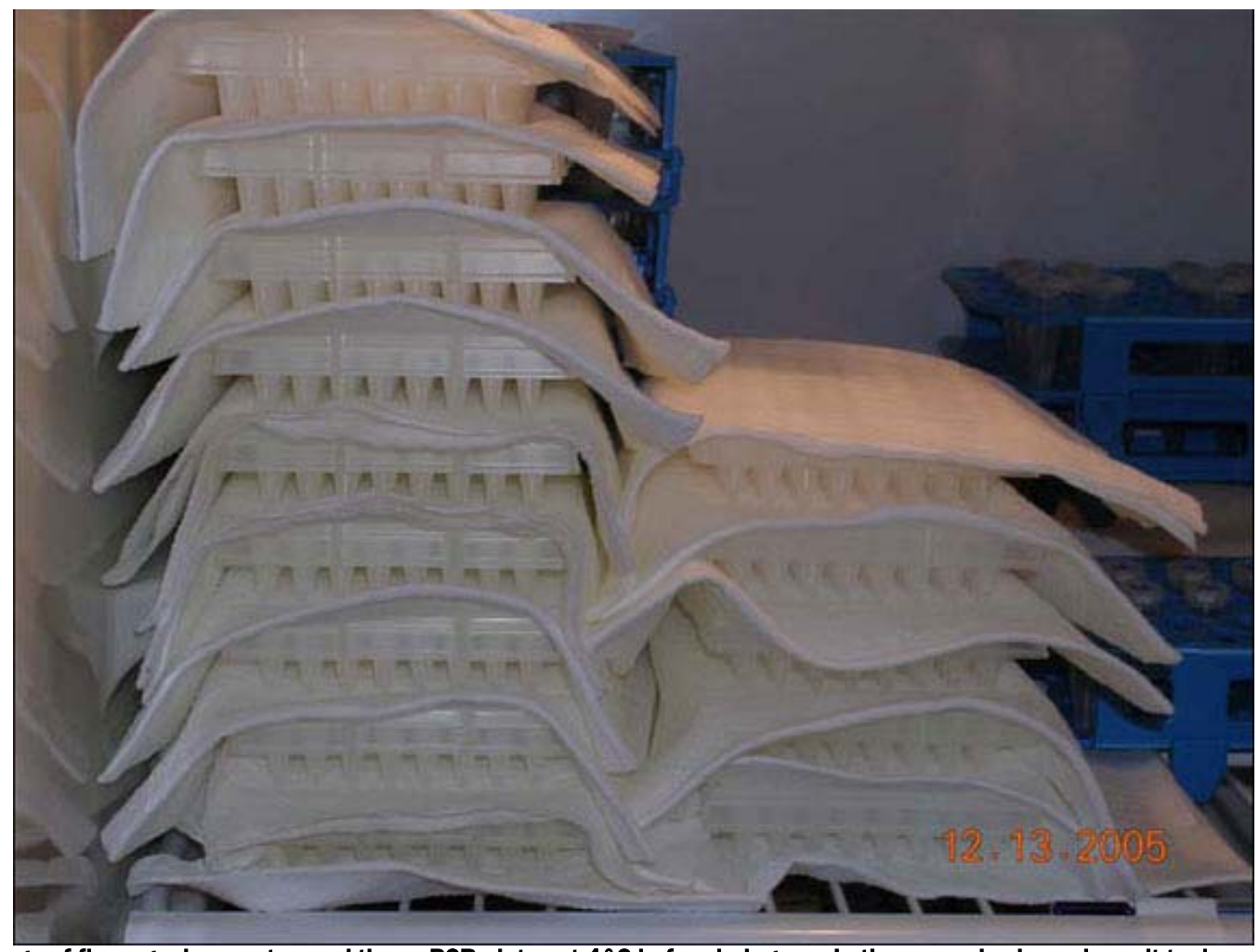

Fig. 44: Typical storage of fluorogenic one-step real-time qPCR plates at $4^{\circ} \mathrm{C}$ before being run. In the example shown here, it took one person 42 hours to run all 14 plates back-to-back. Liquid-handling robot technology has been welcomed in many labs on account of the elaborate, time-consuming set-ups that frequently accompany truly interrogative qPCR. Electronic pipettes can be used otherwise to help shorten set-up time.

Gallup and Ackermann - Addressing fluorogenic real-time qPCR inhibition using the novel custom Excel file system 'FocusField2-6GallupqPCRSet-upTool$001^{\prime}$ to attain consistently high fidelity qPCR reactions

www.biologicalprocedures.com 

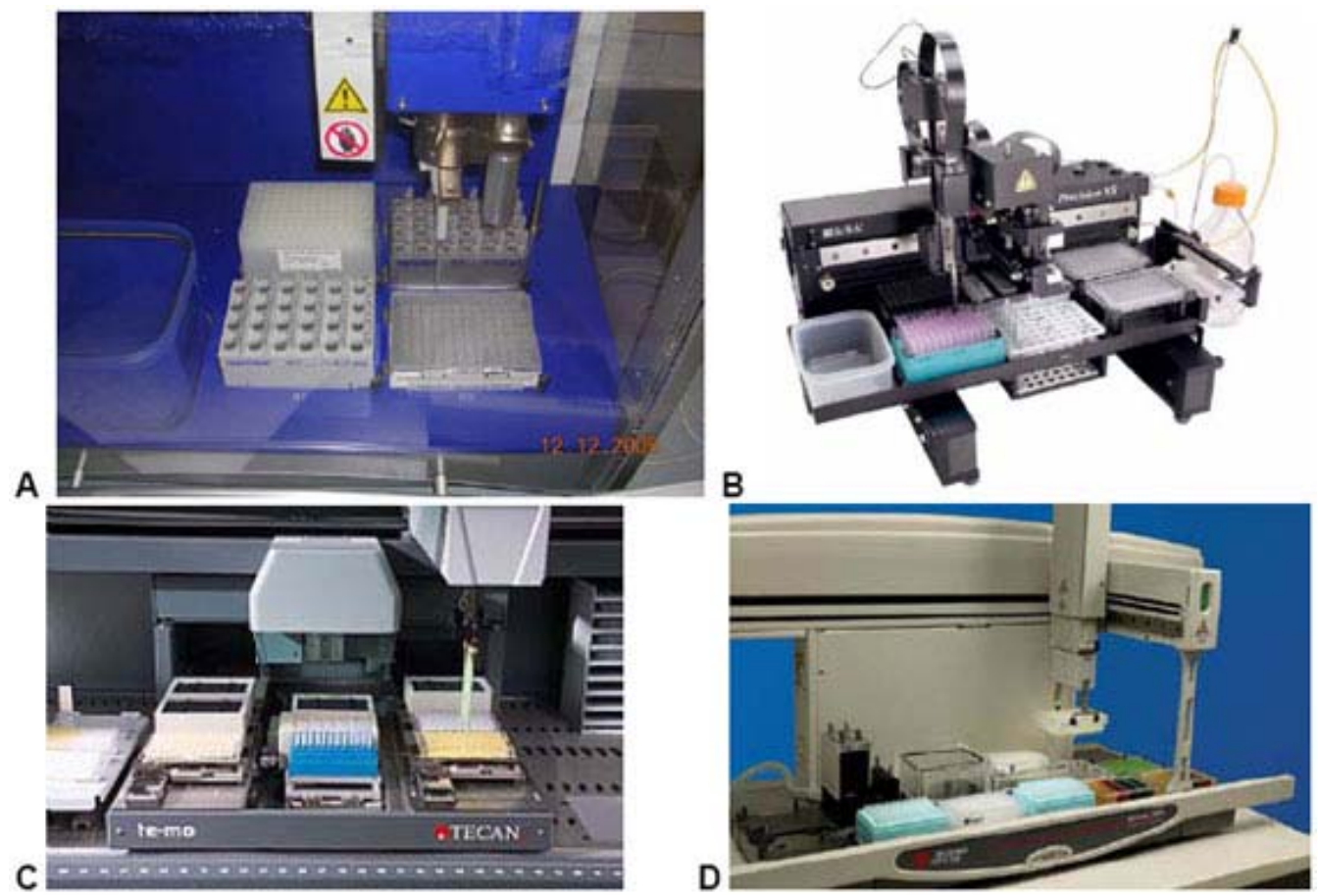

Fig. 45: Liquid handling robots represent a god-send to those who would normally set up all qPCR-related tubes and plates by hand. The Eppendorf 5070 (shown) and 5075 (not shown) liquid-handling robots (A), BioTek's PrecisionXSSilo (B), Tecan's Freedom EVO ${ }^{\circledR}$ (C) and Beckman Coulter's Biomek 3000 (D) are all perfect for this application. In the absence of such technology, investigators are urged to at least employ the use of electronic/digital pipettes to make qPCR set-ups less demanding.

Example showing how hRSV RNA virus gives faulty values when tissue total RNA sample is used too concentrated in the qPCR application:

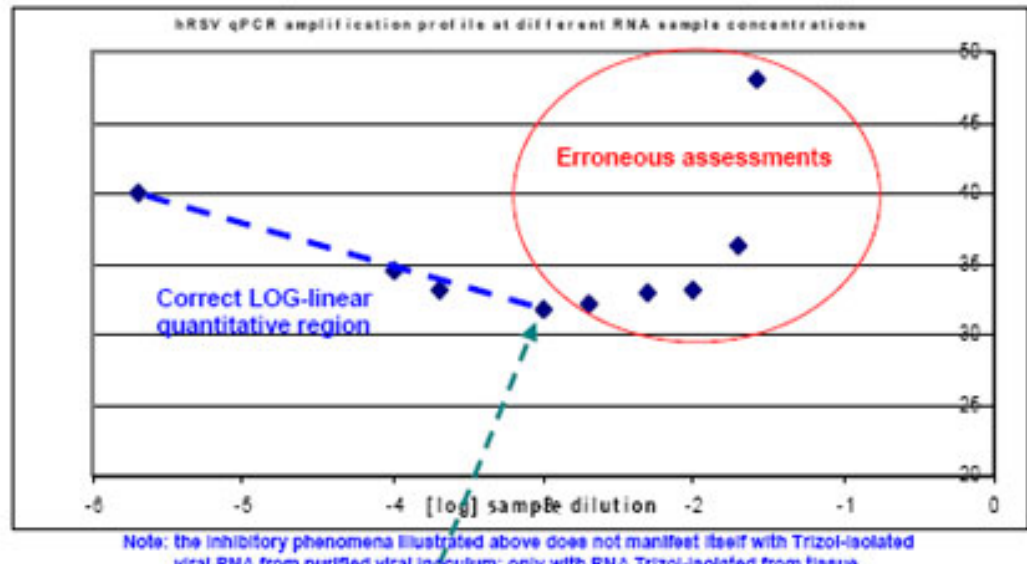

viral RNA from purined viral indoulum; on\&Q with RNA Trizol-1solated from tianus.

The red-circled points are erroneous and suggest much lower vira presence than is actually the case. The blue line indicates those dilutions of the RIA sample which yield true quantitative results in the assay. The first blue-lined point which begins to behave in the desired fashion represents an in-well [RNA] of $0.1248 \mathrm{ng} / \mathrm{uL}$. For three viral signals so far (bRSV, hRSV and PCV-2, a DNA virus), we have found $0.083 \mathrm{ng} / \mathrm{uL}$ to be a very good concentration at which to start using total tissue RNA (containing virus) for qPCR analyses.

The goal is to let this assay be as sensitive as possible. Diluting RNA samples out beyond their ability to generate qPCR signal at all is just as bad as not diluting RNA samples far enough.

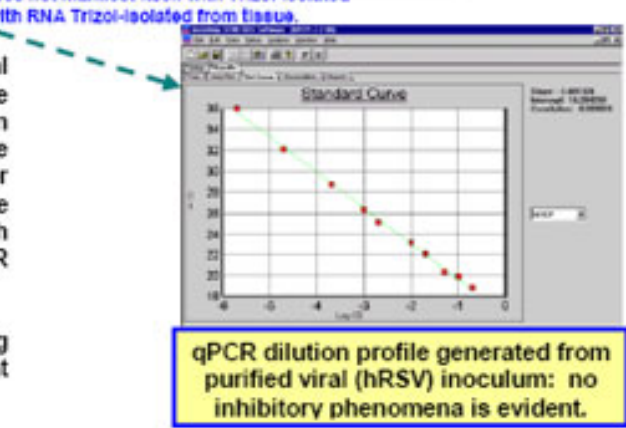

Fig. 46: Important example of how viral load in infected samples can be severely underestimated if qPCR inhibition is present but remains unaddressed. Imagine if the virus in this diagram were a deadly variety of H5N1. The parameters shown above we defined for hRSV using the FF2-6-001 qPCR set-up tool.

Gallup and Ackermann - Addressing fluorogenic real-time qPCR inhibition using the novel custom Excel file system 'FocusField2-6GallupqPCRSet-upTool001 ' to attain consistently high fidelity qPCR reactions www.biologicalprocedures.com 

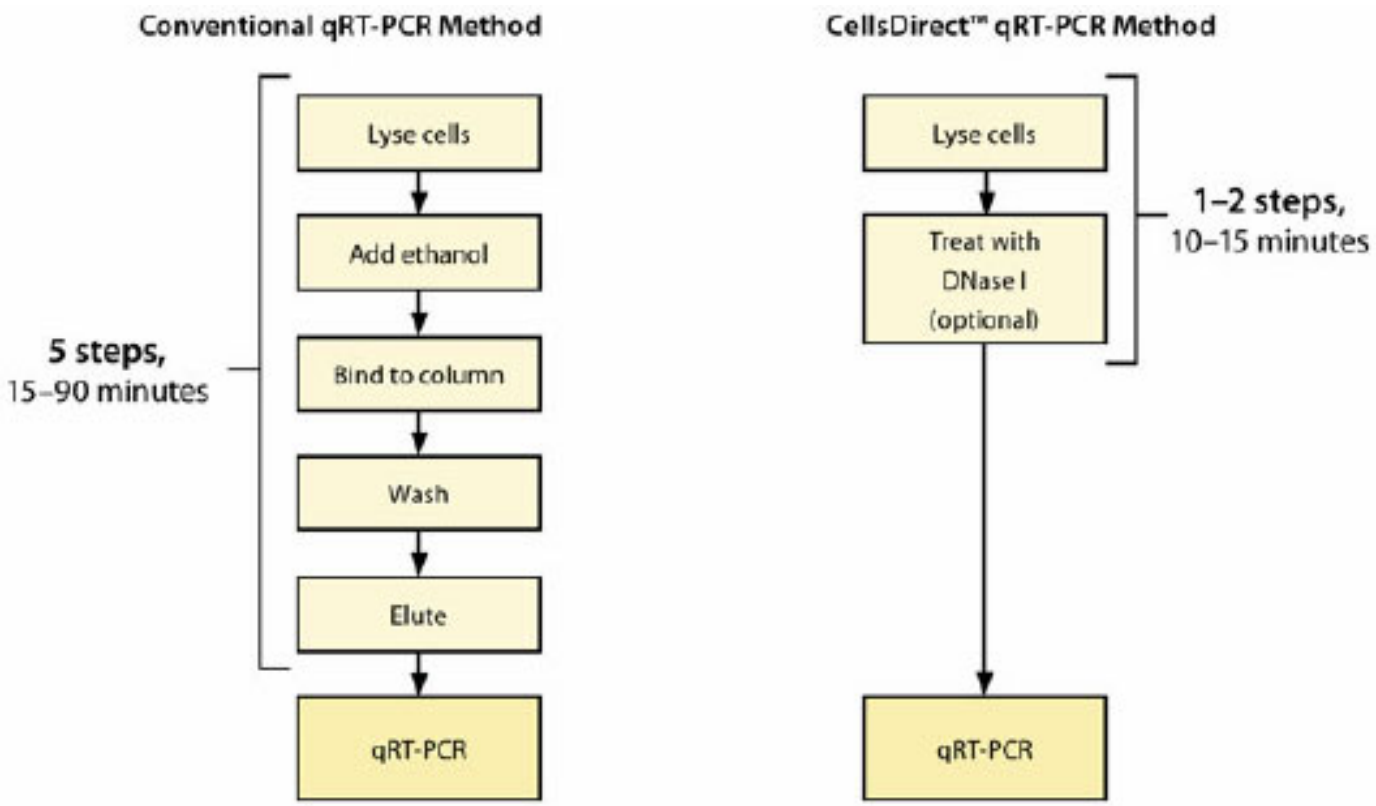

Fig. 47: Chart showing the advantage of using the CellsDirect ${ }^{\mathrm{TM}}$ One-Step RT-PCR Kit, Cat. No. 46-7201 product instead of conventional column-based RNA purification methods. This [new] product adheres to the "high throughput" philosophy of real-time qPCR by shortening the time it takes investigators to obtain qPCR-compatible cell lysates. Real-time qPCR inhibition is effectively eliminated from LCM-derived samples isolated using this method. 


\section{ACKNOWLEDGMENTS}

This work was supported by NIH NIAID Awards 5R01AI062787-02 and 5K08AI055499-03, USDA/CSREES/NRI-CGP 2003-35204-13492, and the J.G. Salsbury Endowment. The authors would like to thank James M. Gallup for his invaluable parallel insights from a keen design/engineering perspective regarding the philosophy of invention, logical protocol and the nature of closed systems. A well-spring of long-overdue thanks goes out to Mary Hull and Nancy Hanna for their professional support and their expert assistance in finalizing the ordering of the reagents and machines for all projects (including this one) undertaken by our department over the past two decades. At the helm of support for us is Dr. Claire B. Andreasen who has been the guiding human force which has enabled our particular department to remain intact and highly productive under her chairwomanship. We also thank Sandra K. Clark for allowing us to gain more insight into the behavior of real-time qPCR assays which use column-isolated RNA from macrophages and dendritic cells; we as well thank Dr. Brett Sponseller for creating and funding that important work. We thank Dr. Branka Grubor for her previous work with us on these very things, her expertise, her positive support of all individuals involved, and for bringing to us Tatjana Lazic (and therefore Dr. Milan Matic) to help our innate immunity research group. We thank Tatjana Lazic for providing us with additionally valuable sheep tissue and cell culture samples. We extend a special thank you to the very gracious Dr. Milan Matic for spanning the oceans to lend us his expertise and his unselfish love for the arts of surgery and medicine. We thank Dr. David K. Meyerholz for his insightful research, his medical, surgical and pioneering academic gifts, and for providing us with many of the experimental samples we have used in our studies. We additionally thank Alicia Olivier for her work on real-time one-step qPCR for hRSV. We also thank Pam Knake, Jennifer S. Christensen, James A. DeGraaff and Kari Loehndorf for their assistance with crucial IHC and qPCR lab procedures. We sincerely thank Dr. Douglas E. Jones, Dr. Jeffrey K. Beetham, Dr. Gary Polking and Jon Mlocek for providing us with the qPCR machines on which we have generated our data. We would also like to thank Invitrogen, Applied Biosystems, Stratagene (Lisa Thompson and Dr. Daniel Schoeffner), Eppendorf (Jason Lockefeer), Ambion and Arcturus for providing such excellent products and technical support throughout our studies over the past several years. Most of all, we thank our parents, our wives, and our children.

\section{REFERENCES}

1. Tichopad A, Didier A, Pfaffl MW. Inhibition of realtime RT-PCR quantification due to tissue-specific contaminants. Molecular Cellular Probes 2004; 18:45-50.

2. Bustin SA. A-Z of Quantitative PCR. Bustin SA, editor. (IUL Biotechnology, No. 5), 1st ed. International University Line; August 2004. 882 pages.

3. Wilson IG, Gilmour A, Cooper JE. Detection of toxigenic microorganisms in foods by PCR. In: Kroll RG, Gilmour A, Sussman M, editors. New Techniques in Food and Beverage Microbiology. London: Blackwell; 1993. pp. 163-172.

4. Starnbach MN, Falkow S, Tomkins SL. Speciesspecific detection of Legionella pneumophila in water by DNA amplification and hybridization. Journal of Clinical Microbiology 1989; 27:1257-1261.

5. Wilson IG. Inhibition and facilitation of nucleic acid amplification. Applied and Environmental Microbiology 1997; 63:3741-3751.

6. Rossen L, Norskov P, Holmstrom K, Rasmussen FO. Inhibition of PCR by components of food sample, microbial diagnostic assay and DNA-extraction solutions. International Journal of Food Microbiology 1992; 17:37-45.

7. Tichopad A, Pfaffl MW, Didier A. Tissue-specific expression pattern of bovine prion: quantification using real-time RT-PCR. Molecular and Cellular Probes 2003; 17:5-10.

8. Pfaffl MW, Lange IG, Daxenberger A, Meyer HH. Tissue-specific expression pattern of estrogen receptors (ER): quantification of ER alpha and ER beta mRNA with real-time RT-PCR. Acta Pathologica Microbiologica et Immunologica Scandinavica 2001; 109:345-355.

9. Rijpens NP, Jannes G, Van Asbroeck M, Rossau R, Herman LMF. Direct detection of Brucella spp. In raw milk by PCR and reverse hybridization with 16S-23S rRNA spacer probes. Applied Environmental Microbiology 1996; 62:1683-1688. 
10. Thellin $\mathrm{O}$, Zorzi W, Lakaye B, De Borman B, Coumans B, Hennen G, Grisar T, Igout A, Heinen E. Housekeeping genes as internal standards: use and limits. Journal of Biotechnology 1999; 75:291-295.

11. Schmittgen TD, Zakrajsek BA. Effect of experimental treatment on housekeeping gene expression: validation by real-time, quantitative RT-PCR. Journal of Biochemical and Biophysical Methods 2000; 20:69-81.

12. Suzuki T, Higgins PJ, Crawford DR. Control selection for RNA quantitation. BioTechniques 2000; 29:332-337.

13. Lee J, Duncan A, Warrick S. Techniques for optimizing RT-PCR reactions. PharmaGenomics 2003; January: 50-55.

14. Invitrogen Life Technologies TRIzol ${ }^{\circledR}$ Reagent product literature/insert. Cat. No. 15596-026, Form No. $18057 \mathrm{~N}$.

15. Invitrogen Life Technologies Instruction Manual. SuperScript III CellsDirect cDNA Synthesis System (for Catalog Nos. 18080-200 and 18080-300) Version B, 25-0731 18 April 2005; 2. \& Instruction Manual: SuperScript $^{\mathrm{TM}}$ III CellsDirect, cDNA Synthesis System Catalog Nos. 18080-200 and 18080-300, Version A, 14 May 2004, 25-0731, page vi).

16. Gallup JM, Kawashima K, Lucero G, Ackermann MR. New quick method for isolating RNA from laser captured cells stained by immunofluorescent immunohistochemistry; RNA suitable for direct use in fluorogenic TaqMan one-step real-time RTPCR. Biol Proced Online 2005; 7:70-92.

17. Caverly JM, Diamond G, Gallup JM, Brogden KA, Dixon RA, Ackermann MR. Coordinated Expression of Tracheal Antimicrobial Peptide and Inflammatory Response Elements in the Lungs of Neonatal Calves and with Acute Bacterial Pneumonia. Inf Immun 2003; 71(5):2950-2955.

18. Meyerholz DK, Gallup JM, Grubor BM, Evans RB, Tack BF, McCray PB Jr, Ackermann MR. Developmental expression and distribution of sheep b-defensin-2. Dev Comp Immun 2004; 28:171178.

19. Grubor BM, Gallup JM, Meyerholz DK, Crouch EC, Evans RB, Brogden KA, Lehmkuhl HD, Ackermann MR. Enhanced Surfactant Protein and Defensin mRNA Levels and Reduced Viral Replication during Parainfluenza Virus Type 3 Pneumonia in Neonatal Lambs. CDLI 2004; 11(3):599-607.
20. Ackermann MR, Gallup JM, Zabner J, Evans RB, Brockus CW, Meyerholz DK, Grubor B, Brogden KA. Differential expression of sheep beta-defensin-1 and 2 and interleukin 8 during acute Mannheimia haemolytica pneumonia. Microbial Pathogenesis 2004; 37:21-27.

21. Meyerholz DK, Grubor B, Fach SJ, Sacco RE, Lehmkuhl HD, Gallup JM, Ackermann MR. Reduced Clearance of Respiratory Syncytial Virus in a Preterm Lamb Model. Microbes and Infection 2004; 6(14):13121319.

22. Meyerholz DK, Grubor B, Gallup JM, Lehmkuhl HD, Anderson RD, Lazic T, Ackermann MR. AdenovirusMediated Gene Therapy Enhances Parainfluenza Virus 3 Infection in Neonatal Lambs. J Clin Micro 2004; 42(10):4780-4787.

23. Kawashima K, Meyerholz DK, Gallup JM, Grubor B, Lazic T, Lehmkuhl HD, Ackermann MR. Differential expression of ovine innate immune genes by preterm and neonatal lung epithelia infected with respiratory syncytial virus. Viral Immunology 2006; 19:316-323.

24. Meyerholz DK, Kawashima K, Gallup JM, Grubor B, Ackermann MR. Expression of select immune genes (surfactant proteins A and D, sheep beta defensin, and toll-like receptor 4) by respiratory epithelia is developmentally regulated in the preterm neonatal lamb. Dev Comp Immunol 2006; 30(11):1060-1069.

25. TaqMan ${ }^{\circledR}$ Universal PCR Master Mix Protocol. Applied Biosystems, 2002, Printed in the USA, 04/2002, Part Number 4304449 Rev. C.

26. Stangegaard M, Hufva IH, Dufva M. Reverse transcription using random pentadecamer primers increases yield and quality of resulting cDNA. BioTechniques 2006; 40(5):649-657.

27. Dussault A-A, Pouliot M. Rapid and simple comparison of messenger RNA levels using real-time PCR. Biol Proced Online 2006; 8(1):1-10.

28. Pfaffl MW. A new mathematical model for relative quantification in real-time RT-PCR. Nucleic Acids Res 2001; 29:2002-2007.

29. Gilsbach R, Kouta M, Bönisch H, Brüss $M$. Comparison of in vitro and in vivo reference genes for internal standardization of real-time PCR data. BioTechniques 2006; 40(2):173-177.

30. Burns MJ, Nixon GJ, Foy CA, Harris N. Standardisation of data from real-time quantitative PCR methods - evaluation of outliers and comparison of calibration curves. BMC Biotechnol 2005; 7:5-31. 
31. Applied Biosystems User Bulletin \#2. ABI PRISM 7700 Sequence Detection System, SUBJECT: Relative Quantitation of Gene Expression: Calculating the Input Amount. 2001, p. 8.

32. Swillens S, Goffard J-C, Marechal Y, de Kerchove d'Exaerde A, Housni EH. Instant evaluation of the absolute initial number of cDNA copies from a single real-time PCR curve. Nucleic Acids Res 2004; 32(6):e53.

33. Peirson SN, Butler JN, Foster RG. Experimental validation of novel and conventional approaches to quantitative real-time PCR data analysis. Nucleic Acids Res 2003; 31(14):e73.

34. Broackes-Carter F, Mouchel N, Gill D, Hyde S, Bassett J, Harris A. Quantitative CFTR transcript analysis by TaqMan. Temporal regulation of CFTR expression during ovine lung development: implications for CF gene therapy. Hum Mol Genet 2002; 11:125-131.

35. CellsDirect ${ }^{\mathrm{TM}}$ One-Step qRT-PCR Kits for One-Step Real-Time Quantitative RT-PCR from cell lysate. Catalog Nos. 11753-100, 11753-500, 11754-100, 11754-500 Version A 28 November 2005;25-0870:926.
36. Livak KJ, Schmittgen TD. Analysis of Relative Gene Expression Data Using Real-Time Quantitative PCR and the 2- ${ }^{-\Delta \Delta C_{\mathrm{T}}}$ Method. Methods 2001; 25:402-408.

37. Bustin SA, Nolan T. Pitfalls of Quantitative Real-Time Reverse-Transcription Polymerase Chain Reaction. J Biomolecular Techniques 2004; 15:155-166.

38. Chandler DP, Wagnon CA, Bolton H Jr. Reverse Transcriptase (RT) Inhibition of PCR at Low Concentrations of Template and Its Implications for Quantitative RT-PCR. Appl Environ Biol 1998; 64(2):669-677.

39. Mocellin S, Rossi CR, Pilati P, Nitti D, Marincola MM. Quantitative real-time PCR: A Powerful Ally in Cancer Research. Trends Molec Med 2003; 9(5):189-195.

40. Vandesompele J. Normalization of Gene Expression using Expressed Alu Repeat Elements qPCR. 2005 Symposium Proceedings ISBN 300016687.

41. Buchanan FC, Littlejohn RP, Galloway SM, Crawford AM. Microsatellites and associated repetitive elements in the sheep genome. Mammalian Genome 1993; 4(5):258-264.

42. Primmer CR, Raudsepp T, Chowdhary BP, Møller AP, Ellegren H. Low Frequency of Microsatellites in the Avian Genome. Genome Res 1997; 7:471-482. 